
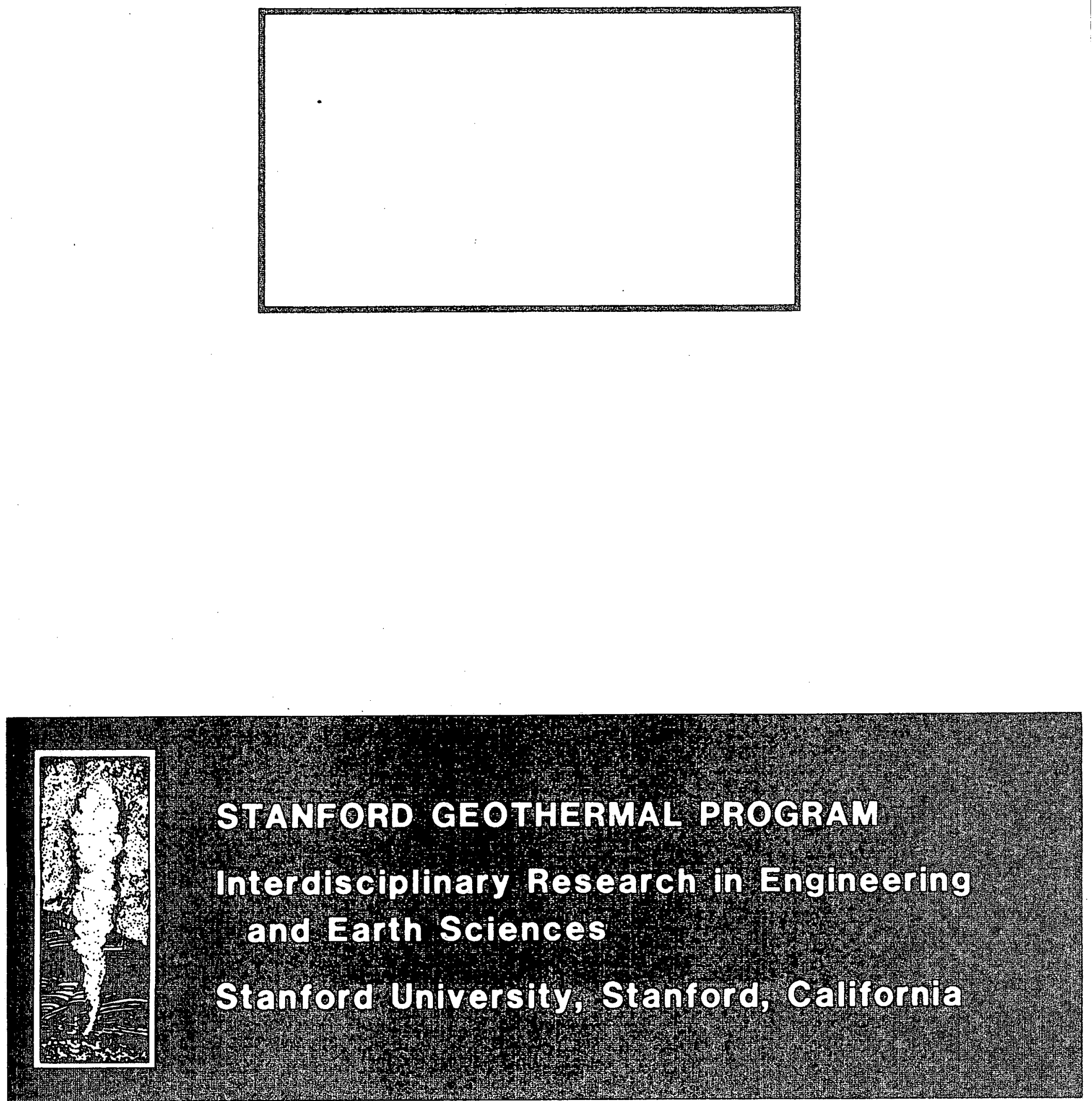


\section{DISCLAIMER}

This report was prepared as an account of work sponsored by an agency of the United States Government. Neither the United States Government nor any agency Thereof, nor any of their employees, makes any warranty, express or implied, or assumes any legal liability or responsibility for the accuracy, completeness, or usefulness of any information, apparatus, product, or process disclosed, or represents that its use would not infringe privately owned rights. Reference herein to any specific commercial product, process, or service by trade name, trademark, manufacturer, or otherwise does not necessarily constitute or imply its endorsement, recommendation, or favoring by the United States Government or any agency thereof. The views and opinions of authors expressed herein do not necessarily state or reflect those of the United States Government or any agency thereof. 


\section{DISCLAIMER}

Portions of this document may be illegible in electronic image products. Images are produced from the best available original document. 
SGP-TR-170

\title{
Relative Permeability Through Fractures
}

\author{
Gracel P. Diomampo
}

August 2001

Financial support was provided through the

Stanford Geothermal Program under

Department of Energy Grant No. DE-FG07-95ID13370

and No. DE-FG07-99ID13763,

and by the Department of Petroleum Engineering,

Stanford University 


\title{
RELATIVE PERMEABILITY THROUGH FRACTURES
}

\section{A REPORT SUBMITTED TO THE DEPARTMENT OF \\ PETROLEUM ENGINEERING \\ OF STANFORD UNIVERSITY}

IN PARTIAL FULFILLMENT OF THE REQUIREMENTS FOR THE

DEGREE OF MASTER OF SCIENCE

\author{
By \\ Gracel P. Diomampo
}

August 2001 



\section{Abstract}

The mechanism of two-phase flow through fractures is of importance in understanding many geologic processes. Currently, two-phase flow through fractures is still poorly understood. In this study, nitrogen-water experiments were done on both smooth and rough parallel plates to determine the governing flow mechanism for fractures and the appropriate methodology for data analysis. The experiments were done using a glass plate to allow visualization of flow. Digital video recording allowed instantaneous measurement of pressure, flow rate and saturation. Saturation was computed using image analysis techniques.

The experiments showed that gas and liquid phases flow through fractures in nonuniform separate channels. The localized channels change with time as each phase path undergoes continues breaking and reforming due to invasion of the other phase. The stability of the phase paths is dependent on liquid and gas flow rate ratio. This mechanism holds true for over a range of saturation for both smooth and rough fractures. In imbibition for roughwalled fractures, another mechanism similar to wave-like flow in pipes was also observed.

The data from the experiments were analyzed using Darcy's law and using the concept of friction factor and equivalent Reynold's number for two-phase flow. For both smoothand rough-walled fractures a clear relationship between relative permeability and saturation was seen. The calculated relative permeability curves follow Corey-type behavior and can be modeled using Honarpour expressions. The sum of the relative permeabilities is not equal one, indicating phase interference. The equivalent homogenous single-phase approach did not give satisfactory representation of flow through fractures. The graphs of experimentally derived friction factor with the modified Reynold's number do not reveal a distinctive linear relationship. 



\section{Acknowledgments}

This research was supported by the US Department of Energy under contract DE-FG0799ID13763. 
$5=$ 


\section{Contents}

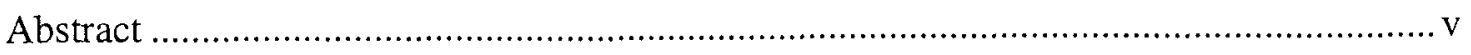

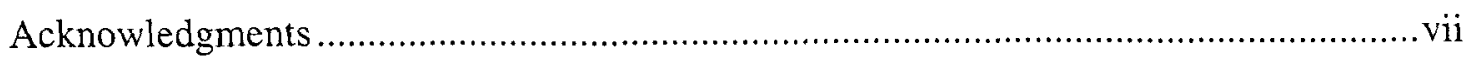

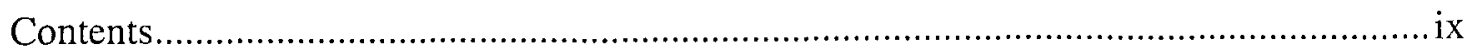

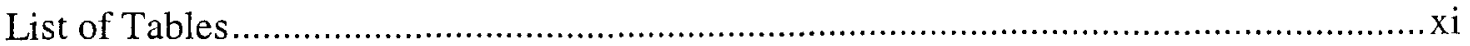

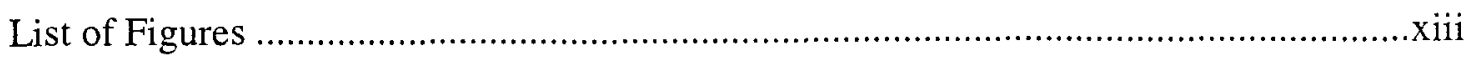

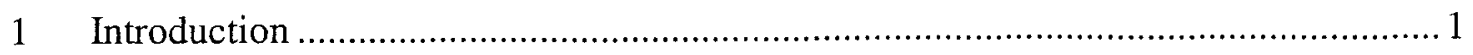

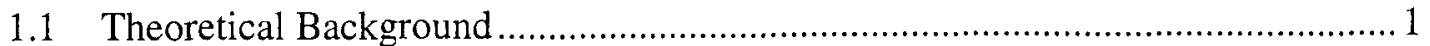

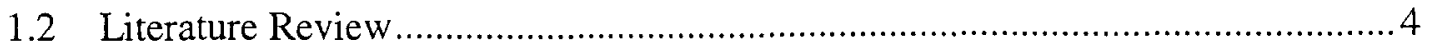

2 Experimental Methodology ....................................................................... 7

2.1 Fracture Apparatus Description .............................................................. 7

2.2 Control and Measurement Techniques …...................................................... 9

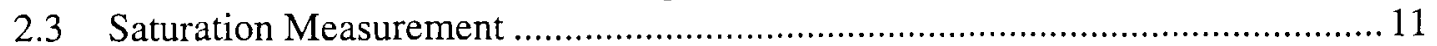

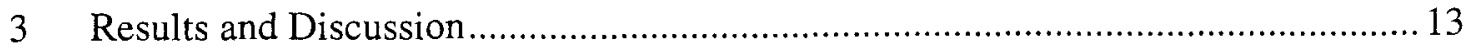

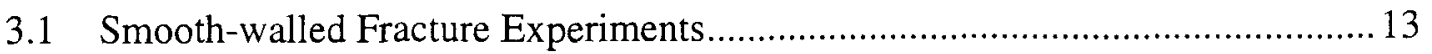

3.1.1 Observed Flow Mechanism.................................................................. 13

3.1.2 Relative Permeability Curve From Porous Medium Approach ................... 16

3.1.3 Homogenuous Single-Phase Pipe Flow Model for Smooth-walled Fracture 20

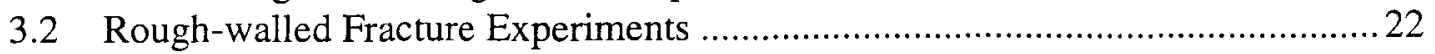

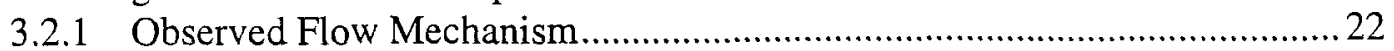

3.2.2 Relative Permeability Curve Through Porous Medium Approach ...............26

3.2.3 Homogeneous Model in Rough-Walled Fracture Experiment..................... 32

3.3 Comparison of Smooth- and Rough-Walled Experiment to Other Studies .......... 35

4 Conclusions and Recommendations................................................................ 37

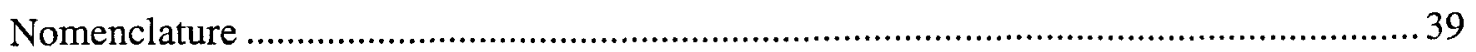

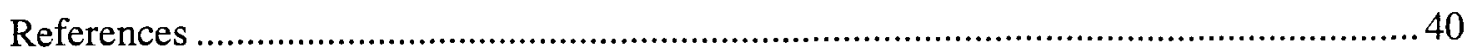

A. Matlab Program for Saturation Measurement .................................................. 43

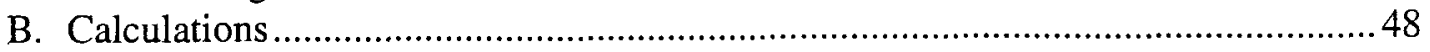




\section{List of Tables}

Table 1 Fit Parameters for smooth-walled fracture experiment ..................................20

Table 2 Honarpour fit parameters for rough-walled experiment................................... 32

Table 3 Homogeneous equivalent single-phase fit parameters. .................................... 35 



\section{List of Figures}

Figure 1.1 Measurement of air-water relative permeabilities in rough-walleded fractures 5

Figure 2.1 Schematic diagram of fracture apparatus................................................. 8

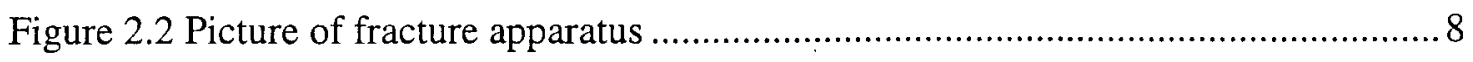

Figure 2.3 Process flow diagram for nitrogen-water experiment .............................. 10

Figure 2.4 Sample video image taken for nitrogen-water runs ................................... 10

Figure 2.5 Comparison of the true and gray scale image used in measuring saturation ... 12

Figure 3.1 Pressure fluctuations cause by the breaking and reforming of gas flow path .. 14

Figure 3.2 Forming and breaking of gas flow path for the time in Figure 3.1 ................ 14

Figure 3.3 Gas flow path increase in width and water invasion.................................. 15

Figure 3.4 Experimental velocity data imposed in Fourar and Bories (1995) flow map 16

Figure 3.5 Absolute fracture permeability for smooth-walled fracture ............................ 17

Figure 3.6 Relative permeability data from smooth-walled fracture experiment............. 18

Figure 3.7 Fitted Honarpour curve for smooth-walled fracture drainage experiment....... 19

Figure 3.8 Fitted Honarpour curve for smooth-walled fracture imbibition experiment.... 20

Figure 3.9 Friction factor vs. Reynold's number for smooth-walled fracture ..................21

Figure 3.10 Friction factor for smooth-walled fracture in comparison to previous works 21

Figure 3.11 Predicted pressure drop and measured data for smooth-walled fracture .......22

Figure 3.12 Gas invasion in drainage experiment with rough-walled fracture ................ 23

Figure 3.13 Gas path, water invasion and residual gases in rough-walled experiment.....24

Figure 3.14 Pressure fluctuations due to building and breaking up of phase path. .........24

Figure 3.15 Stable gas path in high gas-water ratio for rough-walled fracture ................ 25

Figure 3.16 Stable flow path of imbibition experiment in rough-walled fracture............. 25

Figure 3.17 Wave-like fronts in high gas-water ratio at imbibition experiment .............26

Figure 3.18 Absolute permeability phase experiments for rough-walled fracture ............27

Figure 3.19 Relative permeability for drainage experiment for rough-walled fracture..... 28

Figure 3.20 Relative permeability for rough-walled when the gas path is stable.............28 
Figure 3.21 Relative permeability for rough-walled fracture for imbibition experiment .29

Figure 3.24 Saturation measurement for imbibition with rough-walled fracture............. 29

Figure 3.22 Relative permeability for imbibition for flow with stable phase path ........... 30

Figure 3.23 Drainage and imbibition data for rough-walled fracture ............................. 30

Figure 3.25 Fitted Honarpour curve for drainage in rough-walled fracture experiment ... 31

Figure 3.26 Fitted curve for imbibition rough-walled fracture experiment ..................... 31

Figure 3.27 Friction factor with Reynold's number for rough-walled experiment............ 33

Figure 3.28 Friction factor for rough-walled fracture compared to previous works .......... 34

Figure 3.29 Measured vs. calculated pressure drop using homogeneous model............... 34

Figure 3.30 Comparison of relative permeability data with previous work on fractures.. 35 


\section{Chapter 1}

\section{Introduction}

\subsection{Theoretical Background}

Multiphase flow in fractures is an important field of study for areas such as geothermal industry, oil recovery, isolation of nuclear and toxic waste in geological formations. At present, the governing flow mechanism for multiphase flow in fracture is still undetermined. There are two approaches commonly used in modeling multiphase flow in fractures, the porous medium approach and the equivalent homogeneous single-phase approach.

The porous medium approach treats fractures as connected two-dimensional porous media. In this model, a pore space occupied by one phase is not available for flow for the other phase. A phase can move from one position to another only upon establishing a continuous flow path for itself. As in porous media, the competition for pore occupancy is described by relative permeability and governed by Darcy's law. Darcy's law for singlephase liquid flow is:

$$
q_{l}=\frac{k_{a b s}\left(p_{i}-p_{o}\right)}{\mu_{l} L}
$$

where subscript $l$ stands for the liquid phase, $i$ for inlet and $o$ for outlet; $\mu, p, L, q, k_{a b s}$ are the viscosity, pressure, fracture length, Darcy flow velocity and absolute permeability respectively. The Darcy flow velocity is equal to

$$
q=\frac{Q}{b w}
$$

with $Q$ as the volumetric flow rate, $b$ the fracture aperture and $w$ as the fracture width. Absolute permeability of the fracture is a function only of the fracture aperture (Witherspoon et al., 1980) as described in the cubic law

$$
k_{a b s}=\frac{b^{2}}{12}
$$

For liquid phase in two-phase flow, Eqn. (1.1) becomes 


$$
q_{l}=\frac{k_{a b s} k_{r l}\left(p_{i}-p_{o}\right)}{\mu_{l} L}
$$

where $k_{r l}$ is the relative permeability of the liquid phase.

Similarly, Darcy's law derived for single-phase isothermal gas flow in porous media (Scheidegger, 1974) is

$$
q_{g}=\frac{k_{a b s}\left(p_{i}^{2}-p_{o}^{2}\right)}{2 \mu_{g} L p_{o}}
$$

with the subscript $g$ pertaining to the gas phase.

In two-phase flow, Eqn. (1.5) becomes

$$
q_{g}=\frac{k_{a b s} k_{r g}\left(p_{i}^{2}-p_{o}^{2}\right)}{2 \mu_{g} L p_{o}}
$$

with $k_{r g}$ as the gas relative permeability. The sum of the $k_{r l}$ and $k_{r g}$ indicates the extent of phase interference. A sum of relative permeabilities equal to one means the absence of phase interference. Physically this implies each phase flows in its own path without impeding the flow of the other. The lower is the sum of the relative permeabilities from unity the greater is the phase interference.

Relative permeability functions are usually taken to be dependent on phase saturation. The two most commonly used expression for relative permeability for homogeneous porous media are the X-curve and Corey curve (Corey, 1954). The X-curve describes relative permeability as a linear function of saturation

$$
\begin{aligned}
& k_{r l}=S_{l} \\
& k_{r g}=S_{g}
\end{aligned}
$$

where $S_{l}$ and $S_{g}$ are the liquid and gas saturation respectively. The Corey curve relates relative permeability to the irreducible or residual liquid and gas saturation, $S_{r l}$ and $S_{r g}$

$$
\begin{aligned}
& k_{r l}=S^{* 4} \\
& k_{r g}=\left(1-S^{*}\right)^{2}\left(1-S^{* 2}\right)
\end{aligned}
$$




$$
S^{*}=\left(S_{l}-S_{r l}\right) /\left(1-S_{r l}-S_{r g}\right)
$$

The equivalent homogeneous single-phase approach treats flow through fracture as a limiting case of flow through pipes. In this model, phase velocities in a fracture are equal and capillary forces are negligible. A continuous flow path is not required for movement of each phase. A phase can be carried along by one phase as bubbles, slug or other complex structures. As in pipes, flow can be described by the concept of friction factors and using averaged properties (Fourar et al., 1993)

$$
\left(p_{i}-p_{o}\right)=\frac{\Pi f \rho_{m} V_{m}^{2}}{2 A}
$$

where $\Pi$ is the fracture perimeter, $A$ is the cross sectional area to flow, $\rho_{m}$ average density and $V_{m}$ as average flow velocity. The average density is described by

$$
\rho_{m}=\frac{\rho_{g} Q_{g}+\rho_{l} Q_{l}}{Q_{g}+Q_{l}}
$$

The average flow velocity is equal to

$$
V_{m}=\frac{Q_{g}+Q_{l}}{A}
$$

The friction factor, $f$, is derived empirically as a function of the averaged Reynolds number calculated by

$$
N_{\mathrm{Re}}=\frac{2 b V_{m} \rho_{m}}{\mu_{m}}
$$

with $\mu_{m}$ as average viscosity

$$
\mu_{m}=\frac{\mu_{g} Q_{g}+\mu_{l} Q_{l}}{Q_{g}+Q_{l}}
$$

There are several expressions used to relate friction factor and Reynold's number. The commonly used one for flow through fracture is the generalized Blasium form (Lockhart and Martinelli, 1949):

$$
f=\frac{C}{N_{\mathrm{Re}}^{n}}
$$


with $C$ and $n$ as constants derived from experimental data.

The validity of the two models for multiphase flow through fractures is still uncertain.

\subsection{Literature Review}

Only a few published data are available for two-phase flow in fractures. Most of the studies have been done for air-water or for water-oil systems. Earliest is Romm's (1966) experiment with kerosene and water through an artificial parallel-plate fracture lined with strips of polyethylene or waxed paper. Romm found a linear relationship between permeability and saturation, $S_{w}=k_{r w}, S_{n w}=k_{r n w}$ such that $k_{r w}+k_{r n w}=1$. Fourar et al. (1993) artificially roughened glass plates with beads and flowed air-water between them. Fourar and Borries (1995) did similar experiments using smooth glass plates and clay bricks. Both studies observed flow structures like bubble, annular and fingering bubbles comparable to flow in pipes and depicted flow in fractures to be better correlated using the equivalent homogeneous single-phase model. Pan et al. (1996) observed the identical flow structures in their experiment with oil-water systems. They observed that a discontinuous phase can flow as discrete units along with the other phase. Pan et al. (1996) also found their experimental pressure drop to be better predicted by homogenous single-phase model. All of these experiments show significant phase interference at intermediate saturations.

Pruess and Tsang (1990) conducted numerical simulation for flow through rough-walled fractures. They modeled fractures as two dimensional porous media with apertures varying with position. Their study shows the sum of the relative permeabilities is less than 1, residual saturation of the nonwetting phase is large and phase interference is greatly dependent on the presence or absence of spatial correlation of aperture in the direction of flow. Persoff et al. (1991) did experiments on gas and water flow through rough-walled fractures using transparent casts of natural fractured rocks. The experiment showed strong phase interference similar to the flow in porous media. The relative permeability data of Persoff (1991) and Persoff and Pruess (1995) for flow through rough-walled fractures were compared in Horne et al. (2000) against commonly used relative permeability relations for porous media, the X-curve and Corey curve as shown in Figure 1.1.

In both experiments of Persoff (1991) and Persoff and Pruess (1995), flow of a phase is characterized by having a localized continuous flow path that is undergoing blocking and unblocking by the other phase. Recent parallel plate experiment by Su et al. (1999) illustrates the same flow mechanism of intermittent localized fluid flow. Kneafsy and Pruess (1998) observed similar intermittent flow in their experiments with pentane through various parallel plate models made from glass, sandblasted glass or transparent fracture replicas. These observations are contrary to the findings of Fourar et al. (1993), Fourar and Bories (1995), and Pan et al. (1996). 


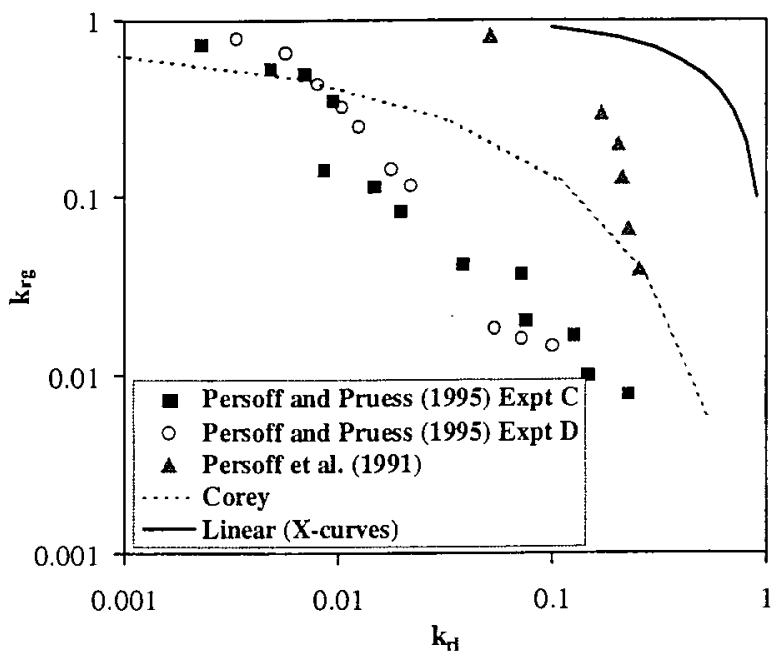

Figure 1.1 Measurement of air-water relative permeabilities in rough-walleded fractures (graph from Horne et al. 2000).

Presently, the mechanism of flow and the characteristic behavior of relative permeability in fractures are still undetermined. Issues such as whether a discontinuous phase can travel as discrete units carried along by another phase or will be trapped as residual saturation as in porous medium are unresolved. The question of phase interference i.e. is the relative permeability curve against saturation an X-curve, Corey or some other function is still unanswered. The main objective of this study is to contribute to the resolution of these issues. 


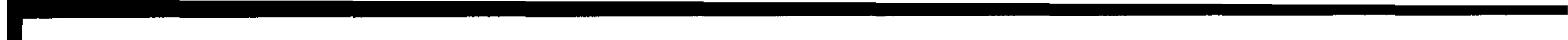




\section{Chapter 2}

\section{Experimental Methodology}

This study conducted of experiments in smooth- and rough-walled fractures. The smooth-walled fracture experiment was done by flowing nitrogen and water in between glass and aluminum plates. The rough-walled fracture experiment was done with nitrogen-water flowing through a wire mesh inserted in between glass and aluminum. The nitrogen-water system was chosen mainly because of its simplicity since it can be done at room temperature and volume changes due to compressibility and solubility are negligible. The system does not have the complication of phase change. The nitrogenwater experiments will aid in establishing a reliable methodology for future study of flow characterization and permeability calculation for more complex systems such as steamwater flow.

\subsection{Fracture Apparatus Description}

The fracture apparatus consists of a smooth glass plate on top of an aluminum plate. The whole apparatus is confined by another metal frame bolted to the bottom plate. This was done to improve the seal and to prevent deformation of the glass due to system pressure. The metal frame has several windows and a mirror attached to it for flow visualization. (See Figure 2.1 and Figure 2.2)

An o-ring (Viton 1/8" thick \#2-272) was placed in between the glass and aluminum plates as seal (see orange color lining in Figure 2.2). Placing this o-ring in the channel is not enough to provide a good seal because the channel was custom made in width and length. Thinly cut rubber sheets were placed at the outer boundary to push the o-ring to the sides of the aluminum plate. These provided excellent seal when compressed with the glass and metal frame. Since the o-ring is cylindrical in shape and the aluminum plate is rectangular, there will be a narrow channel in between the o-ring and the plate when squeezed together. A thin lining of copper based adhesive (Permatex Ultra Copper) was applied to minimize this channel. It is important to eliminate this channel for it serves as an easy conduit for the fluid to pass through instead of the fracture.

The phases enter the fracture through two separate canals. Each canal has several ports drilled in a way that they align on the surface (see Figure 2.1). The surface of the fracture apparatus was designed such that there is a 12 " by 4" space available for flow. Throughout this flow area, tiny temperature ports the size of needles were drilled. Needle-size ports were drilled so as to minimize surface discontinuity. A pressure port was drilled at each end of the flow path. The two-phase fluid exits through a single outlet. 
Top view

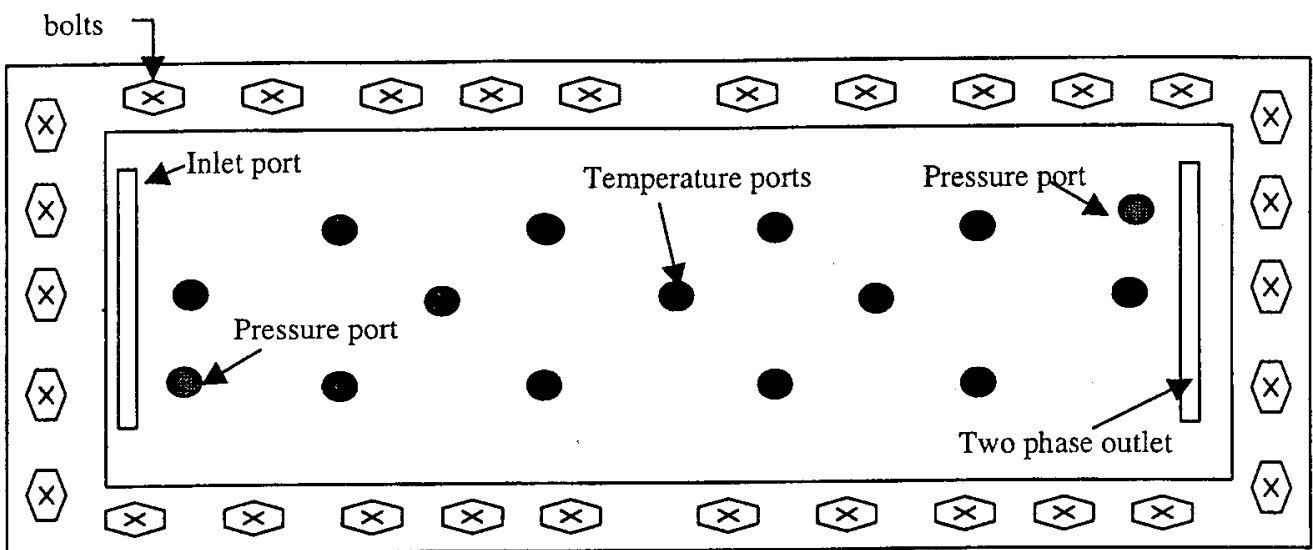

Side view

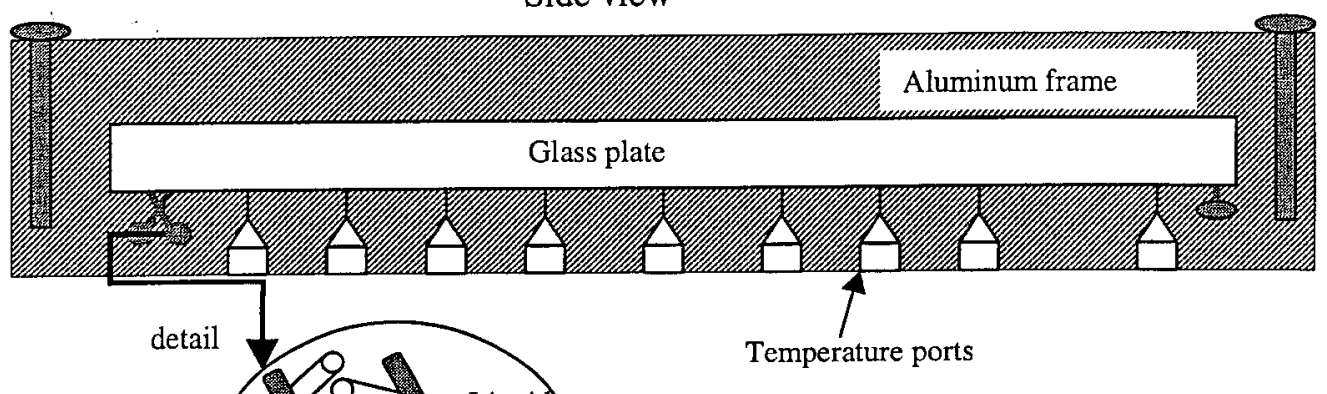

Figure 2.1 Schematic diagram of fracture apparatus.

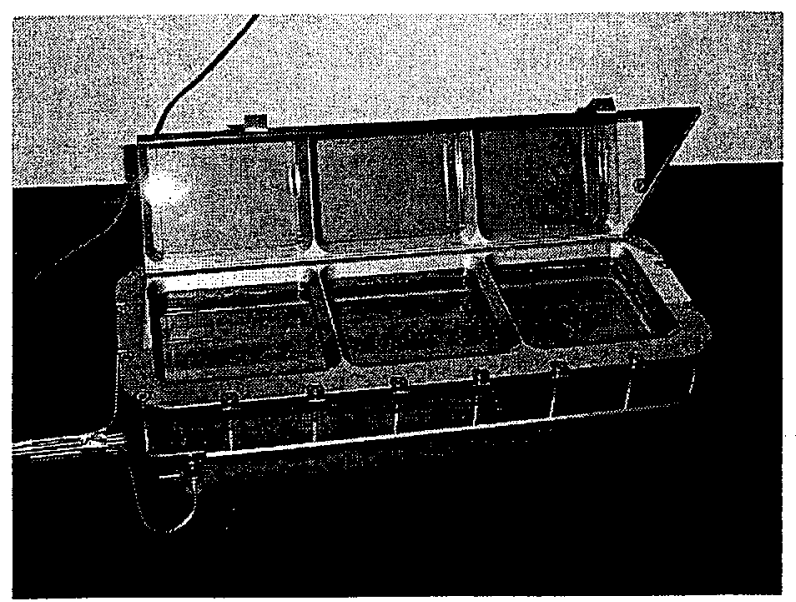

Figure 2.2 Picture of fracture apparatus. 


\subsection{Control and Measurement Techniques}

There are two canals available for input of gas and liquid. The options to input nitrogen and water as separate streams or as mixed fluid in a single stream were tried. It was found that mixing the gas and water prior to input caused no significant improvement in fluid distribution. Thus, the gas and water streams were injected separately for simplicity, ease of flow rate control and inlet pressure reading.

Gas injection was controlled through a flow regulator (Matheson Flow Controller Model 8270). The gas regulator is connected to a gas meter (Matheson Flow Meter model 8170) that gives out a digital display. For water, a meter pump (Constameter pump model III) controls the rate of injection. Distilled deaerated water was used as injection fluid. Red dye was dissolved in the water for better phase identification.

Nitrogen and water enters at the far left of the apparatus. Both phases flow in between the glass and aluminum plate and exit at the far right through a single channel. Attached to the exit is a cross of larger diameter that enables the separation of the phases for outlet pressure measurement. Figure 2.3 is a schematic diagram of this configuration.

Low capacity differential transducers were used to measure the gas phase pressure drop, liquid phase pressure drop and the gas-phase outlet pressure. The liquid differential transducer (Celesco Transducer Model CD 10D range 0-5psi) is attached to the input water stream and to the bottom of the cross separating the phases at the outlet. The gas differential transducer (Celesco Transducer Model CD $10 \mathrm{D}$ range 0-5psi) is connected to the nitrogen inlet and to the top of the cross separator. Another gas transducer (Celesco Transducer Model CD $10 \mathrm{D}$ range $0-0.5 \mathrm{psi}$ ) is attached to the top of the cross separator. This last transducer measures the outlet pressure of the gas. These transducers send electrical signals to a Labview program designed to record pressure data at user specified time interval. See Figure 2.3.

Experience showed that these fracture experiments are unsteady state by nature. At a single gas-water input ratio, there is significant pressure fluctuations accompanied by saturation changes and change in gas flow rate (see Section 3.1.1). The water flow rate is considered constant since it is injected by meter pump. Due to this unsteady nature, data acquisition then requires gathering of instantaneous pressure, flow rate and saturation data.

Instantaneous data gathering was accomplished by the use of a digital video camera. Video shots were taken of the pressure, flow rate and saturation data displayed all at the same time. The pressure data were displayed by voltmeters attached to each transducer outlet. The digital output of the gas meter displays the gas flow rate. The saturation was taken from the image of the whole flow area of the fracture. Still images were then taken from the recorded video film. The data gathered from the video was connected with the Labview data through the time read from a digital clock recorded along with the other data. Figure 2.4 shows a typical video image taken from the experiments. See also Figure 2.3. 


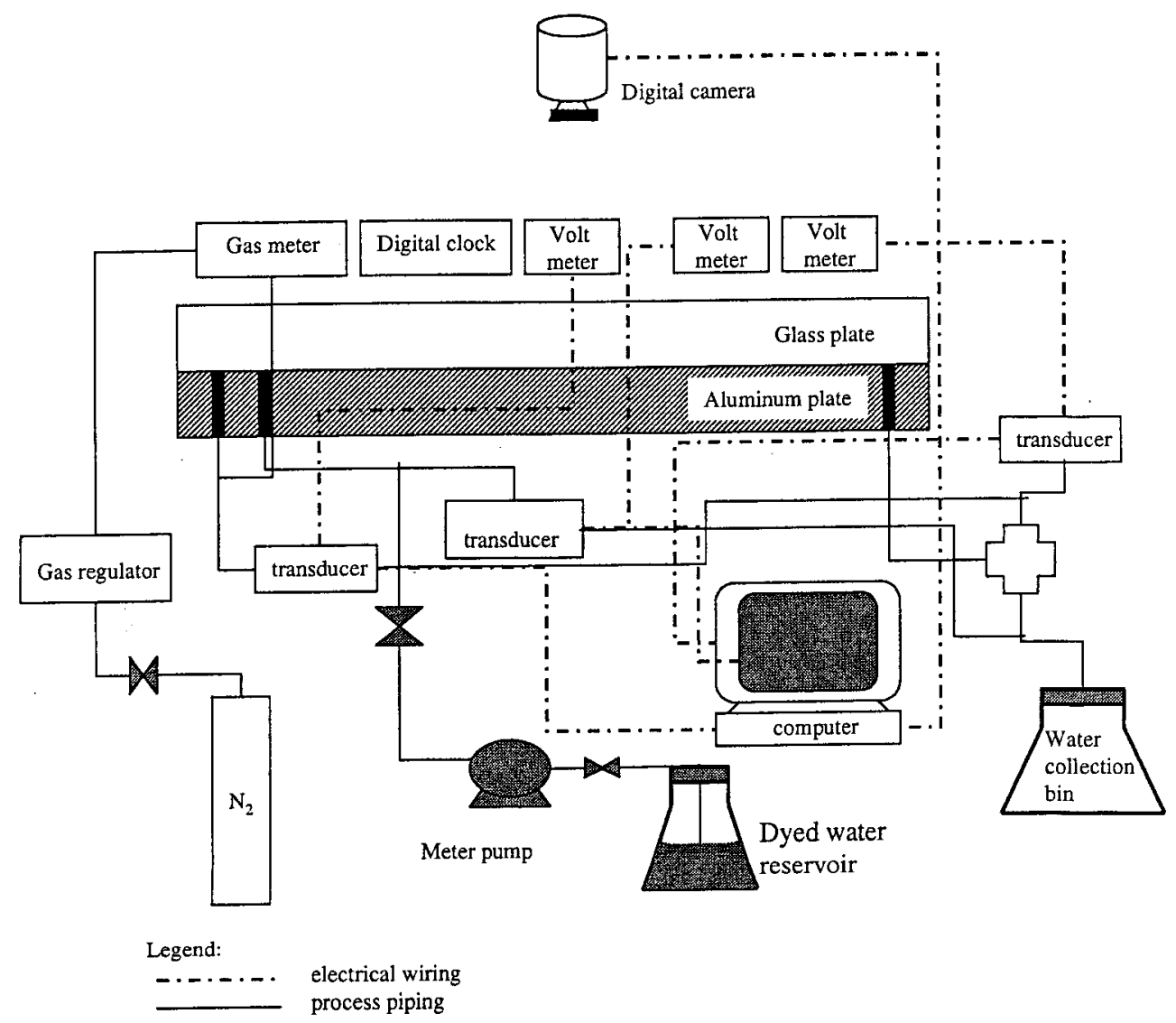

Figure 2.3 Process flow diagram for nitrogen-water experiment.

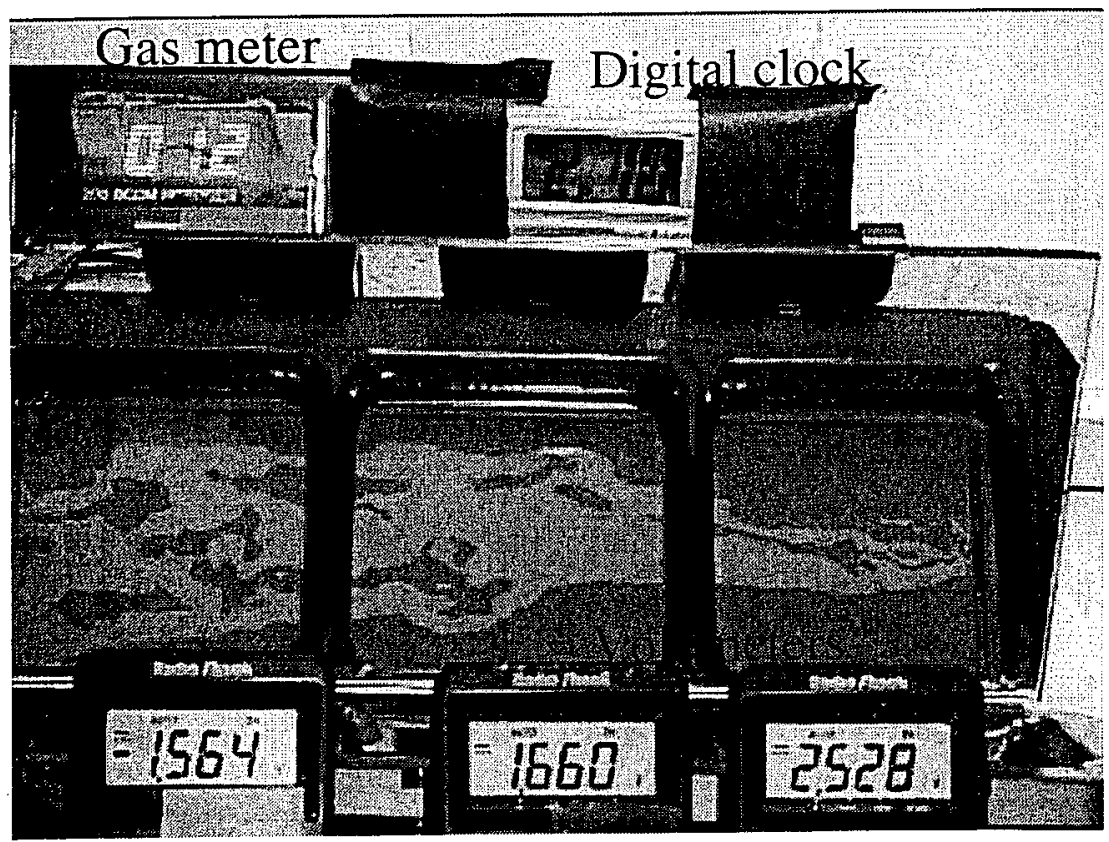

Figure 2.4 Sample video image taken for nitrogen-water runs. 
Drainage and imbibition experiments were done for smooth- and for rough-walled fractures. The glass against the aluminum plate represented the smooth-walled fracture while the rough-walled was achieved by inserting a wire mesh between the glass and aluminum plate. The wire mesh is made from $0.00065^{\prime \prime}(0.0026 \mathrm{~cm})$ diameter stainless steel wire and has $30 \times 30$ mesh size. For both the rough- and smooth-walled fracture configurations, stainless steel shims were inserted at the perimeter of the flow area in between the glass and aluminum plate. The shims are $0.003 "(0.0076 \mathrm{~cm})$ thick.

Drainage experiments were performed first. To start, the fracture was fully saturated with water. Unlike in porous media, parallel plates can be easily saturated with water if the aperture is small enough. Full saturation is achieved simply by flowing water at slow rate into the completely dried apparatus. This approach was used for both the smooth- and rough-walled configurations. The drainage experiment proceeded with the water injected at a constant rate and gas rate increased incrementally. If saturation change was not evident, then both the gas and the water rate were changed. The reverse was done for imbibition. At a specific gas-water ratio, the experiment was made to run for several minutes (usually 30 minutes) or up to a time when the pressure change was minimal or when pressure fluctuations seemed to be in certain range before taking video record.

\subsection{Saturation Measurement}

From the still image of the fracture flow shown in Figure 2.4, saturation was computed by measuring the area that each phase occupied. The photographs were processed in a Matlab program. The program first cuts the photograph to display just the image of the flow area. Using this cut image, the program does quadratic discriminant analysis to group the pixels of the picture into three groups: the water phase, gas phase and the frame. The grouping is based on color differences. Saturation is calculated as total pixels of liquid group over the sum of the gas and liquid group. Figure 2.5 is a comparison of the gray scaled image produced by the program and the original cut photograph from the digital camera. The accuracy of the program in calculating the saturation can be related to the similarity in details of the gray scale image to the true image. From the figure, it can be said that the program has reasonable accuracy. A copy of the Matlab program described here is attached in Appendix A.

Pan et al. (1996) also used this technique for measurement of saturation. Their study noted that the sources of error in this technique were the quality of the photographs and the water film adsorbed on the surfaces of the plates with the latter being of minimal effect. Good quality photographs are the ones with clear distinction between the gas and liquid phase. The use of dyed liquid enhanced visualization of phase boundaries. Good lighting is also necessary so that the colors in the image come out clearly. The lighting should also be positioned in a way that it does not produce shadow on the flow area. The program will mistakenly take the shadow as liquid phase even if there is gas. The light should be not too bright or focused too directly on the image to prevent reflection. Reflection will cast a white background on the picture. This will be taken automatically by the program as gaseous phase. In the experiment, good lighting was obtained by 
taking the picture in the dark with lamps directed on the white ceiling to create adequate lighting on the apparatus.

File: run312hrionin3.jpg
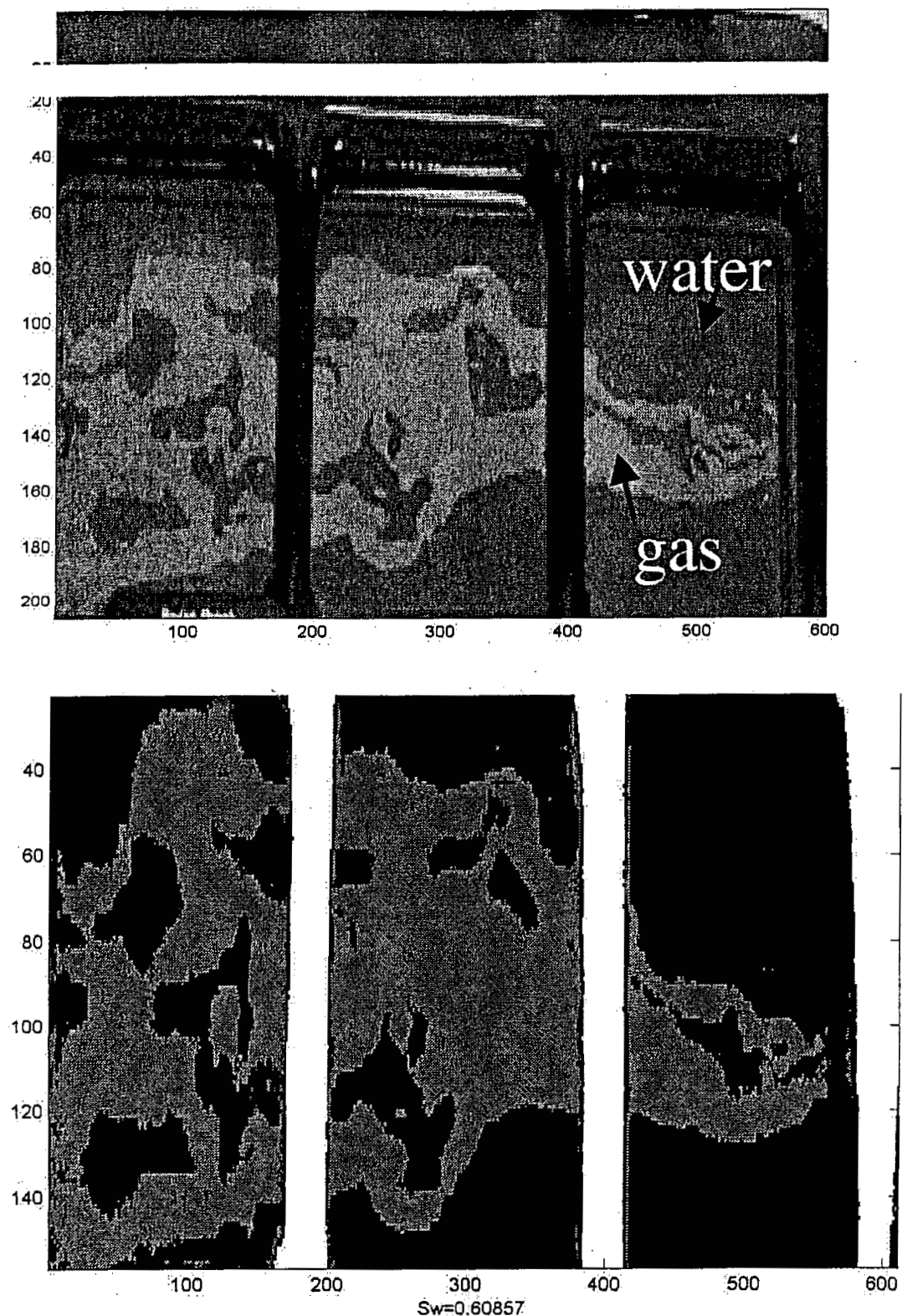

Figure 2.5 Comparison between the true color image of the fracture flow and gray scale image from Matlab program used in measuring saturation. 


\section{Chapter 3}

\section{Results and Discussion}

\subsection{Smooth-walled Fracture Experiments}

\subsubsection{Observed Flow Mechanism}

One dominant flow mechanism was observed in the smooth-walled fracture experiment. Each phase travels through the fracture by forming a localized continuous flow path. This flow path is unstable as the other phase constantly blocks and unblocks certain points in the path.

For example in the drainage experiment, the gas forms its own flow path through the liquid-dominated fracture. This flow path undergoes continuous snapping and reforming due to the invasion of water. This blocking and unblocking of flow path causes continuous pressure fluctuations throughout the experiment even at a constant gas-water ratio. Figure 3.1 shows the pressure fluctuations and the corresponding events observed. Snap shot images of the flow at these times are seen in Figure 3.2. These pictures were taken at a gas rate of $19 \mathrm{cc} / \mathrm{min}$ and water rate of $8.5 \mathrm{cc} / \mathrm{min}$. It was observed that the lower pressure drop corresponds to the time when gas is establishing its channel (see time 2:14 p.m. in Figure 3.1 and Figure 3.2). Upon establishing a complete path, gas is able to rush through the fracture length. This causes an increase in the gas pressure drop. As the gas surges, there is more space for water to come through the fracture. Water invades the gas channel (see time 2:16 p.m. in Figure 3.1 and Figure 3.2). As water breaks through there is an increase in liquid phase pressure drop. These are the pressure peaks seen in Figure 3.1. The cycle continues with the gas forming its pathway and water invading it (see time 2:17 p.m. and 2:18 p.m. in Figure 3.1 and Figure 3.2).

This flow mechanism of moving through a continuous flow path was observed over a wide range of gas-water ratios from $10^{-1}$ to $10^{4}$. The width of the flow path increases as gas rate increases. This flow path, however, was continuously being broken up by the water phase and reforming again. Figure 3.3 illustrates some examples.

This flow mechanism shows the unsteady nature of the experiment. Even at constant gas and liquid injection rate, pressure fluctuates and saturation changes as fracture space change from being a gas path to water path and vice versa. This emphasizes the importance of acquiring instantaneous pressure, saturation and flow rate measurements. 


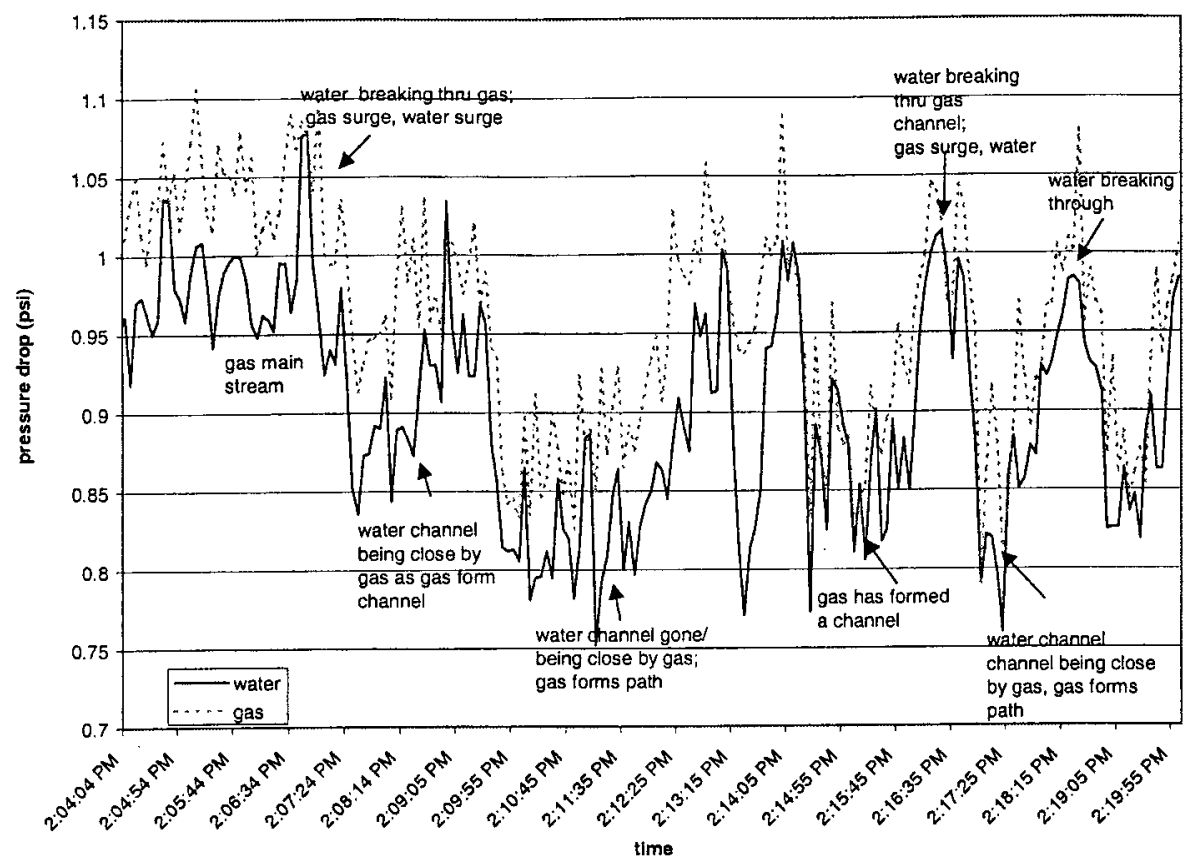

Figure 3.1 Pressure fluctuations cause by the breaking and reforming of gas flow path.

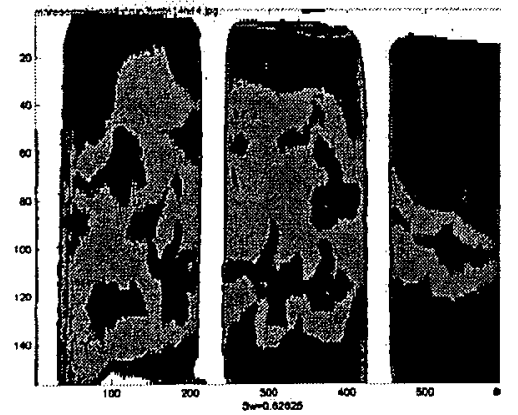

Time: $2: 14 \mathrm{pm}$

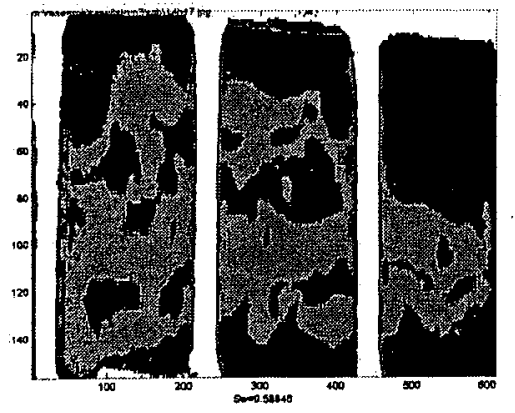

Time: $2: 17 \mathrm{pm}$

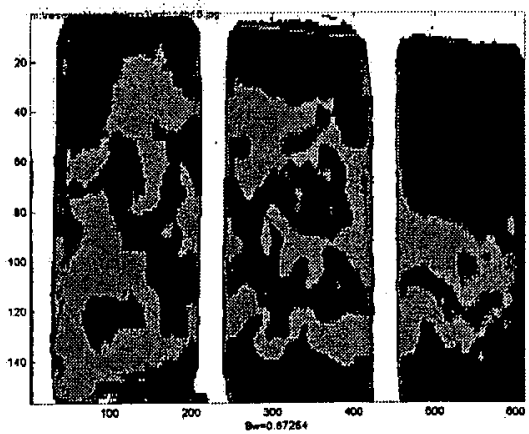

Time: $2: 16 \mathrm{pm}$

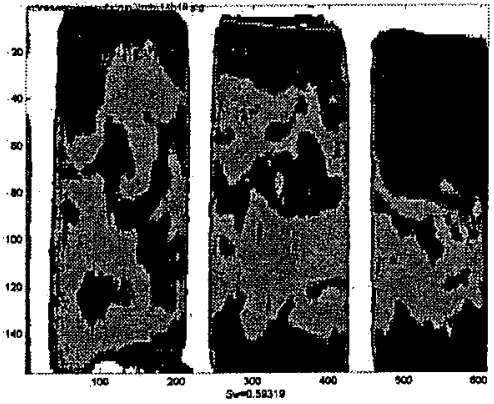

Time: $2: 18 \mathrm{pm}$

Figure 3.2 Images showing the forming and breaking of gas flow path corresponding to the time in Figure 3.1. 
Gas rate: $0.5 \mathrm{cc} / \mathrm{min}$ water rate $8.5 \mathrm{cc} / \mathrm{min}$
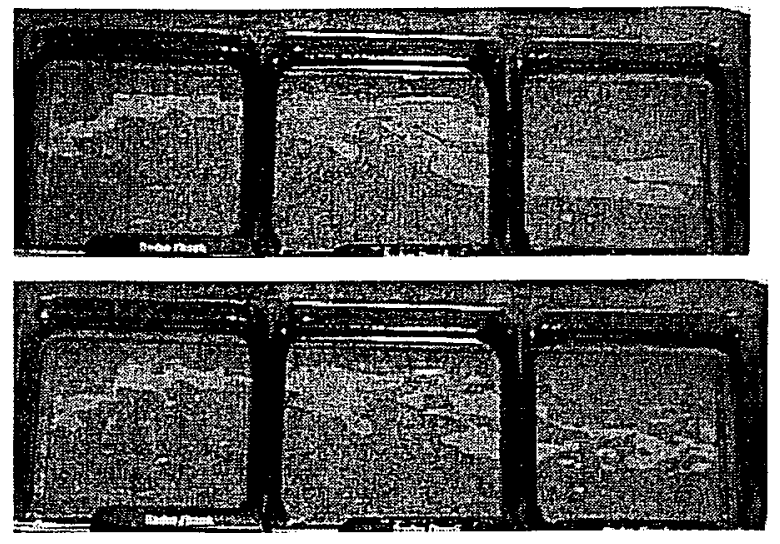

Gas rate: $19 \mathrm{cc} / \mathrm{min}$ water rate $8.5 \mathrm{cc} / \mathrm{min}$
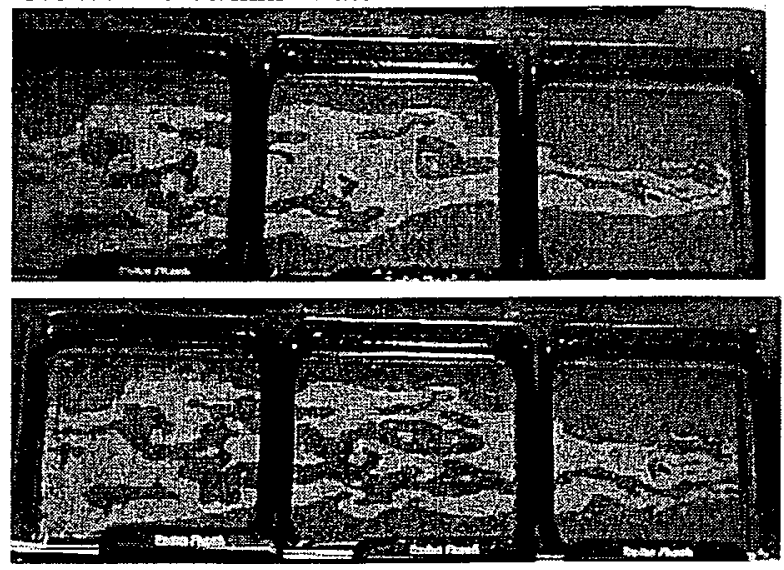

Gas rate: $140 \mathrm{cc} / \mathrm{min}$ water rate $8.5 \mathrm{cc} / \mathrm{min}$
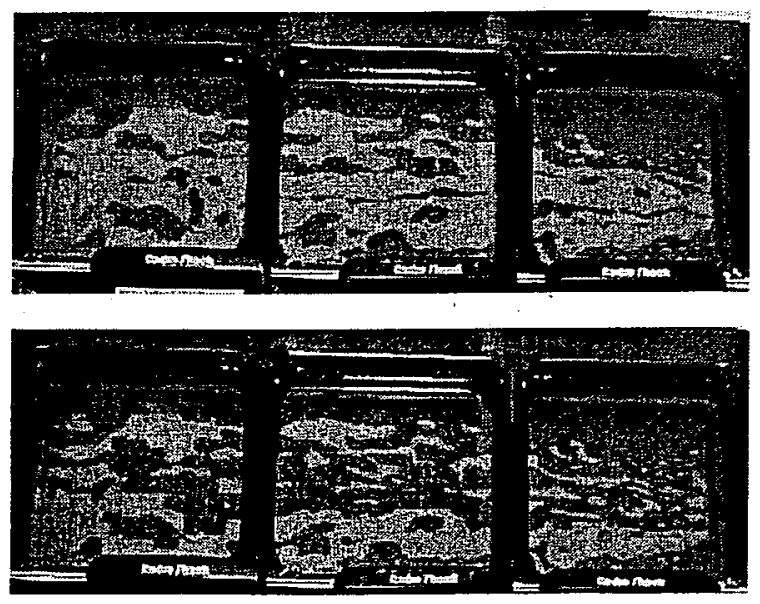

Figure 3.3 Examples of gas flow path increase in width as gas flow rate increases and water breaking up this flow path. 
Persoff and Pruess (1995) observed a similar flow mechanism in their experiment with air-water flow in a transparent fracture replica. They also related the pressure fluctuations with the blocking and unblocking of flow path. They modeled the behavior as flow through a cylindrical tube of constant radius with a certain critical throat point of radius very much smaller than the tube. Through their model they were able to prove that a phase flow path in fractures will be unstable and will consequently be invaded by the other phase. This observation is also consistent with the findings by Su et al. (1999), Kneafsy and Pruess (1998) and numerical simulation by Pruess and Tsang (1990) where the flow mechanism was described as intermittent localized flow.

Intermittent localized flow observation is contrary to that of the concept of moving "islands" or flow structures carried by one phase as observed by Fourar and Bories (1995), Fourar et al. (1993), and Pan et al. (1996). The superficial velocities for the smooth-walled experiment are graphed on Fourar and Bories (1995) flow pattern map in Figure 3.4. Although, the data covered a wide range of the proposed flow patterns, these flow patterns were not seen in the experiment here. The intermittent localized flow observed is more comparable to flow in porous media. Phases in the experiment move only through continuous phase paths like in porous media. But unlike porous media, the phase paths or occupancy are not constant but are rapidly changing and reforming.

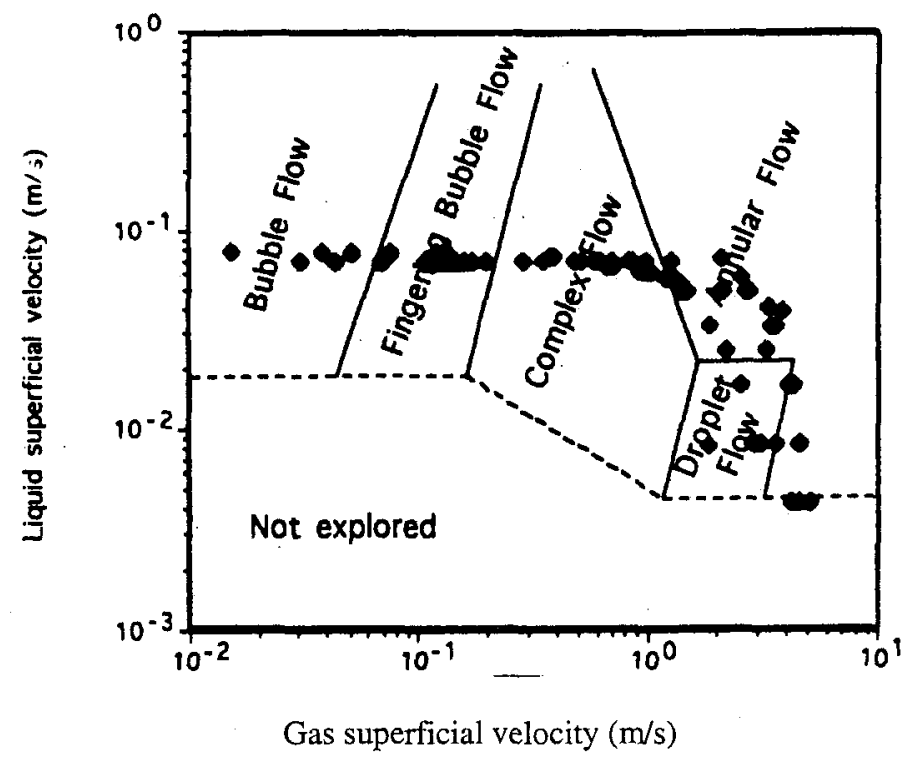

Figure 3.4 Smooth-walled fracture experimental velocity data imposed in Fourar and Bories ( 1995) flow map for glass channel.

\subsubsection{Relative Permeability Curve From Porous Medium Approach}

Eqn. (1.4) and Eqn. (1.5) for Darcy flow of two-phase flow were used to calculate relative permeabilities. The use of these equations requires the knowledge of the fracture 
absolute permeability. The absolute permeability was derived using Eqn. (1.1) with the pressure drop and flow rate coming from single-phase liquid experiments.

Two single-phase experiments were done. The results of these are illustrated in Figure 3.5. Run \#1 was done in sequence with the smooth-walled experiments. After noticing that the absolute permeability changes with flow rate Run \#2 was done several weeks later with a different pump to investigate a wider flow rate range. Both runs show that for pressures bellow $0.5 \mathrm{psi}, k_{a b s}$ is changing with flow rate. This is implies that the fluid is lifting the glass as it flows through the fracture. At pressures greater than $0.5 \mathrm{psi}$, the glass is lifted to its maximum height defined by the confinement of the metal frame. At this pressure range, the absolute permeability is constant. All the data points in the experiment lie in this range of constant absolute permeability (see Appendix B). However, the results of the two experiments were conflicting in terms of magnitude. The choice of which absolute permeability to use will affect the magnitude of the calculated relative permeability but will not affect the shape of the relative permeability curve. The highest absolute permeability derived from Run \#1 was used.

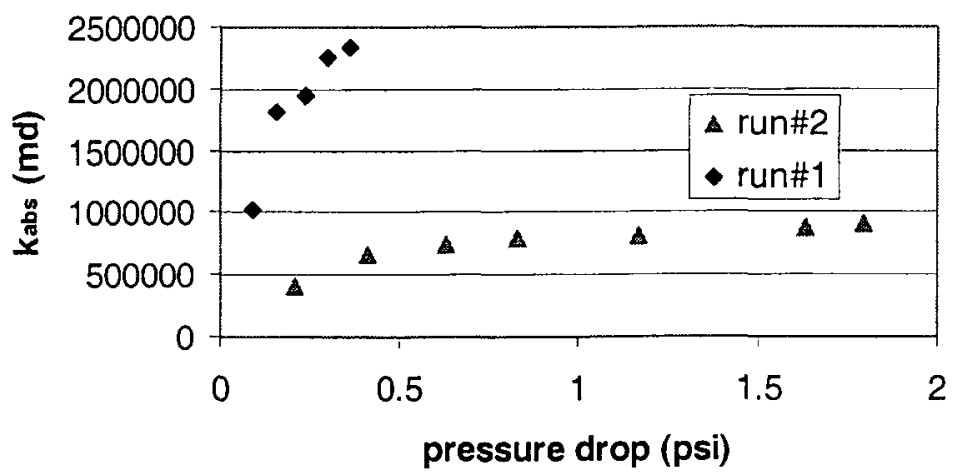

Figure 3.5 Absolute fracture permeability derived form single-phase liquid experiments for smooth-walled fracture

Appendix B shows the detailed calculation of relative permeability. The results are graphed in Figure 3.6. In this figure, neglecting the data enclosed in blue square box, the relative permeability curve has the shape of Corey curve (Corey, 1954). This follows with the observation that the flow in the smooth-walled fracture is comparable to flow in porous media. It is also noticeable that the sum of the relative permeabilities at a particular saturation is less than unity. This indicates phase interference. This is consistent with the observed flow mechanism where the gas and water compete in establishing pathways through the fracture. 


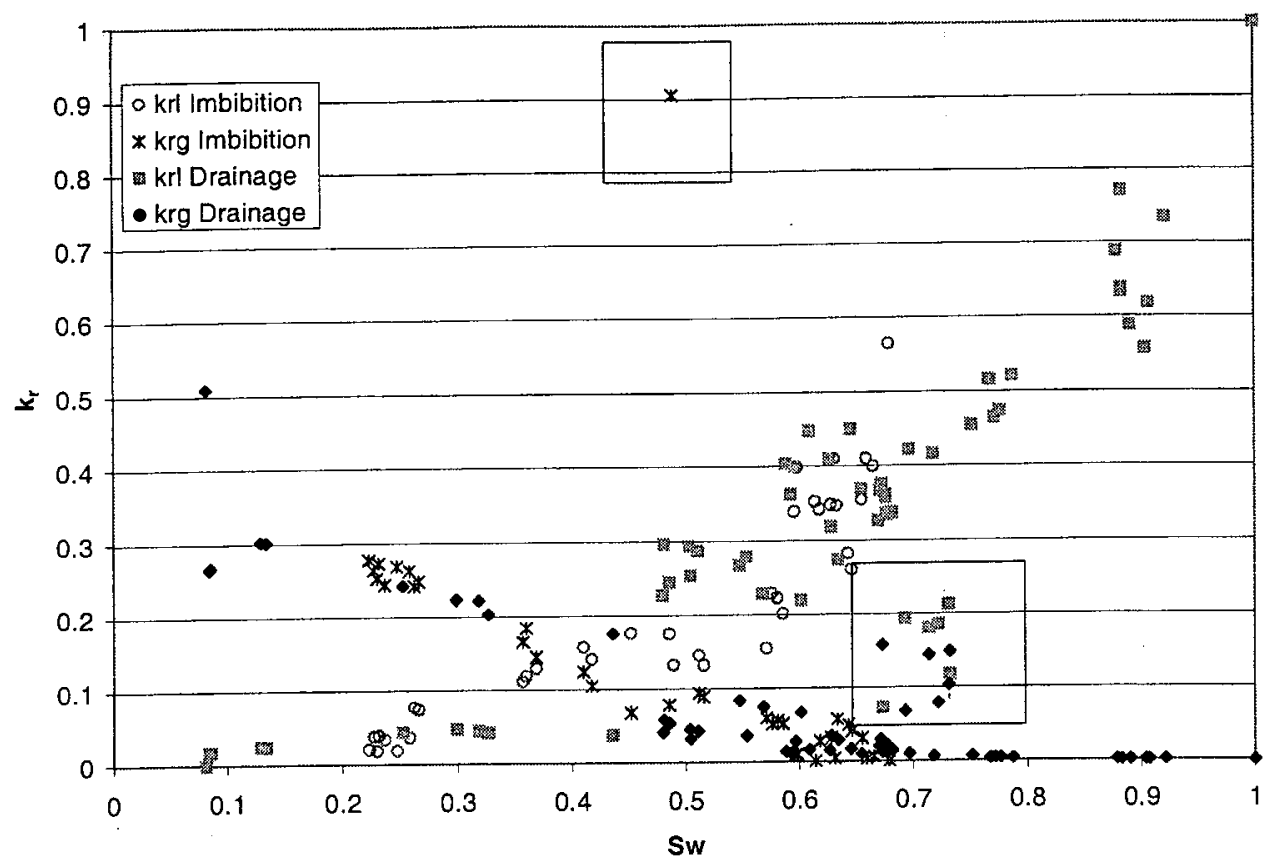

Figure 3.6 Relative permeability data obtained from smooth-walled fracture experiment

The data for both imbibition and drainage experiments were fitted separately with the Honarpour et al. (1982) expression:

$$
\begin{aligned}
& k_{r w}=k_{r w o}\left[\frac{\left(S_{w}-S_{w r}\right)}{\left(1-S_{w r}-S_{g r}\right)}\right]^{n_{w}} \\
& k_{r g}=k_{r g o}\left[\frac{\left(1-S_{w}-S_{g r}\right)}{\left(1-S_{w r}-S_{g r}\right)}\right]^{n_{g}}
\end{aligned}
$$

with

$$
\begin{aligned}
& k_{r w o}=k_{r w}\left(S_{w i}\right) \\
& k_{r g o}=k_{r g}\left(S_{w r}\right)
\end{aligned}
$$

$S_{w i}$ being the initial water saturation for drainage while for imbibition

$$
k_{r w o}=k_{r w}\left(S_{g r}\right)
$$




$$
k_{r g o}=k_{r g}\left(S_{w i}\right)
$$

The resulting curves are graphed in Figure 3.7 and Figure 3.8. The parameters for the fitted curved are tallied in Table 1. In both graphs, the fitted Honarpour curves give good representation of the trend of relative permeability data with saturation. The fitted curves have different exponents for the Honarpour expression for imbibition and drainage. This is even though the data for both drainage and imbibition seem to lie in same trend as seen in Figure 3.6. This shows the effect of saturation history on relative permeability. Compared to the Corey expression from Eqn. (1.9) and (1.10), the drainage experiments have dissimilar exponents. For imbibition, however, the value of $n_{w}(4.57)$ and $n_{g}(1.92)$ are close to Corey exponents of 4 for $n_{w}$ and 2 for $n_{g}$.

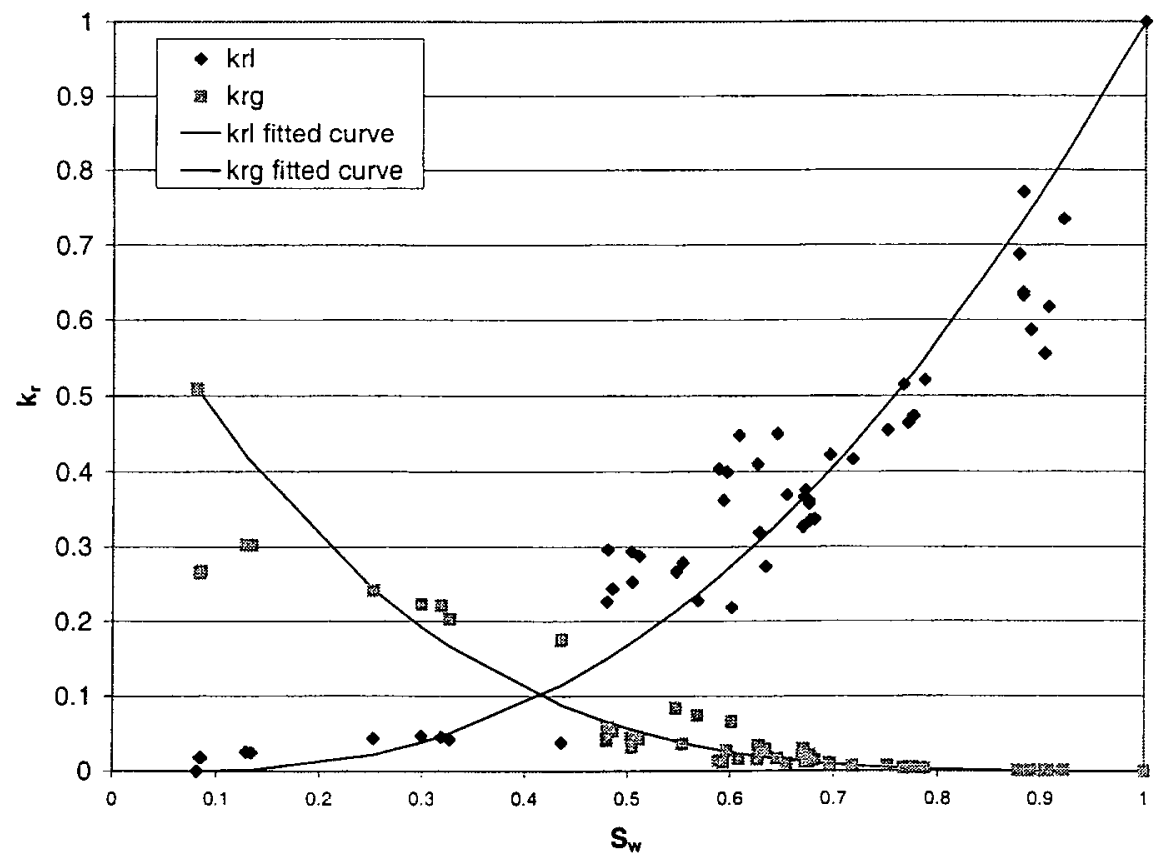

Figure 3.7 Fitted Honarpour expression for smooth-walled fracture drainage experiment. 


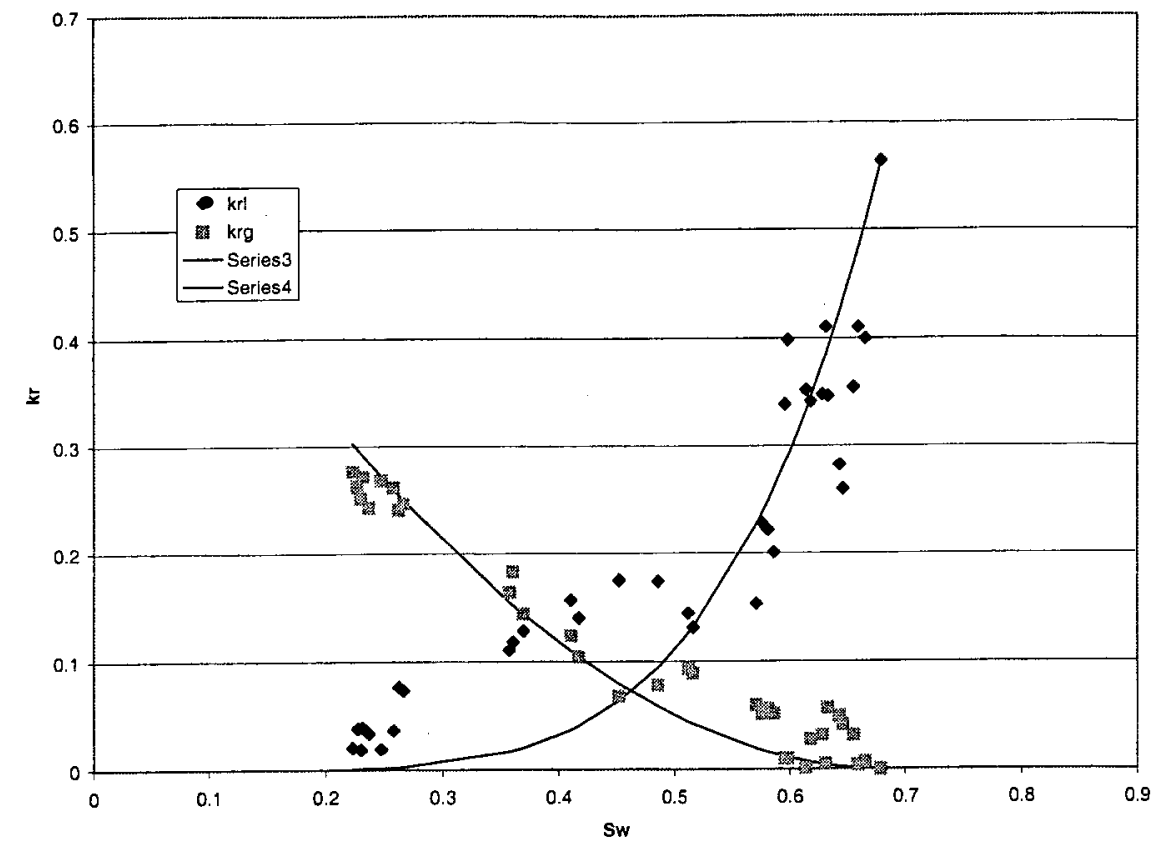

Figure 3.8 Fitted Honarpour expression for smooth-walled fracture imbibition experiment.

Table 1 Fit Parameters for smooth-walled fracture experiment

\begin{tabular}{|l|c|c|}
\cline { 2 - 3 } \multicolumn{1}{c|}{} & Drainage & Imbibition \\
\hline Swr & 0.081 & 0.081 \\
\hline Sgr & 0 & 0.321 \\
\hline krwo & 1 & 0.564 \\
\hline krgo & 0.509 & 0.509 \\
\hline nw & 2.27 & 4.57 \\
\hline ng & 3.59 & 1.92 \\
\hline
\end{tabular}

\subsubsection{Application of Homogenuous Single-Phase Pipe Flow Model for Smooth-walled Fracture}

The homogeneous single-phase pipe flow model was also applied in the data for the smooth-walled fracture. The table of calculation for this model is included in Appendix B. Figure 3.9 depicts the calculated friction factor with the modified Reynold's number in a log-log chart. From the fitted linear equation, the constants $C$ and $n$ in Eqn. (1.17) are 3.23 and 0.75 respectively. Figure 3.10 compares this result to previous works for parallel plate experiments. The slope of the fitted line $(-0.75)$ is lower than the usual finding of negative unit slope for laminar flow. Among all the studies, the data is closer to Romm (1966). 
The fit of Eqn. (1.17) for friction factor as a function of Reynold's number with the experimental data is not so good. Thus, pressure drop calculated from Eqn. (1.12) inadequately predicts the experimental data (see Figure 3.11). This was expected since the observed flow mechanism was not similar to flow regimes in pipes on which this model is based.

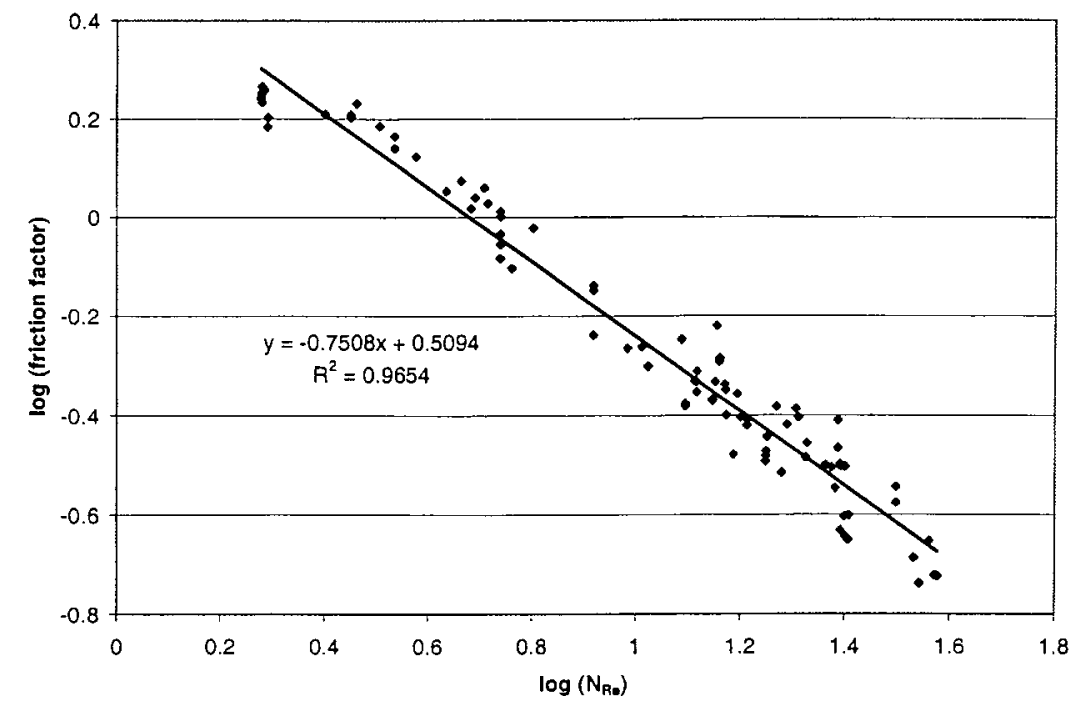

Figure 3.9 Natural logarithm of friction factor with natural logarithm of Reynold's number from data of smooth-walled fracture experiment.

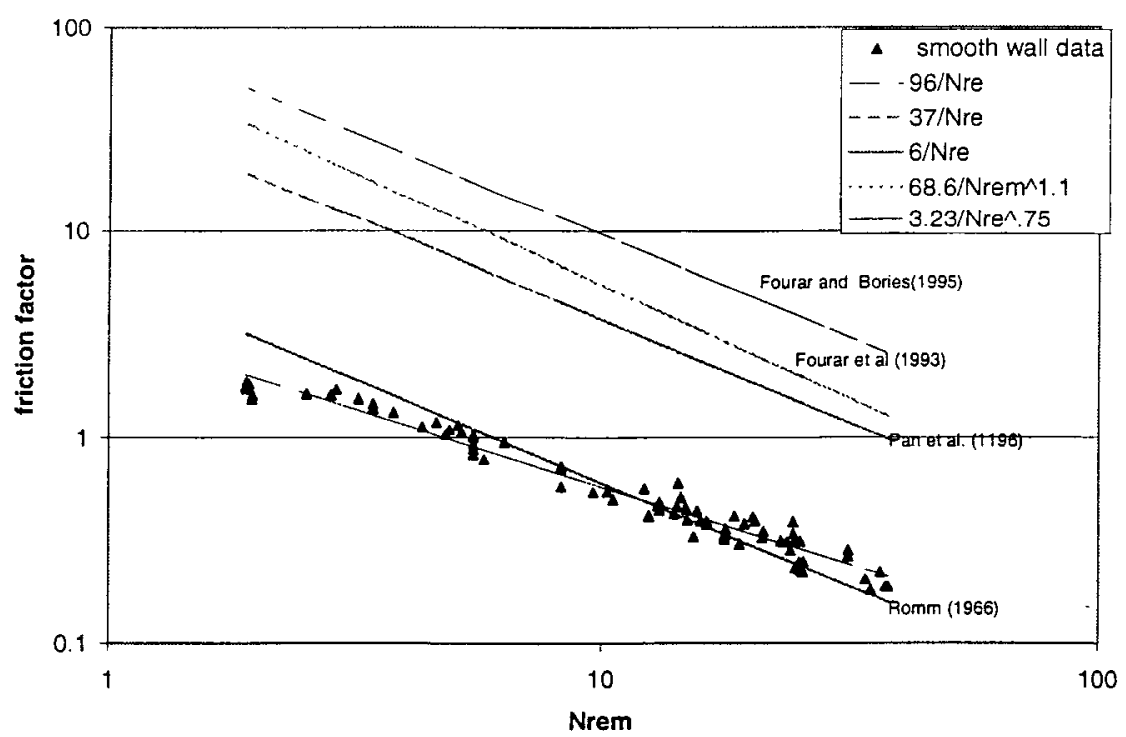

Figure 3.10 Friction factor against modified Reynold's number for smooth-walled fracture in comparison to previous works. 


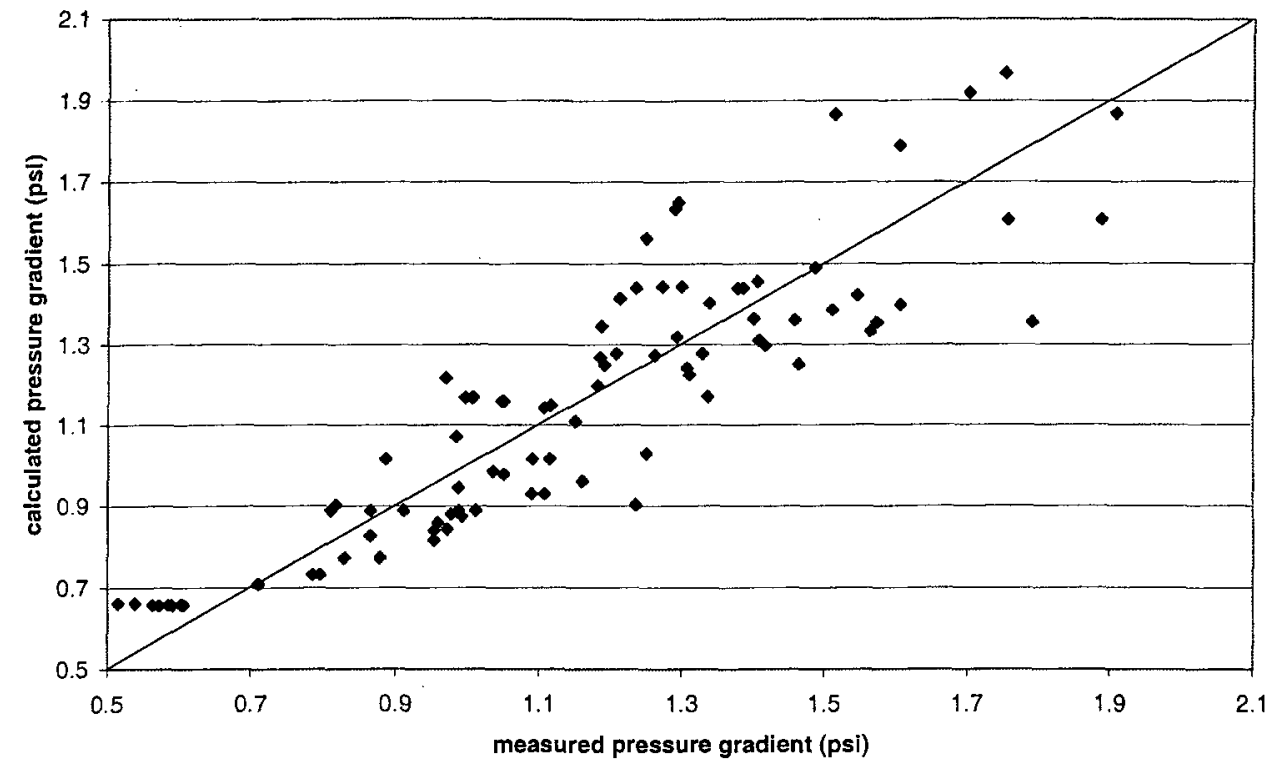

Figure 3.11 Comparison of the predicted pressure drop from homogeneous model and measured data for smooth-walled fracture.

\subsection{Rough-walled Fracture Experiments}

\subsubsection{Observed Flow Mechanism}

Similar to the smooth-walled fracture experiments, a phase in the rough-walled fracture experiment during drainage moved by establishing a continuous flow path for itself. However, the stability of the phase path varied greatly with gas-water ratio.

At low gas-water ratio, the gas invades the liquid-dominated fracture and establishes a path (see Figure 3.12). The path built is wider than that in the smooth-walled fracture at the same gas-water ratio. This maybe because the mesh gives the gas a way to move horizontally in the fracture even at low gas-water ratio. This path is very unstable. Water quickly invades it almost completely leaving few scattered residual gas areas. The residual gas areas left are not enough to establish a path. Thus, the fracture after the invasion of water can be said to return to its liquid-dominated condition. Within this liquid-dominated condition, the gas will again construct its own flow path and the cycle continues. Figure 3.13 shows two examples of gas flow channels, the water invasion that proceeds it and the residual gas areas left after the water invasion.

The formation of the gas path and the consequent water invasion again goes along with pressure fluctuations. Figure 3.14 shows the pressure data for Figure 3.12 and picture set (A) in Figure 3.13. Similar to the smooth-walled fracture (see Section 3.1.1), the low pressure drop corresponds to the forming of the gas path, followed by a peak of both gas and liquid pressure related to the surge of the two fluids through the fracture. It was 
observed that the magnitude of the pressure peaks decreases as the gas-water ratio increases.

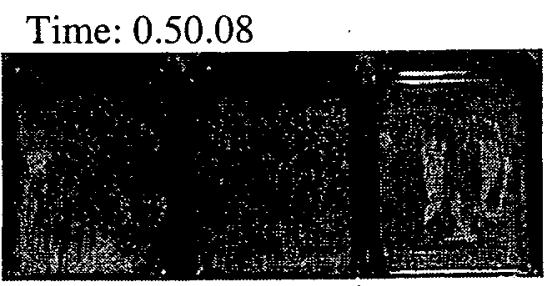

\section{Time: 0.50 .20}

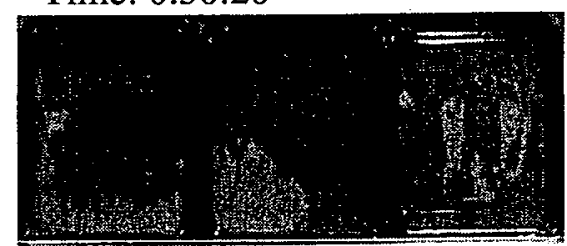

\section{Time: 0.50 .38}

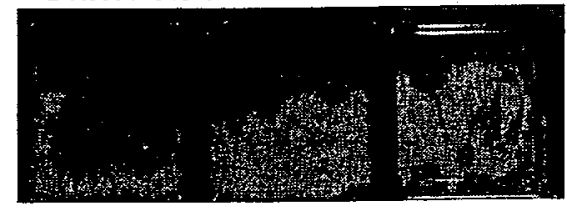

$$
\mathrm{Q}_{\mathrm{g}}=0.6 \mathrm{cc} / \mathrm{min} \mathrm{Q}_{1}=8.5 \mathrm{cc} / \mathrm{min}
$$

Figure 3.12 Gas invasion in drainage experiment with rough-walled fracture.

The diminishing magnitude of the pressure fluctuations relates to the point when the gas has established a stable path. With a stable path, gas can travel more smoothly and surge flow does not occur. Without surge flow, large pressure fluctuations are not observed. A stable gas path was reached at high gas-water ratio. As in the smooth-walled fracture, the stable gas channels increase in width with increasing gas-water ratio (see Figure 3.15). Within these established gas paths, water sometimes forms narrow channels but these channels are unstable. Water flow is mostly at the edge of the gas path. In the ratios of stable phase paths, saturation can be considered constant at one gas-water injection rate. 
Picture Set A
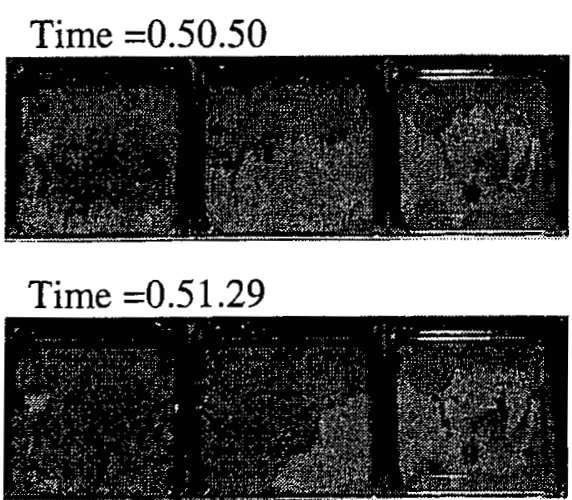

Time $=0.51 .50$

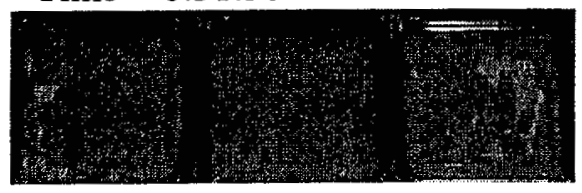

$$
\mathrm{Q}_{\mathrm{g}}=0.6 \mathrm{cc} / \mathrm{min} \mathrm{Q}_{1}=8.5 \mathrm{cc} / \mathrm{min}
$$

Picture Set B

Time $=2.54 .04$

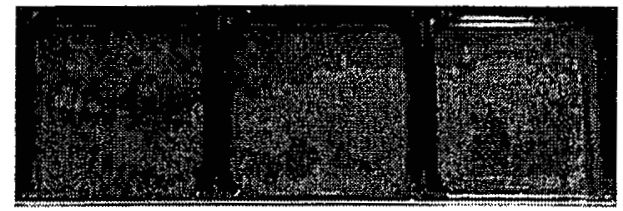

Time $=2.54 .17$

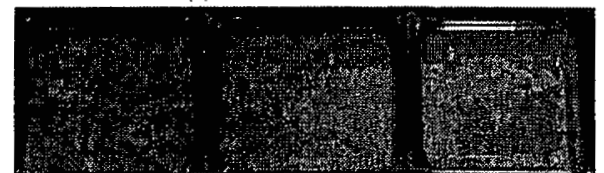

Time $=2.54 .25$

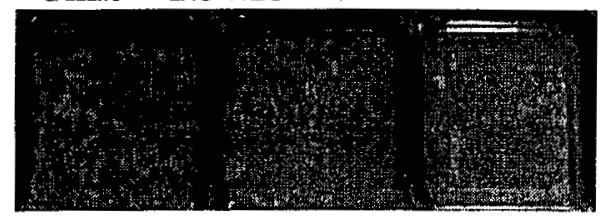

$\mathrm{Q}_{\mathrm{g}}=13 \mathrm{cc} / \mathrm{min} \mathrm{Q}_{1}=8.5 \mathrm{cc} / \mathrm{min}$

Figure 3.13 Examples of gas flow path, the invasion of water that follows and the residual gases left in rough-walled drainage experiment.

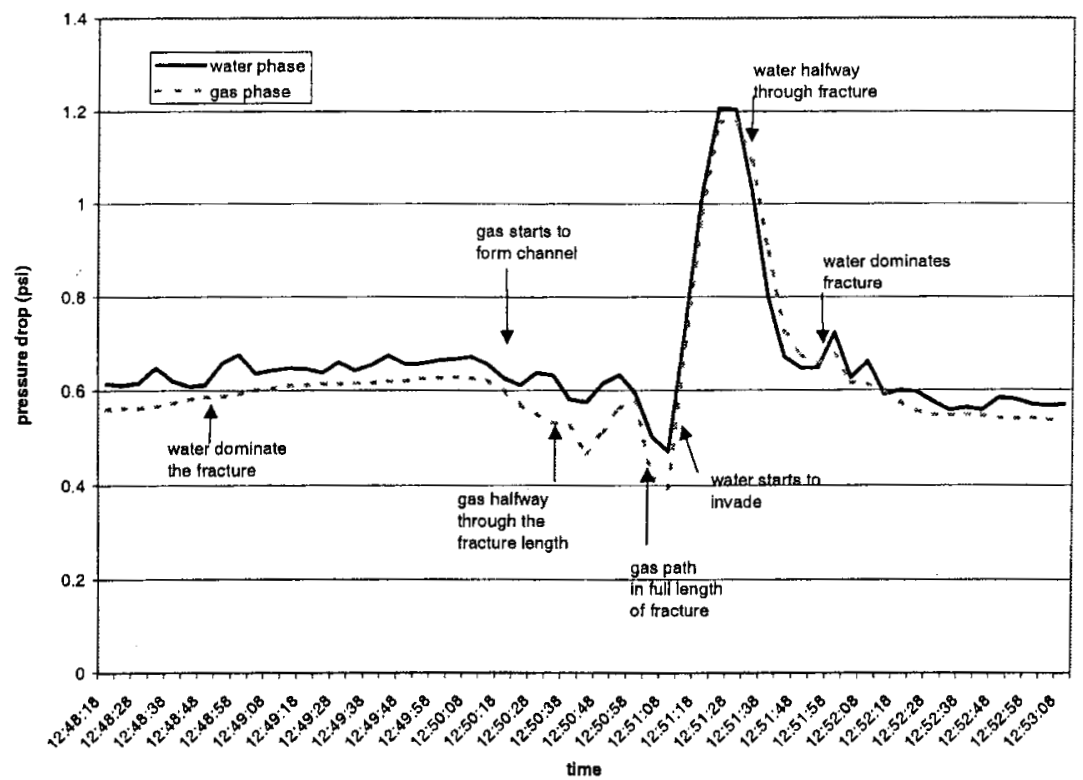

Figure 3.14 Example of pressure fluctuations caused by the building and breaking up of gas and water path. Pictures for this time span is shown in Figure 3.12 and picture set $\mathrm{A}$ in Figure 3.13. 
For the imbibition experiment, two flow mechanisms were observed. At low gas-water ratio, a stable flow path was seen (see Figure 3.16). This stable flow path is similar to that in the smooth-walled fracture and for the drainage experiment in the rough-walled fracture. At high gas-water ratio (50 and above), a wave-like flow similar to flow in pipe was observed. In this flow, water travels like wave or a steady front covering the entire fracture. This wave flow caused an increase in the pressure drop exceeding the maximum of the pressure transducer. Thus, the magnitude of the pressure drop when a wave front occurs can be higher than 5psi. Figure 3.17 shows a sample of wave-like front and its corresponding pressure peaks.
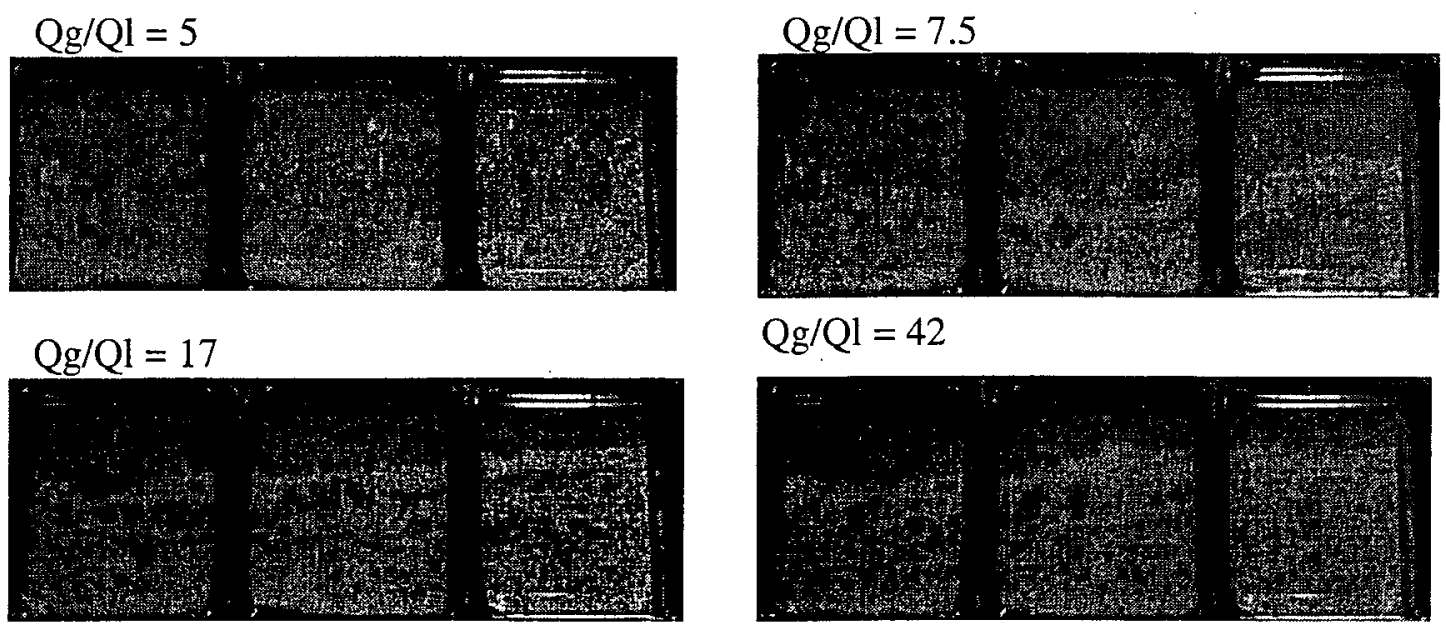

$$
\mathrm{Qg} / \mathrm{Ql}=42
$$

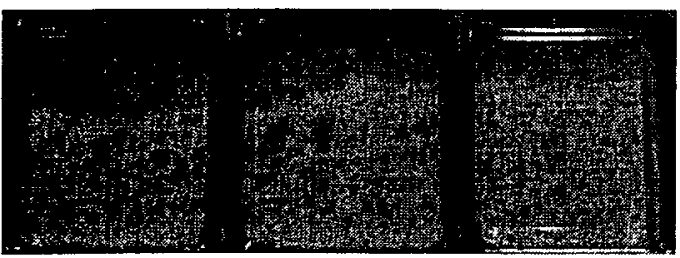

Figure 3.15 Images showing stable gas path in high gas-water ratio for rough-walled fracture.

$$
\mathrm{Q}_{\mathrm{g}}=125 \mathrm{cc} / \mathrm{min} \mathrm{Q}_{\mathrm{l}}=7.5 \mathrm{cc} / \mathrm{min}
$$
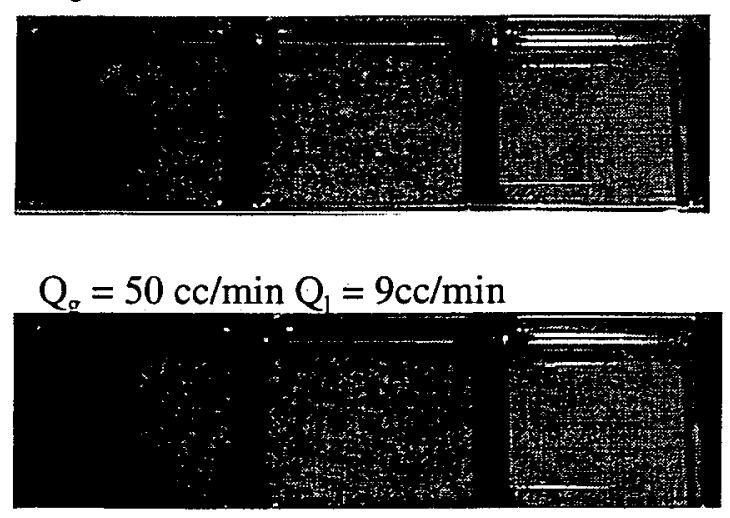

Figure 3.16 Images showing examples of stable flow path of imbibition experiment in the roughwalled fracture. 


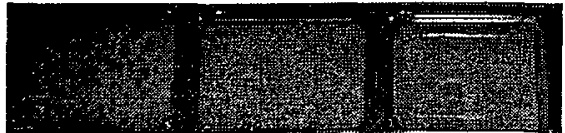

Time: 12.24 .09

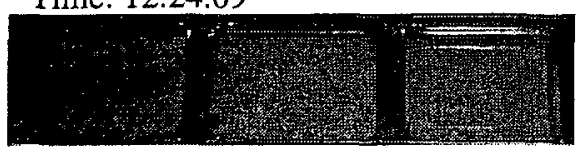

Time: 12.24 .11

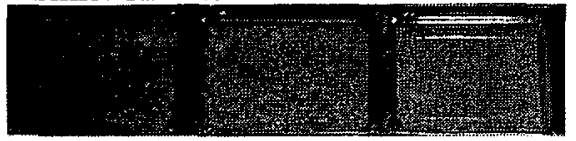

Time: 12.24 .12
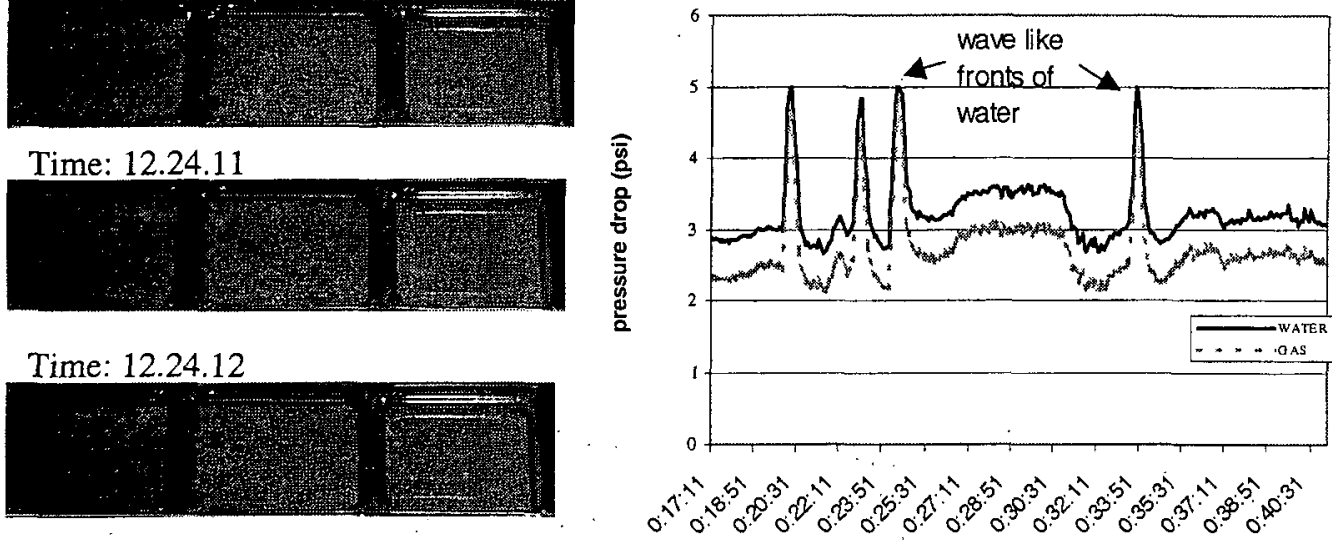

Time: 12.24 .13

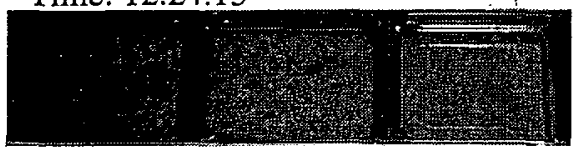

Figure 3.17 Picture of wave-like fronts seen in high gas-water ratio at imbibition experiment and its corresponding pressure peaks.

In all the experiments for the rough-walled fracture, there was considerable amount of trapped phases in the fracture as seen in the red and white isolated spots in pictures from Figure 3.12 to Figure 3.17. This is likely since the mesh provided small corners for the wetting phase to cling to and be trapped in the gas-dominated area of the fracture. It also provided a means to trap the nonwetting gas phase in the small empty space of the mesh as the water surrounds the walls.

\subsubsection{Relative Permeability Curve Through Porous Medium Approach}

The calculation procedure done in Section 3.1.2 for relative permeability was repeated for the data gathered in the rough-walled fracture experiments. A detailed list of the values is shown in Appendix B.

Several single-phase rough wall experiments were done to determine the absolute permeability of the fracture. The calculated absolute permeabilities from these experiments are shown in

Figure 3.18. The reason for the variation of the absolute permeability value with pressure was discussed in Section 3.1.2. As in the smooth-walled fracture, the absolute permeability remains constant at pressures greater than 0.5 psi. Since all the experiments 
were at pressures higher than $0.5 \mathrm{psi}$, absolute permeability was taken as the average of the measurements with pressures greater than $0.5 \mathrm{psi}$. The absolute permeability value used was 1,950 darcy.

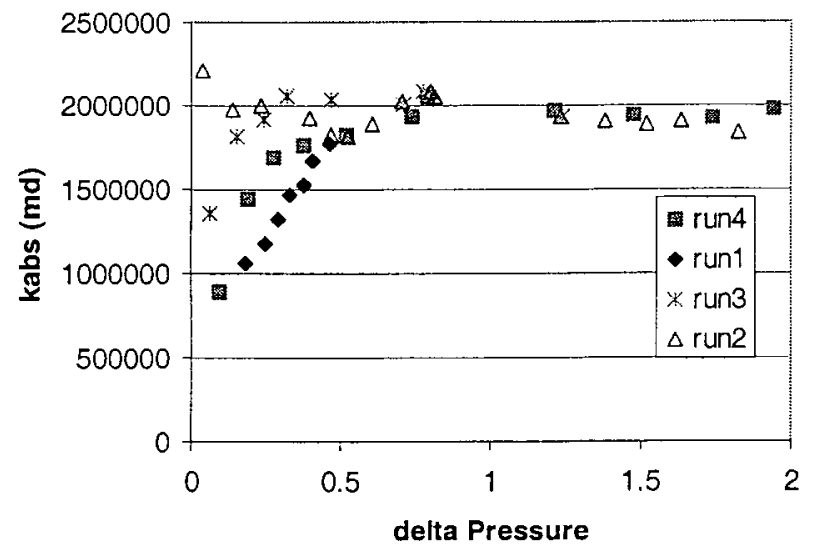

Figure 3.18 Absolute permeability from single-phase experiments for rough-walled fracture model.

Figure 3.19 shows the complete data from the drainage experiment for the rough-walled apparatus. This graph shows the relative permeability taken when the gas path was an unstable surging conduit and when it was a stable channel. Noticing that the flow is more comparable to porous flow when the gas has established a stable path, the data for the unstable gas surge was removed. The remaining data are seen in Figure 3.20. This figure displays a more defined trend. This indicates that the porous medium approach is more applicable to model flow through the rough-walled fracture when flow is characterized by established phase paths. It also suggests that other means of data analysis is needed for the data corresponding to unstable gas surge.

For imbibition, the calculated relative permeability for all types of flow mechanism observed is seen in Figure 3.21. The graph of relative permeability is too scattered showing no obvious relationship. One factor that may have caused this is the uncertainty with regards to saturation measurement for the imbibition experiment of rough-walled fracture. The picture for the imbibition experiment has lower picture quality than the other experiments and saturation analysis was more difficult due to trapped water and gas phase scattered throughout the flow area. Figure 3.22 demonstrate how the programs for saturation measurement were unable to capture the finer details of trapped phases. This effect diminishes as the stable fluid pathway is established with decreasing gas-water ratio. 


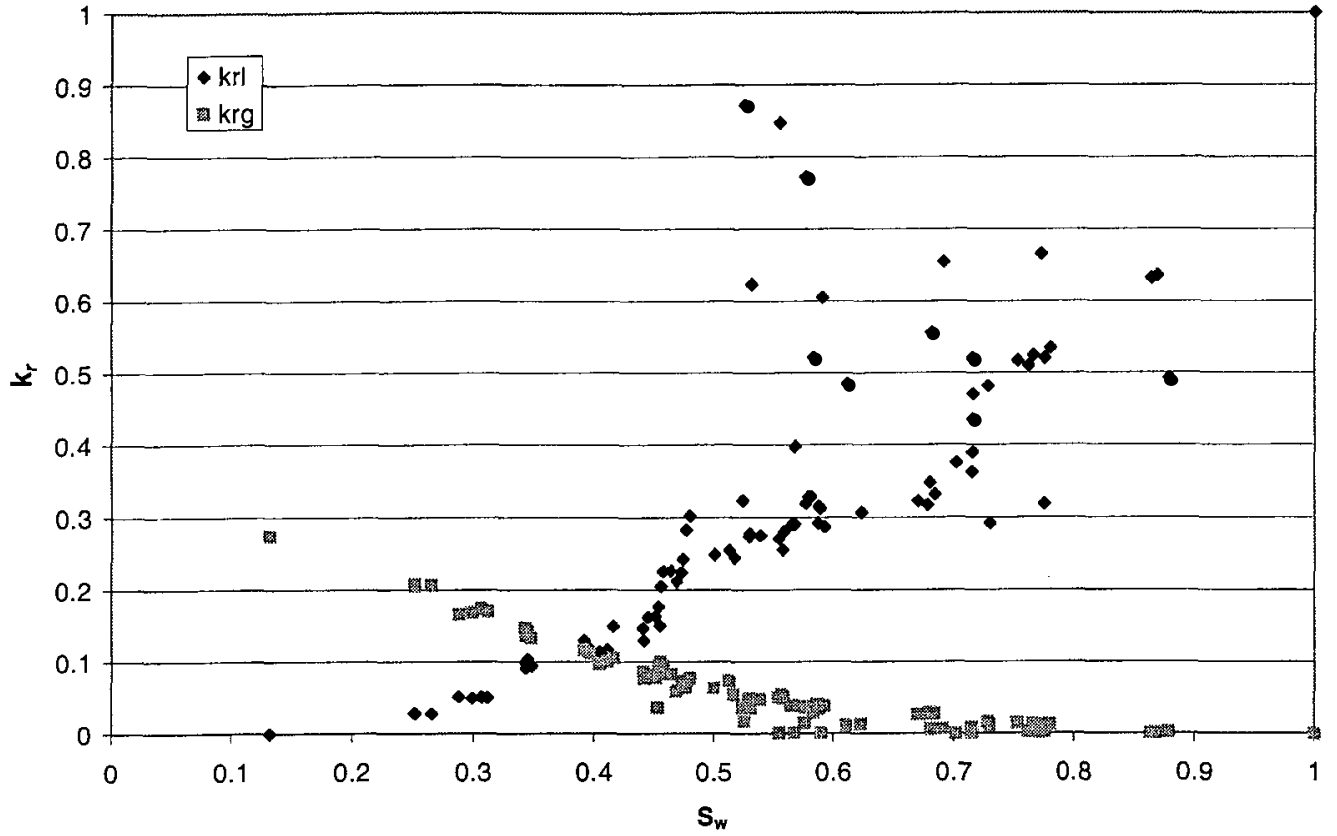

Figure 3.19 Relative permeability data for drainage experiment for rough-walled fracture model.

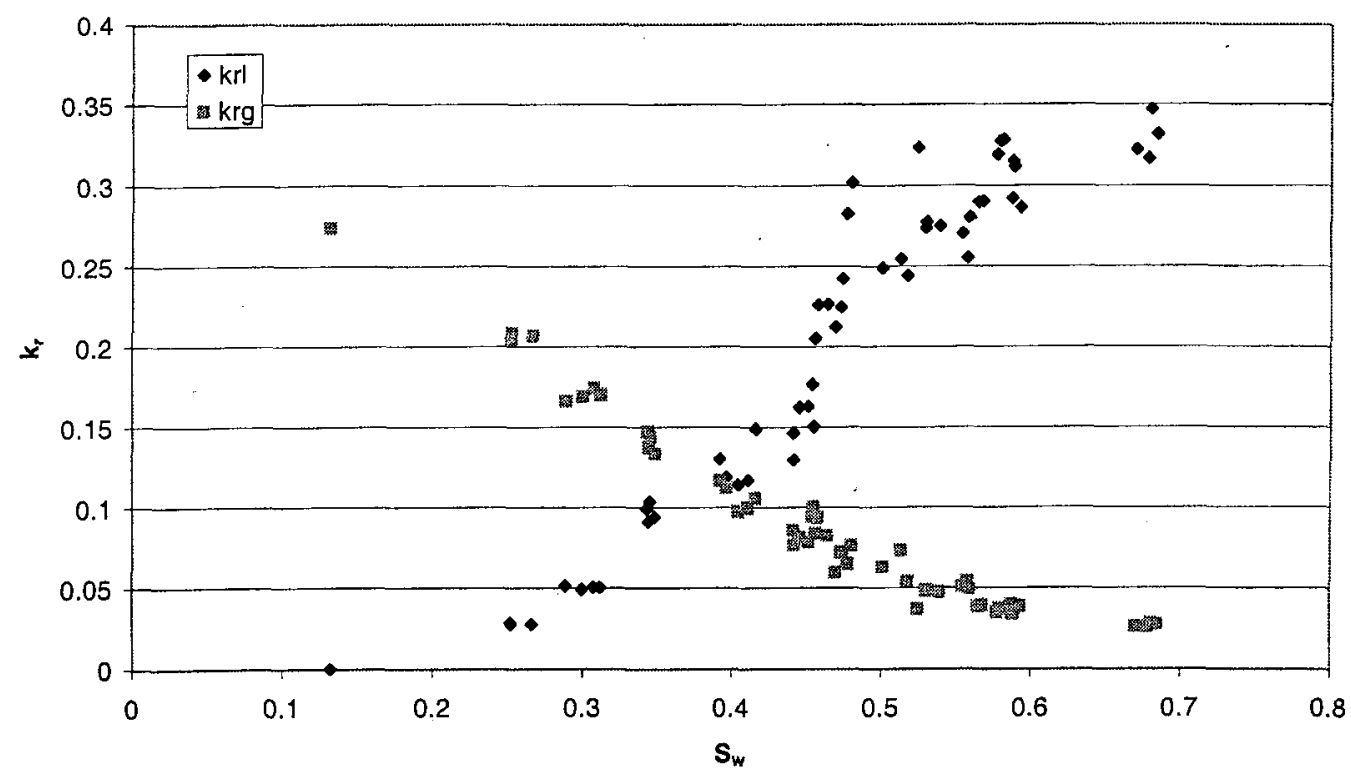

Figure 3.20 Relative permeability data for rough-walled model when the gas path is stable. 


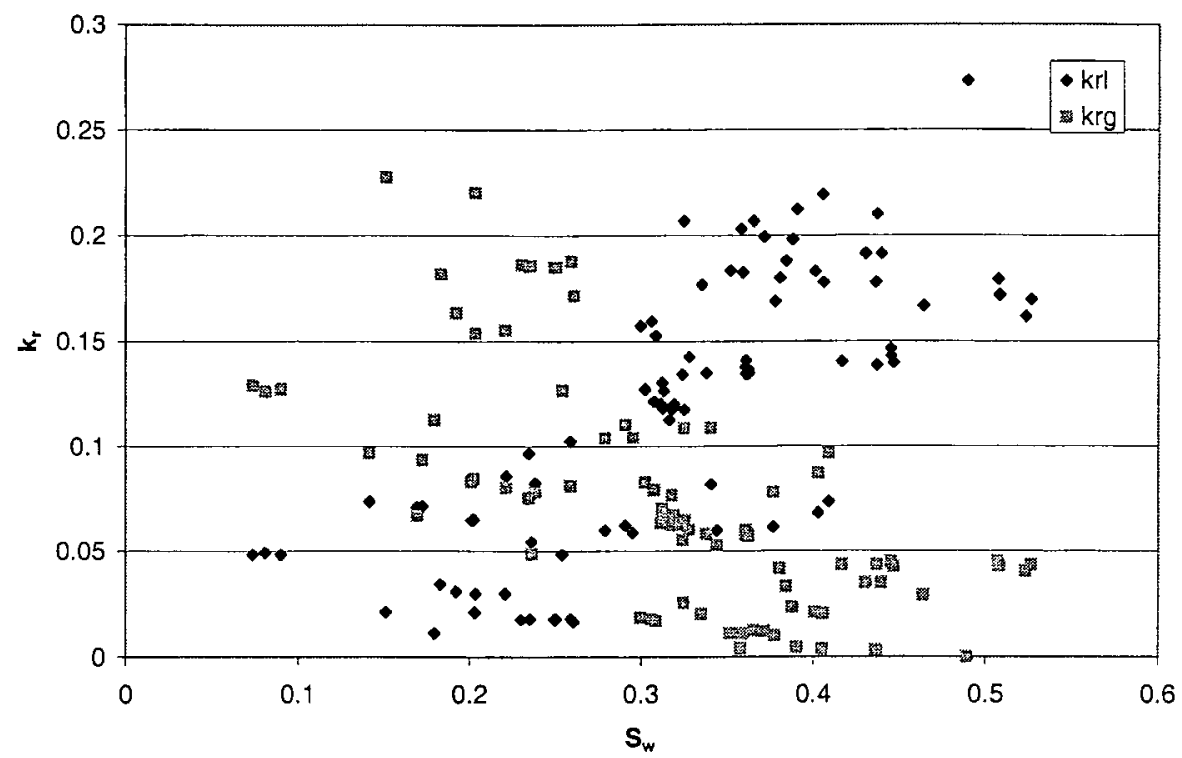

Figure 3.21 Relative permeability data for rough-walled fracture imbibition experiment.
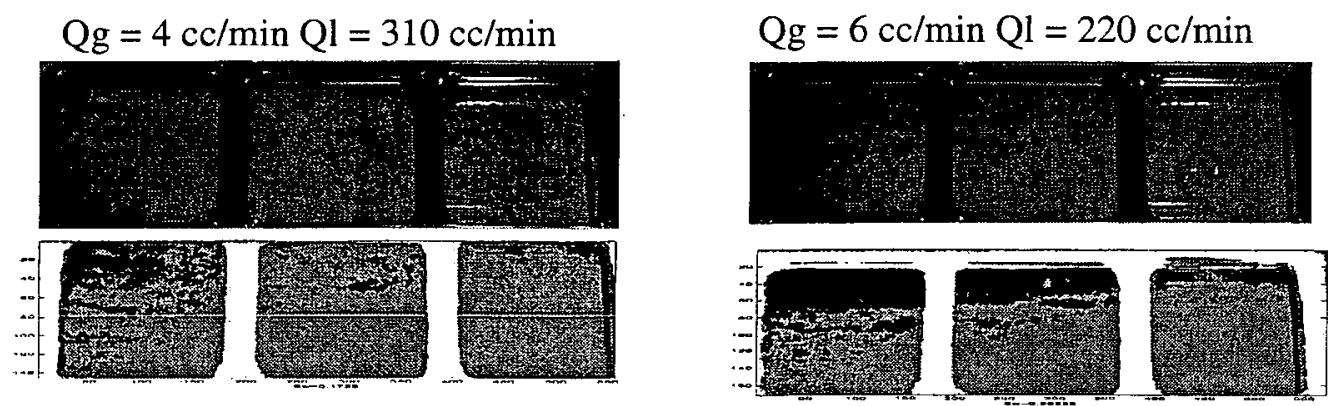

$$
S_{w}=0.1723
$$

$$
\mathrm{S}_{\mathrm{w}}=0.3023
$$

Figure 3.22 Examples of saturation measurement for imbibition experiment with rough-walled fracture.

The data corresponding only to flow characterized by stable fluid pathway was chosen and graphed in Figure 3.23. Although Figure 3.23 is an improvement over Figure 3.21, the association between relative permeability and saturation is still unclear. These data for imbibition are graphed along with the drainage data in Figure 3.24. This graph shows that relative permeability for the nonwetting phase in imbibition is lower than that of drainage while the opposite is true for the wetting phase. This is consistent with studies for oil-water systems (Amyx et al., 1960) and steam-water systems (Li et al., 1999). Amyx et al. (1960) noted that the imbibition process causes the nonwetting phase (oil) to lose its mobility at high values of wetting phase saturation while the drainage process causes the wetting phase to lose its mobility at higher values of wetting phase saturation. 


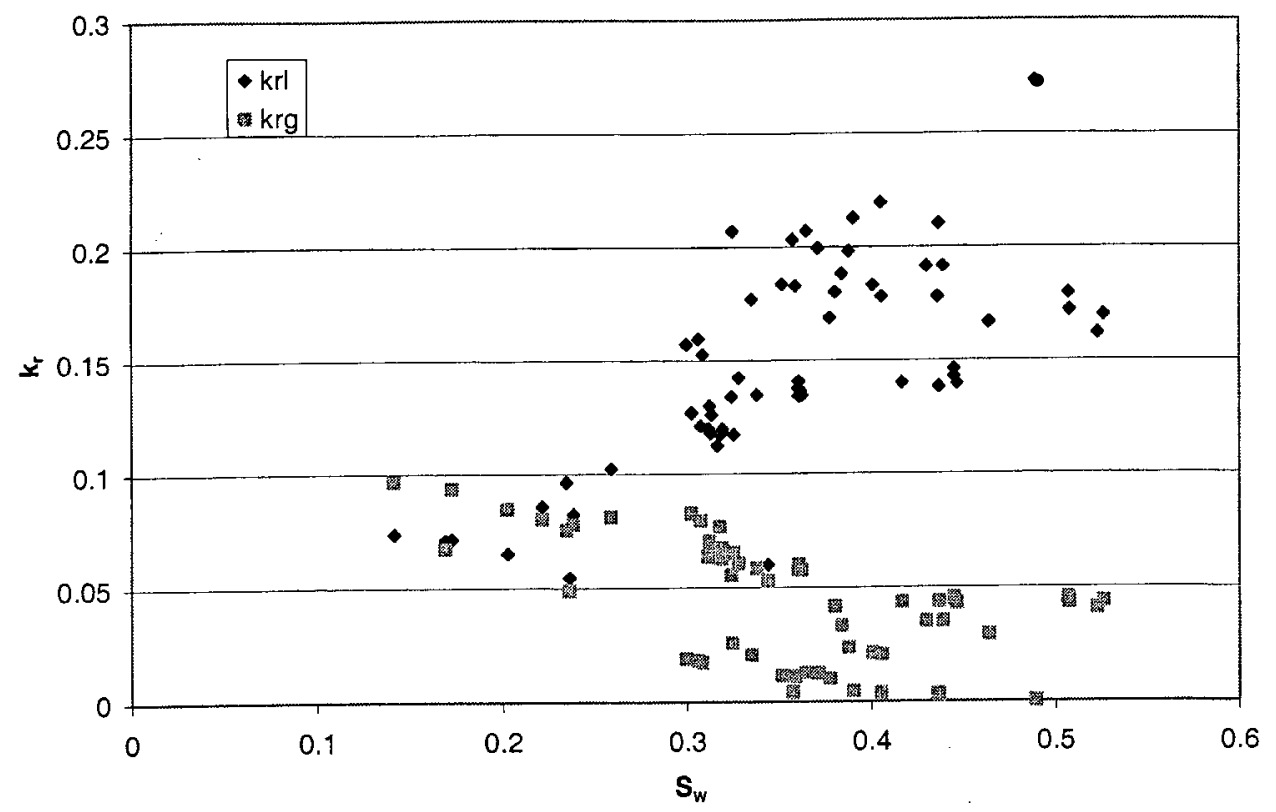

Figure 3.23 Relative permeability for rough-walled imbibition experiment for flow with stable phase path.

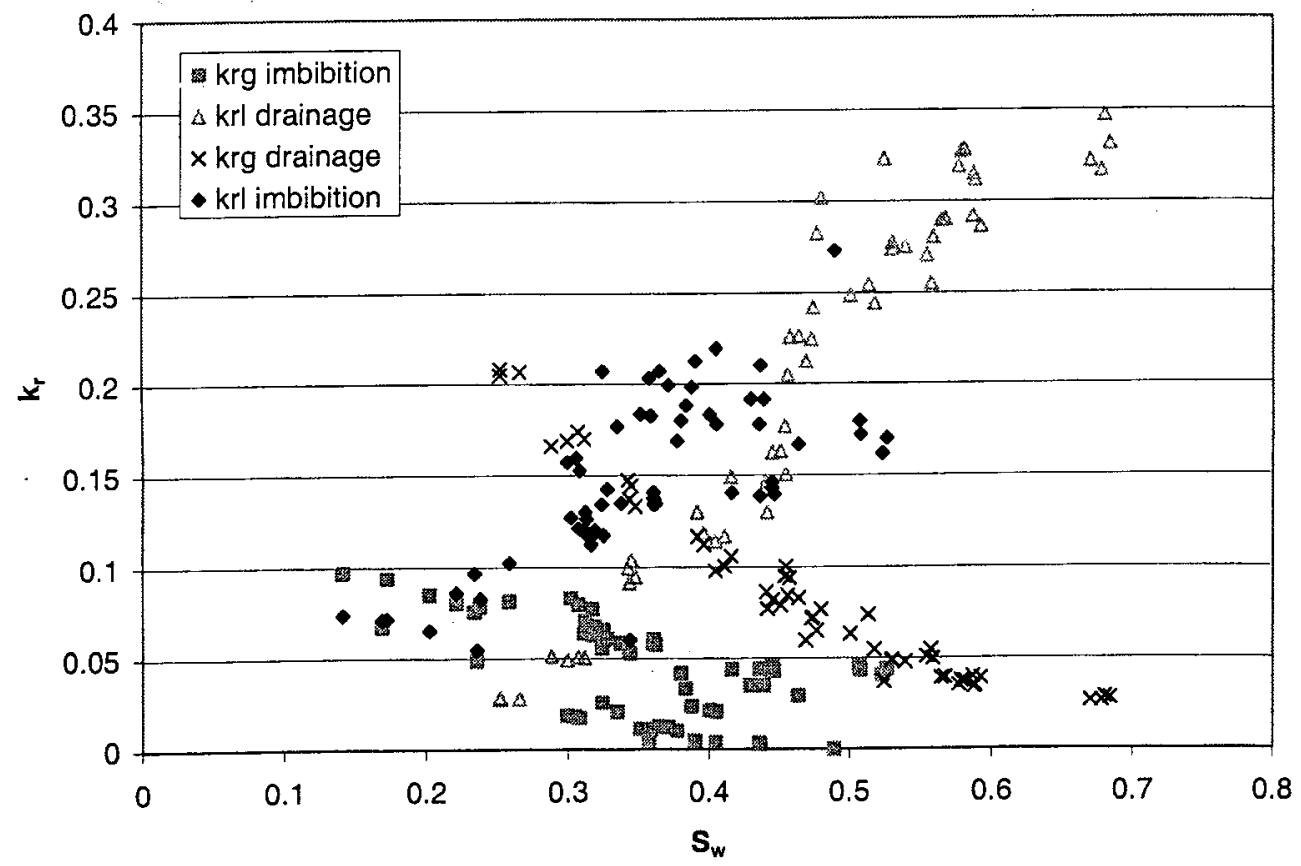

Figure 3.24 Drainage and imbibition data for rough-walled fracture. 
The Honarpour relation in Eqn. (3.1) and Eqn. (3.2) was fitted to the drainage and imbibition data separately. The resulting fit parameters are tabulated in Table 2. As expected, there is a good fit with the drainage data but not with the imbibition data. The exponents of the fitted curves are different for imbibition and drainage and both are far from Corey values.

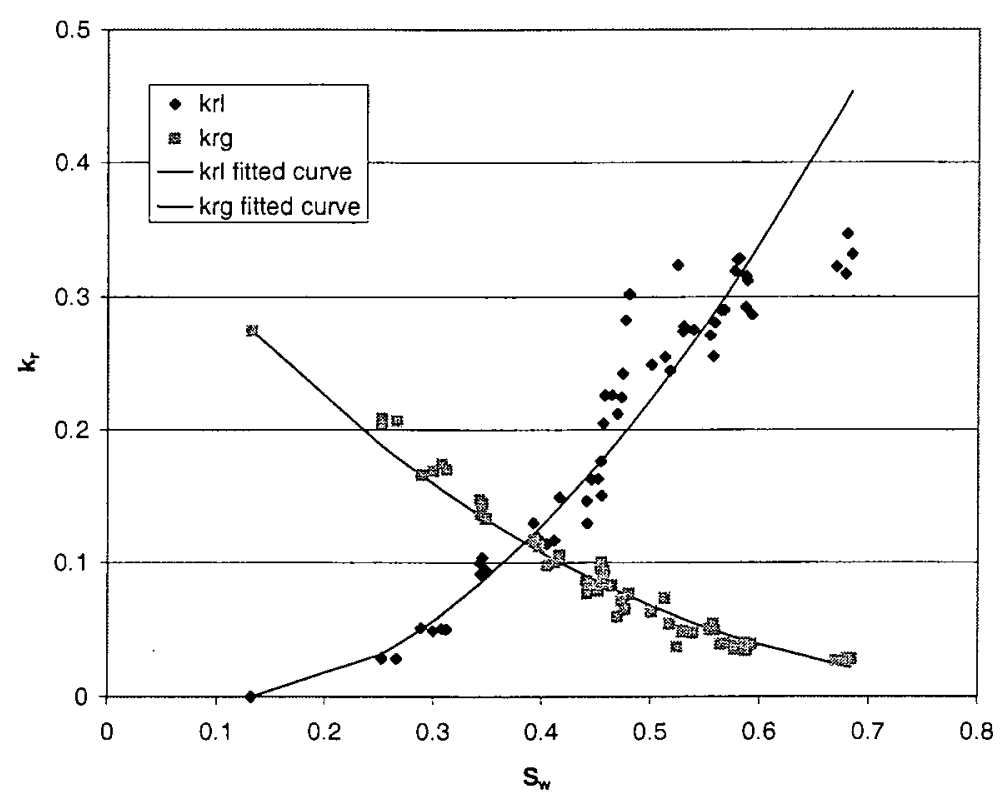

Figure 3.25 Fitted Honarpour curve for drainage data in rough-walled fracture experiment.

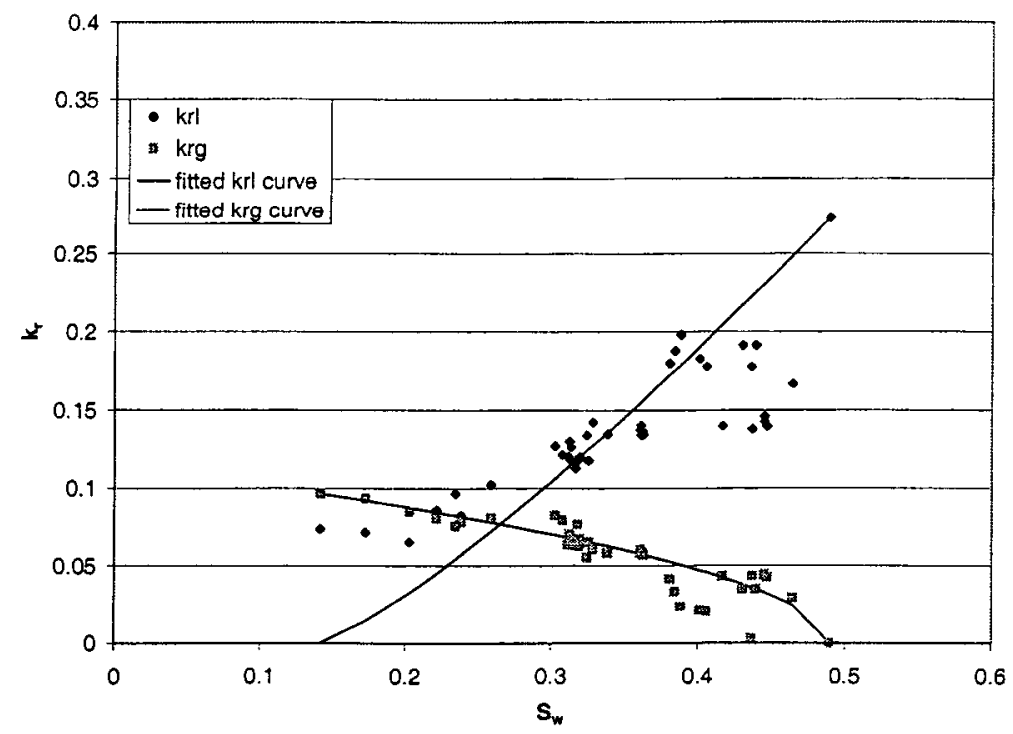

Figure 3.26 Fitted curve for imbibition rough-walled fracture experiment. 
Table 2 Honarpour fit parameters for rough-walled experiment.

\begin{tabular}{|l|c|c|}
\cline { 2 - 3 } \multicolumn{1}{c|}{} & Drainage & Imbibition \\
\hline Swr & 0.132 & 0.141 \\
\hline Sgr & 0 & 0.51 \\
\hline krwo & 1 & 0.27 \\
\hline krgo & 0.274 & 0.1 \\
\hline nw & 1.75 & 1.2 \\
\hline ng & 2.53 & 0.52 \\
\hline
\end{tabular}

\subsubsection{Application of Homogeneous Model for Rough-Walled Fracture Experiment}

It was discovered in the previous section that the porous medium approach when applied only through flow characterized by stable phase paths yields better defined relative permeability curves. This indicates that different flow mechanisms may require different mathematical approaches. Thus in the application of the homogeneous model to the rough-walled fracture experiment, the appropriateness of the model was reviewed for all data and for data corresponding only to unstable surge flow.

The natural logarithm of the calculated friction factor and Reynold's number is seen in Figure 3.27. Graph A includes all the data while graph B consists only of the data corresponding to unstable surge flow. Comparisons of graphs A and B shows that removing the stable flow data removed the cluster of data points. The observation that stable flow data tend to cluster in plots of friction factor with Reynold's number suggests that the homogeneous single-phase model is not the appropriate model for this kind of flow. However, considering only the surge data as was done in graph B of Figure 3.27 also did not improve the goodness of fit. For both graphs, there exist some data points that lie vertically with respect to each other. This can indicate either two things that the friction factor may not be a sole function of Reynold's number or that Reynold's number is not a good correlation variable for friction factor in flow through fractures. The calculated friction factor and Reynold's number are compared to other data in Figure 3.28. Again both data sets have slopes lower than unity and the data are closer to Romm's expression (Romm, 1966). The values for the constants $C$ and $n$ are listed in Table 3. The pressure drop calculated from these values are compared to measured data in Figure 3.29. Since the fit of the friction factor with the experimental data was not so good, the computed pressure drop from Eqn. (1.12) was not able to satisfactorily predict the experimental pressure gradient. 


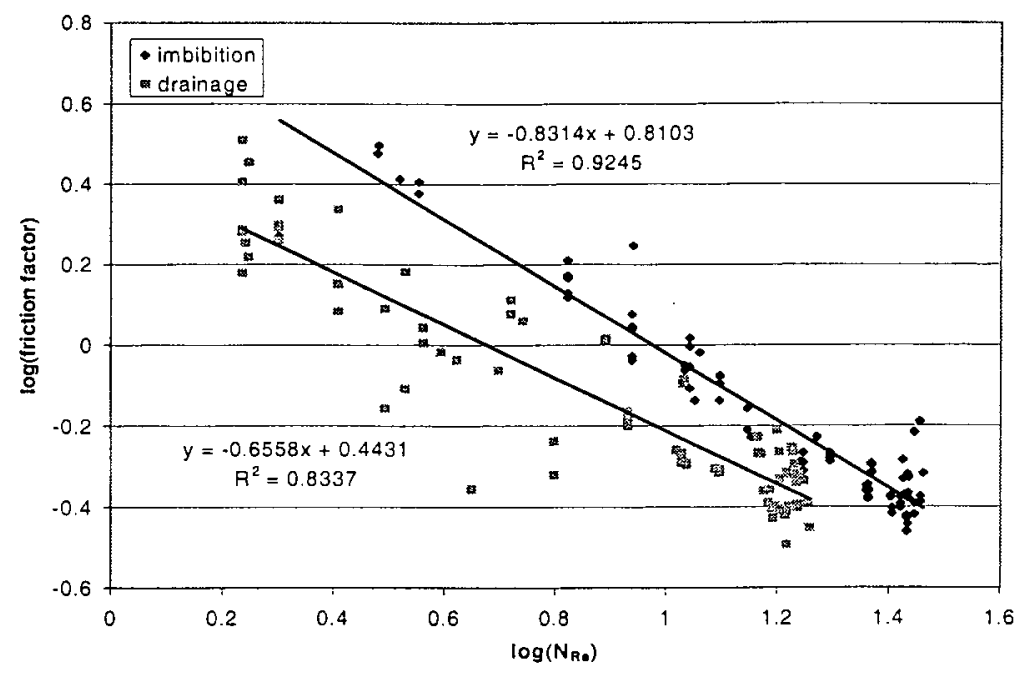

(A)

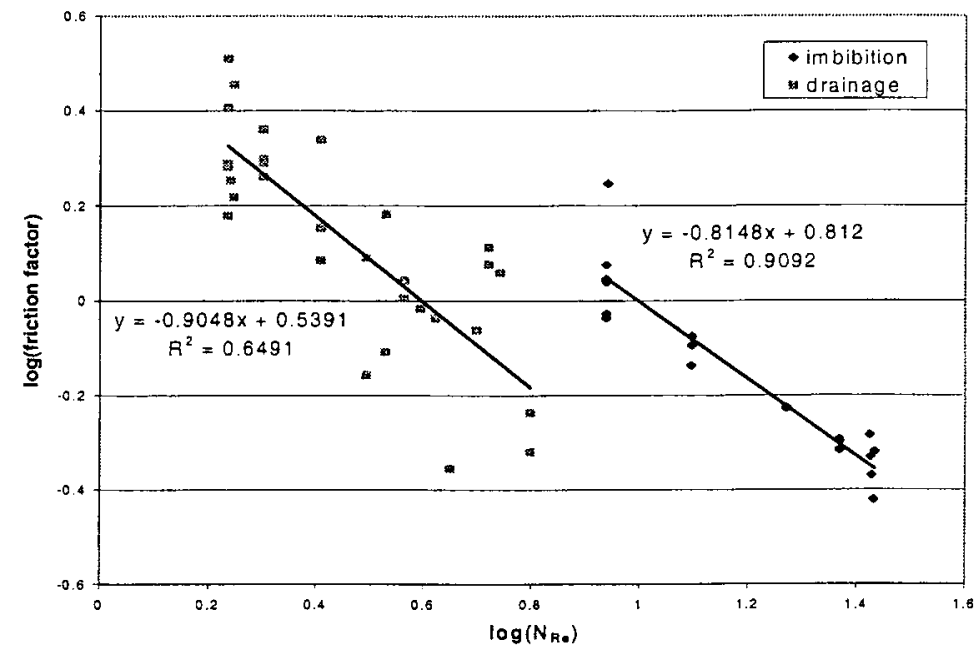

(B)

Figure 3.27 Natural logarithm of friction factor with natural logarithm of Reynold's number for (a) all rough-walled data and (b) for data with unstable surge flow. 


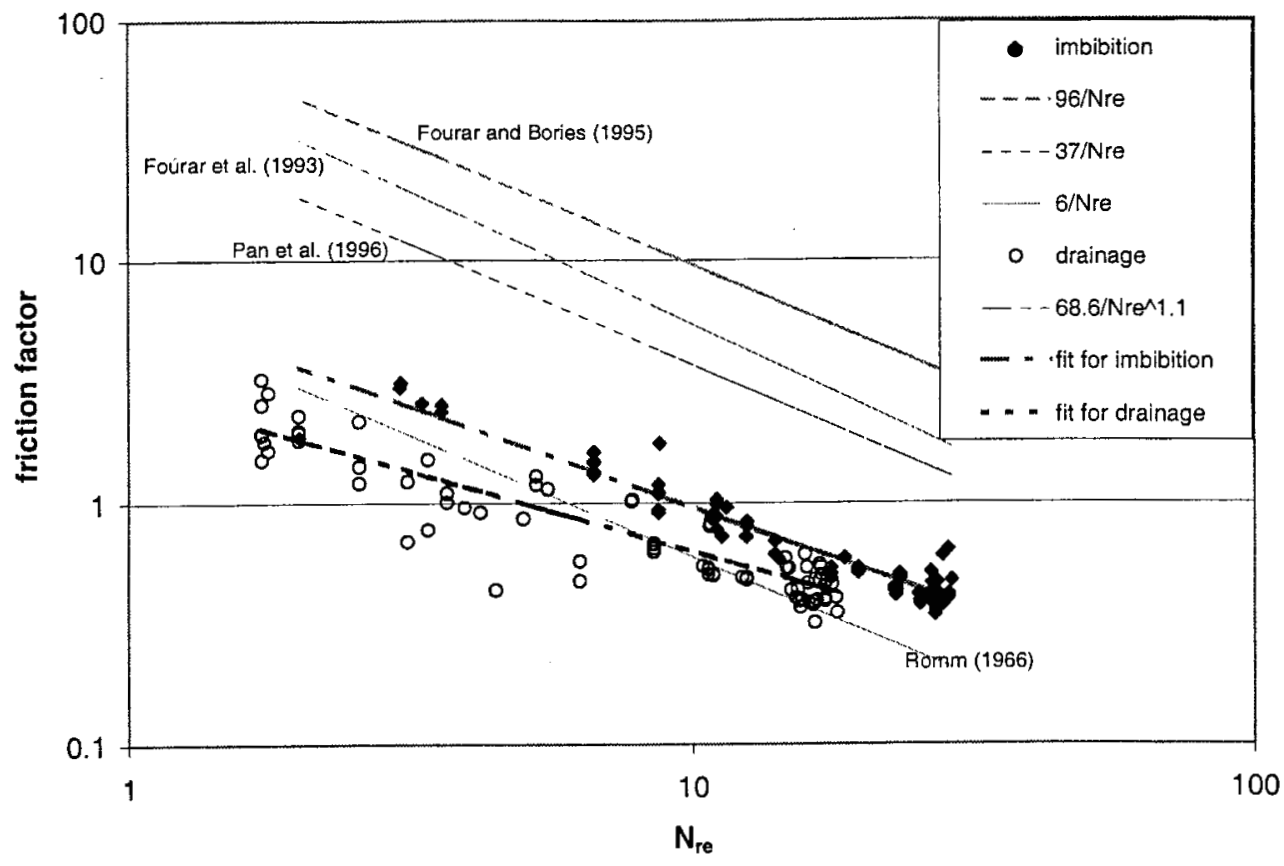

Figure 3.28 Friction factor with modified Reynold's number for rough-walled experiment.

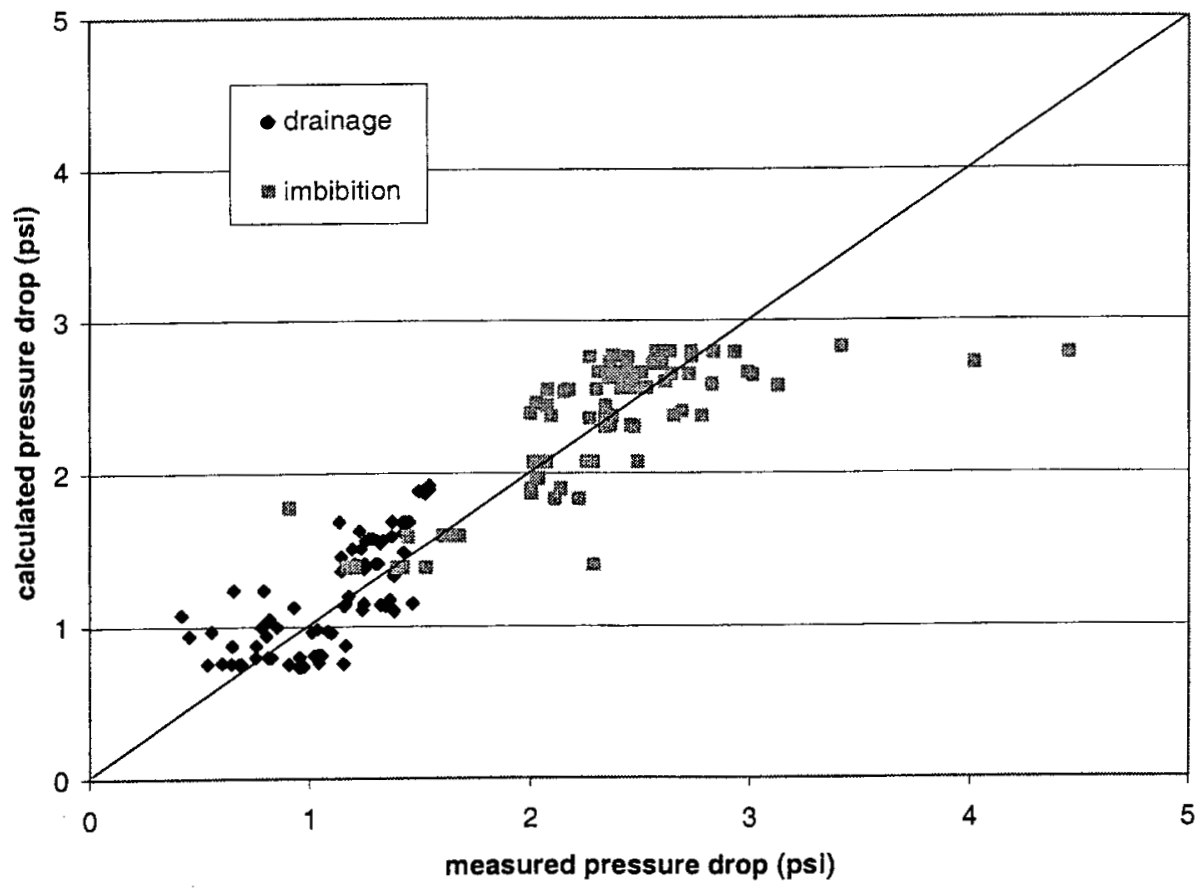

Figure 3.29 Comparison of the measured pressure drop against calculated pressure drop from homogeneous equivalent single-phase model. 
Table 3 Homogeneous equivalent single-phase fit parameters.

\begin{tabular}{|l|c|c|}
\cline { 2 - 3 } \multicolumn{1}{l|}{ Experiment } & $\mathbf{C}$ & $\mathrm{n}$ \\
\hline Imbibition rough wall experiment & 6.5 & -0.83 \\
\hline Drainage for rough wall experiment & 2.8 & -0.66 \\
\hline Smooth wall experiment & 3.23 & -0.75 \\
\hline
\end{tabular}

\subsection{Comparison of Smooth- and Rough-Walled Experiment to Other Studies}

The data for both smooth and rough-walled experiments were entered in Figure 1.1 for comparison to previous studies and to known correlations for porous media (see Figure 3.30). Compared to other data, the experimental data in this study is higher than that of Persoff and Pruess (1995) experiments but lower than Persoff (1991). With this, no apparent conclusion can be made as to whether the data from this study contradicts or agree with previous relative permeability experiments. However, more importantly Figure 3.30 shows that the experimental data mostly conform to Corey type of relative permeability curve. This suggests that flow through fractures can be analyzed by treating it as limiting case of porous media and by using the relative permeability variable. The relative permeabilities as seen in Figure 3.30 for fractures sum up to less than one and are not in linear relationsip with saturation as suggested by the $X$-curve. This reiterates results from previous studies that phase interference in fractures does occur. Comparing the results for smooth and rough fractures, the relative permeability values for the smooth and the rough-walled drainage experiment do not differ much. However, the relative permeability for imbibition experiment in the rough-walled fracture is lower than these two experiments.

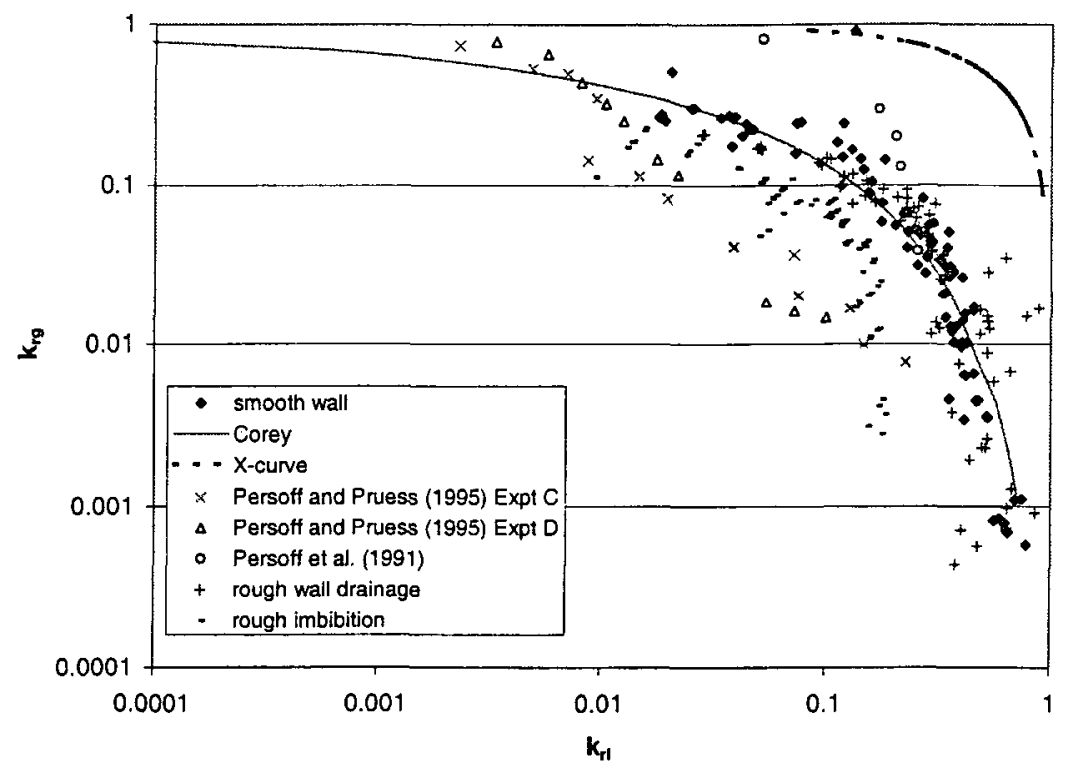

Figure 3.30 Comparison of relative permeability data with previous work on rough-walled fractures. 



\section{Chapter 4}

\section{Conclusions and Recommendations}

The experiments and analysis presented in this paper have led to the following conclusions:

1. Two-phase flow through smooth and rough parallel plate fractures is characterized by each phase establishing localized continuous flow paths. The stability of these flow paths is dependent on the flow rate ratio of the phases. A phase flow path undergoes constant cycles of breakage and reformation as certain points are blocked and unblocked by the other phase. The breaking and reforming of phase paths cause pressure, flow rate and saturation fluctuations even at constant input conditions. This reveals the unsteady nature of flow through fractures.

2. The imbibition process through a rough-walled fracture also undergoes wave-like flow similar to flow in pipes at high gas-water ratio. Other than this, flow through smooth- and rough-walled fractures is more similar to flow in porous media where a phase moves by establishing continuous channels. The flow mechanism of having moving discontinuous flow structures as bubbles or "islands" carried along by another continuous phase was not observed throughout the experiments.

3. Two-phase flow through smooth- and rough-walled fractures can be modeled adequately by a porous medium approach. In this approach, Darcy's law governs flow and phase interference is represented by the relative permeability variable. The resulting relative permeability curve from experimental data shows a clear relationship between relative permeability and phase saturation. The experimental relative permeability curves follow the Corey shape and can be fitted to reasonable accuracy by the Honarpour expression.

4. There is considerable phase interference in flow through fractures. This is deduced from the sum of the gas and liquid relative permeability for all experiments being less than unity.

5. The equivalent homogenous single-phase approach did not give satisfactory representation of flow through fractures. The graphs of experimentally derived friction factor with the modified Reynold's number do not reveal distinctive linear relationship. This leads to inadequate pressure drop prediction of the model.

The apparatus and methodology used in this study proved to be an effective means of investigating flow through fractures. However, improvement is needed to ensure control 
of fracture aperture i.e. preventing the glass plate from being lifted by the flowing fluids. The method for saturation measurement is dependable when picture quality is good and when distinct boundaries of phases are seen. It is recommended to experiment with techniques for enhancing picture color contrasts. This will improve the program's accuracy in differentiating phases. This will be useful for cases when small isolated phases are dispersed throughout such as the case in imbibition for rough-walled fractures.

It is recommended that further experiments with smooth-walled fractures be done this time with certainty as to the fracture absolute permeability. This is to establish the magnitude of relative permeability in smooth-walled fractures. It is also recommended to conduct experiments to investigate other variables in fracture flow that were not included in this study such as effect of aperture, viscosity, gravity, degree of roughness etc. 


\section{Nomenclature}

$$
\begin{array}{ll}
A & =\text { area } \\
b & =\text { fracture aperture } \\
C & =\text { constant in Blasium equation } \\
f & =\text { friction factor } \\
k_{a b s} & =\text { absolute permeability } \\
k_{r} & =\text { relative permeability } \\
L & =\text { fracture length } \\
n & =\text { constant in Blasium equation } \\
N_{R e} & =\text { modified Reynold's number } \\
p & =\text { pressure } \\
Q & =\text { volumetric flow rate } \\
q l & =\text { Darcy flow velocity } \\
S & =\text { saturation } \\
V & =\text { superficial velocity } \\
w & =\text { fracture width } \\
\Pi & =\text { fracture perimeter } \\
\mu & =\text { viscosity } \\
\rho & =\text { density }
\end{array}
$$

Subscripts:

$$
\begin{array}{ll}
g & =\text { gas phase } \\
i & =\text { inlet } \\
l & =\text { liquid phase } \\
m & =\text { mean } \\
o & =\text { outlet } \\
r & =\text { residual } \\
\mathrm{w} & =\text { water }
\end{array}
$$




\section{References}

Amyx, J. W., Bass, D.M, and Whiting, R.L. Petroleum Reservoir Engineering Physical Properties, McGraw-Hill Book Co.,New York, 1960, pp 199-200.

Corey, A.T.,: The interrelationship between gas and oil relative permeabilities, Prod. Mon., Vol. 19, 1954, pp. 38-41.

Fourar, M. and Bories, S.,: "Experimental Study of Air-Water Two-Phase Flow Through A Fracture (Narrow Channel)," Int. J. Multiphase Flow Vol. 21, No. 4, Toulouse, France (1995) pp. 621-637.

Fourar, M., Bories., Lenormand, R., and Persoff, P.,: "Two-Phase Flow in Smooth and Rough Fractures: Measurement and Correlation by Porous-Medium and Pipe Flow Models," Water Resources Research Vol. 29 No. 11. November 1993, pp. 3699-3708.

Hanselman, D. and Littlefield, B.: Mastering Matlab 5 A Comprehensive Tutorial and Reference, Prentice-Hall, Inc.,New Jersey, 1998.

Horne, R.H., Satik, C., Mahiya, G., Li, K., Ambusso, W., Tovar, R., Wang, C., and Nassori, H.: "Steam-Water Relative Permeability," Proceedings of the World Geothermal Congress 2000, Kyushu-Tohoku, Japan, May 28-June 10, 2000.

Kneafsy, T. J. and Pruess, K.,: "Laboratory Experiments on Heat-Driven Two-Phase Flows in Natural and Artificial Rock Fractures," Water Resources Research Vol. 34, No. 12, December 1998, pp. 3349-3367.

Li, K. and Horne, R.N.: "Accurate Measurement of Steam Flow Properties," Proceedings of Geothermal Resource Council, Reno, California, USA, October 17-20, 1999.

Lockhart, R. W. and Martinelli, R.C.,: "Proposed Correction of Data for Isothermal two-phase component flow in pipes," Chem. Eng. Prog., Vol. 45, No. 39, 1949.

Pan, X., Wong, R.C., and Maini, B.B.: Steady State Two-Phase Flow in a Smooth Parallel Fracture, presented at the $47^{\text {th }}$ Annual Technical Meeting of the Petroleum Society in Calgary, Alberta, Canada, June 10-12, 1996.

Persoff, P. K., Pruess, K. and Myer, L.: "Two-Phase Flow Visualization and Relative Permeability Measurement in Transparent Replicas of Rough-Walled Rock Fractures," Proceedings $16^{\text {th }}$ Workshop on Geothermal Reservoir Engineering, Stanford University, Stanford, California, January 23-25, 1991.

Persoff, P., and Pruess, K.: "Two-Phase Flow Visualization and Relative Permeability Measurement in Natural Rough-Walled Rock Fractures," Water Resources Research Vol. 31, No. 5, May, 1995, pp. 1175-1186. 
Pruess, K., and Tsang, Y. W.: "On Two-Phase Relative Permeability and Capillary Pressure of Rough-Walled Rock Fractures," Water Resources Research Vol. 26 No. 9, September 1990, pp 1915-1926.

Scheidegger, A.E. The Physics of Flow Through Porous Media, $3^{\text {rd }}$ ed., University of Toronto, Toronto. 1974.

Su, G. W., Geller, J. T., Pruess, K. and Wen, F.,: " Experimental Studies of Water Seepage and Intermittent Flow in Unsaturated, Rough-Walled Fractures," Water Resources Research, Vol. 35, No. 4, April 1999, pp. 1019-1037.

Witherspoon, P.A., Wang, J.S.W., Iwai, K. and Gale, J.E., : Validity of cubic law for fluid flow in a deformable rock fracture, Water Resources. Research. Vol. 16, No. 6, 1980, pp 1016-1024. 



\section{Appendix A}

\section{A. Matlab Program for Saturation Measurement}

$\%$ This program calculate the saturation of two-phase area.

$\%$ It is done by linear discriminant method.

clear;

\% This part will ask user for the image to be processed.

File = input('InEnter file name: ','s');

figure;

Image $=\operatorname{imread}($ File);

$\%$ This will display the image and ask user to cut it to his desired dimension.

image(Image);

Sentinel $=0$;

iter $=1$;

FileNo = 1;

while (Sentinel $\sim=1$ )

Ymax = input('Enter $y$-axis maximum cutoff value: ');

Ymin = input('Enter y-axis minimum cutoff value: ');

$\mathrm{Xmax}=$ input('Enter $\mathrm{X}$-axis maximum cutoff value: ');

$\mathrm{Xmin}=$ input('Enter $\mathrm{x}$-axis minimum cutoff value: ');

cutImg = Image $(Y \min : Y \max , X \min : X \max ,:)$;

figure;

image(cutImg);

text $(3,5$, File $)$

Sentinel = input('Is this good? Enter 1 if yes, 2 for no: ');

if $($ Sentinel $==2$ )

close; 
end
end

[rImg,cImg]=size (cutImg);

sample = GenerateSample(cutImg);

\%generation of phase data set

NtrnL=input('No. of liquid sample data: ');

liq = GetTrainingData(cutImg);

for $i=1:(N \operatorname{trnL}-1)$

liqNew = GetTrainingData(cutImg);

trnl=[liq;liqNew];

end

trl=CheckVariance(trnl);

Ntrng=input('No. of gas sample data: ');

gas = GetTrainingData(cutImg);

for $i=1$ : (Ntrng-1)

gasNew = GetTrainingData(cutImg);

trng=[gas;gasNew];

end

trg=CheckVariance(trng);

Ntrnbk=input('No. of black strip data: ');

stp = GetTrainingData(cutImg);

for $\mathrm{i}=1:($ Ntrnbk-1)

stpNew = GetTrainingData $($ cutImg);

trnstp $=[\operatorname{stp} ; \operatorname{stpNew}]$;

end

trstp=CheckVariance(trnstp);

$\operatorname{trn}=[\operatorname{trl} ;$ trg; trstp $]$

$\%$ generation of grouping

[RTrl,CTr1] = size $(\operatorname{trnl})$; 


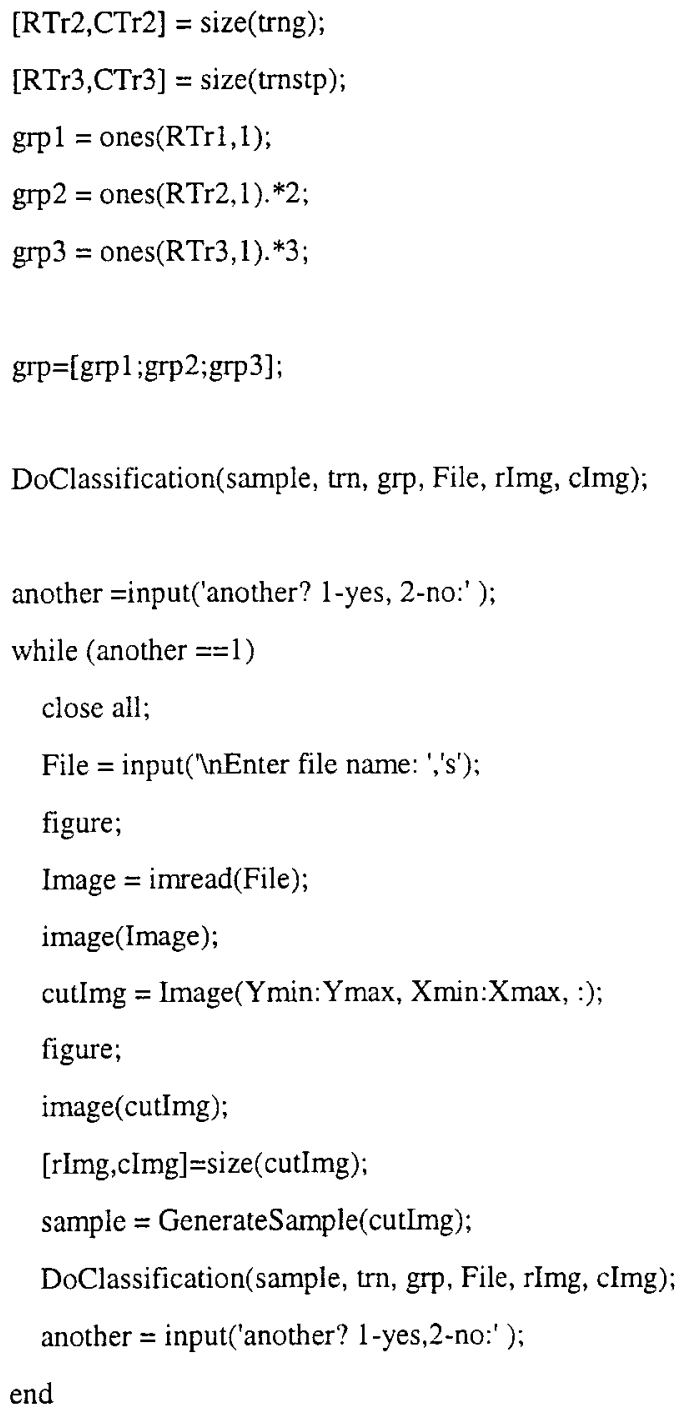

\% This part will create the group based on the number of rows of trl and tr2

function sample $=$ GenerateSample(cutImg)

red $=$ double $($ cutImg(:,:,1));

green $=$ double $($ cutImg $(:,,, 2))$;

blue $=$ double $($ cutImg $(:,:, 3))$;

sample $=[\operatorname{red}(:)$,green(:),blue(:)];

GenerateSample $=$ sample;

************************File GetTrainingData

function $\operatorname{Trn}=$ GetTrainingData(image)

$\%$ This function creates a matrix of training data using the polygon

$\%$ specified by the user 


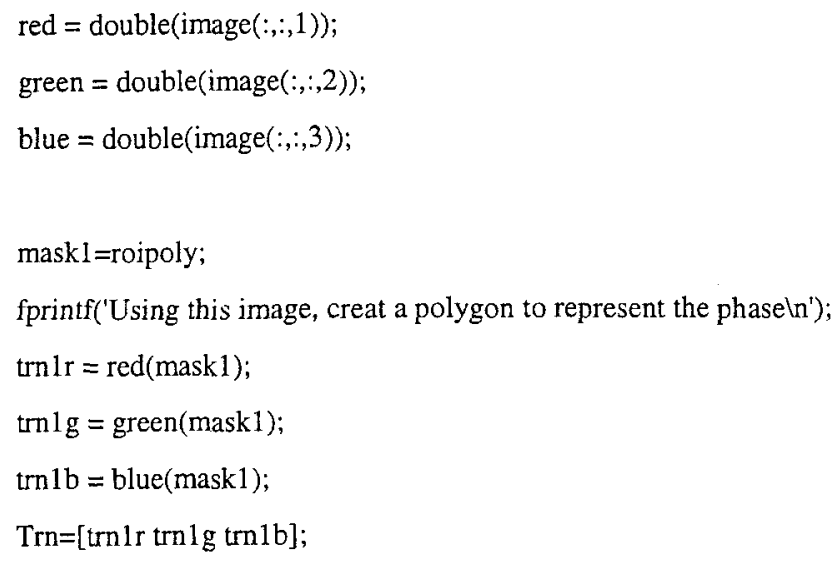


function DoClassification(sample, trn, grp, File, rImg,cImg)

class =classify(sample,trn,grp);

classImg =reshape(class,IImg,cImg/3);

figure;

imagesc(classImg);

colormap(gray);

$\mathrm{Sw}=\operatorname{sum}($ class $==1) /(\operatorname{sum}($ class $==1)+\operatorname{sum}($ class $==2))$

text( 1,1, File, 'Color','r');

satString $=\operatorname{num} 2 \operatorname{Str}(\mathrm{S} w)$;

satLabel = strcat('Sw=', satString)

xlabel(satLabel); 


\section{Appendix B}

\section{B. Calculations}

Notes:

Runs 2, 3, and 4 were all done for smooth-walled fractures while runs 5,6, and 7 were for rough-walled fractures. All the calculations in the following tables use these constants:

Fracture length: $1 \mathrm{ft}$.

Fracture width: $0.33 \mathrm{ft}$

Nitrogen viscosity: $0.018 \mathrm{cp}$

Water viscosity: $1 \mathrm{cp}$

Water density: $62.3 \mathrm{lb} / \mathrm{cu} . \mathrm{ft}$

Nitrogen density: $0.0782 \mathrm{lb} / \mathrm{cu} . \mathrm{ft}$ 


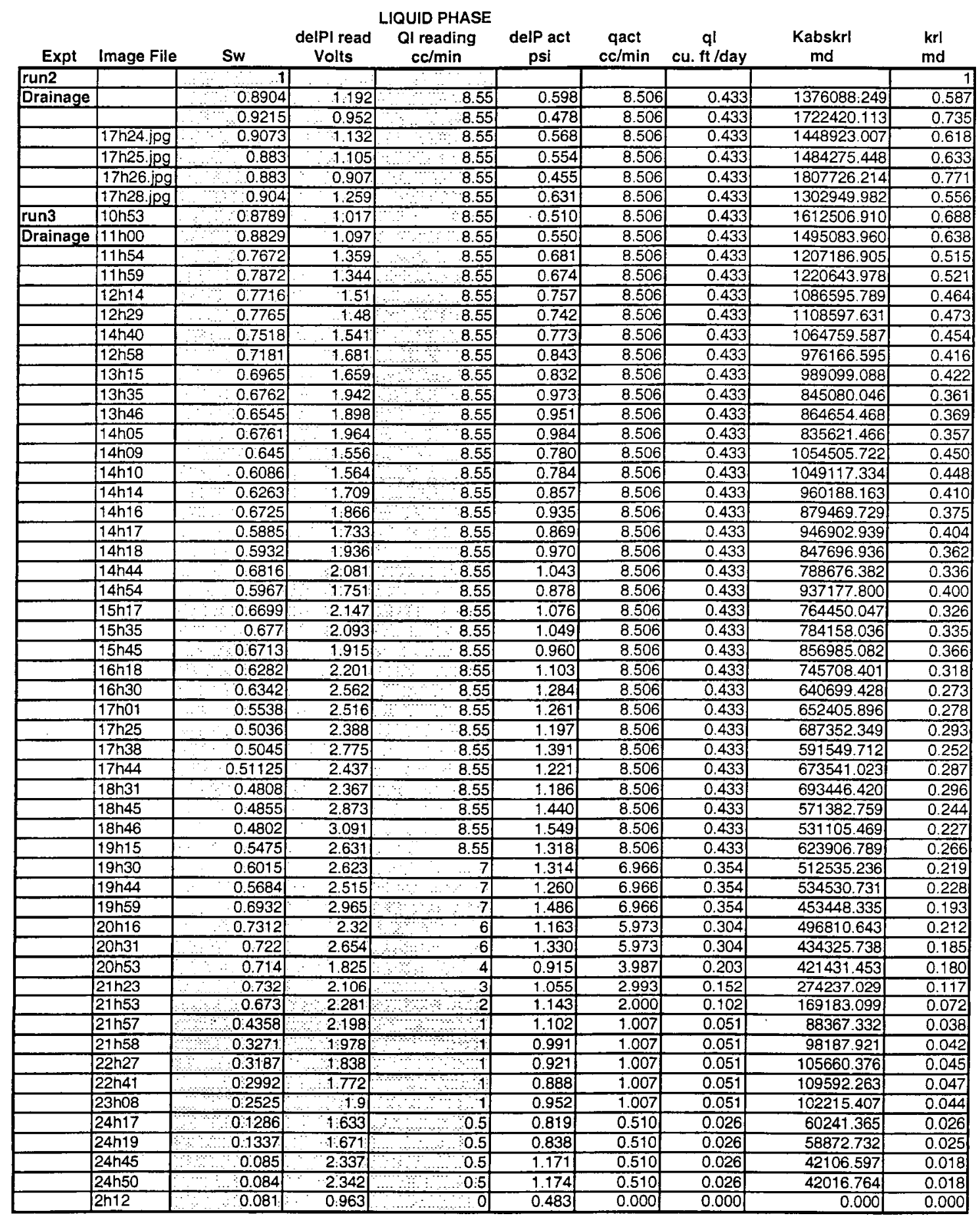


Gas Phase

qG reading qg actual qg dPG read P2 reading delP actual P2 actual $\quad K$ krg $\quad$ krg uncalib krg calib Expt Image File cc/min cc/min cu. Fvday volts volts

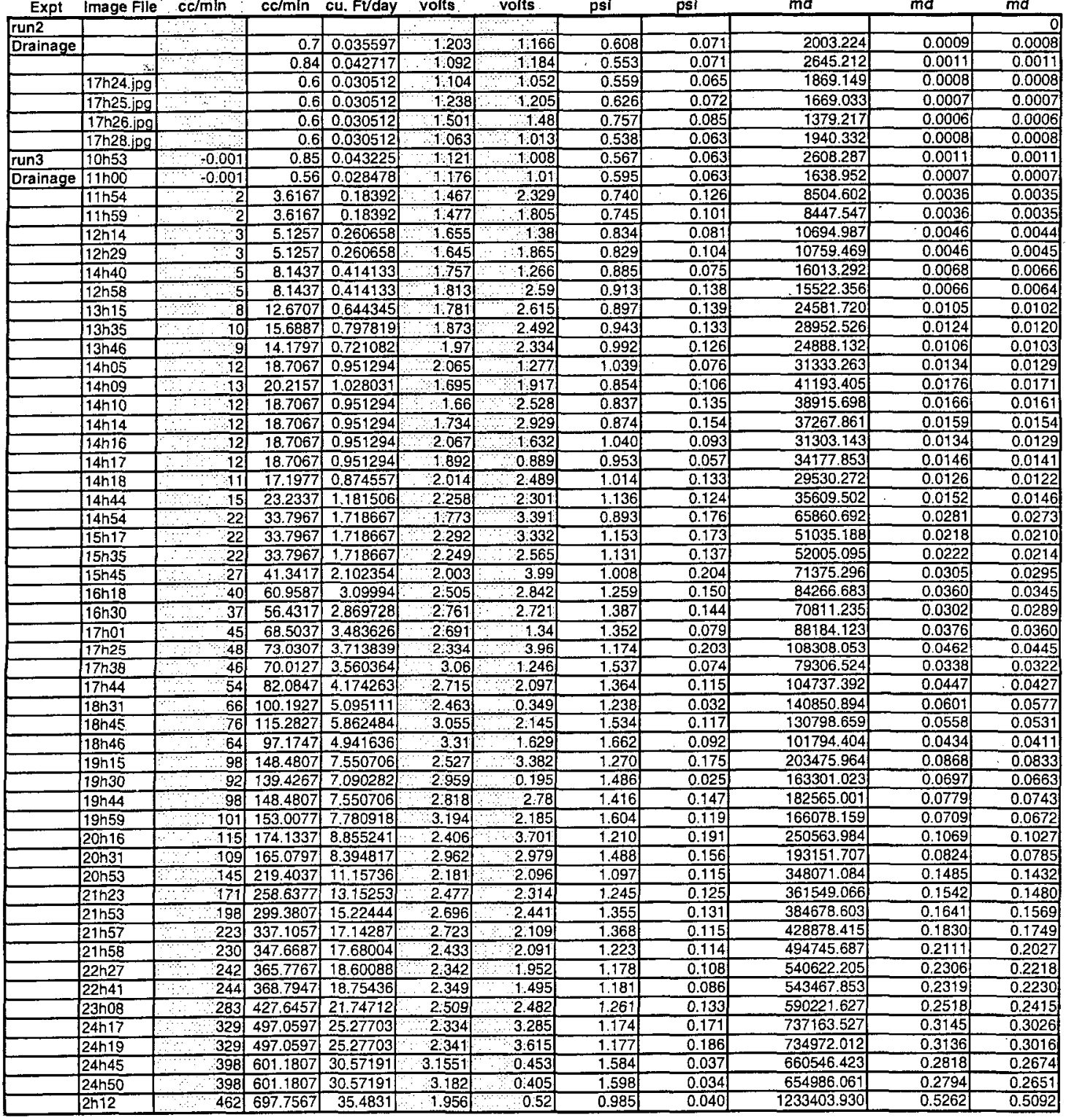


LIQUID PHASE

\begin{tabular}{|c|c|c|c|c|c|c|c|c|c|}
\hline Expt & Image File & Sw & $\begin{array}{l}\text { delPI read } \\
\text { Volts }\end{array}$ & $\begin{array}{c}\text { Ql reading } \\
\mathrm{cc} / \mathrm{min}\end{array}$ & $\begin{array}{c}\text { delP act } \\
\text { psi }\end{array}$ & $\begin{array}{c}\text { qact } \\
\mathrm{cc} / \mathrm{min}\end{array}$ & $\begin{array}{c}q \mathrm{l} \\
\text { cu. ft/day }\end{array}$ & $\begin{array}{c}\text { Kabskrl } \\
\text { md }\end{array}$ & $\begin{array}{l}\mathrm{krl} \\
\mathrm{md}\end{array}$ \\
\hline Imbibitio & $\sqrt{21-22}$ & 0.223 & 2.06 & 0.5 & 1.03245 & 0.50995 & 0.02593 & 47764.12 & 0.0204 \\
\hline run4 & $21-22 b$ & 0.23 & 2.278 & 0.5 & 1.14162 & 0.50995 & 0.02593 & 43196.39 & 0.0184 \\
\hline & $21-31$ & 0.2473 & 2.198 & 0.5 & 1.10156 & 0.50995 & 0.02593 & 44767.46 & 0.0191 \\
\hline & $21-34$ & 0.2314 & 2.13 & 1 & 1.06750 & 1.00660 & 0.05119 & 91186.33 & 0.0389 \\
\hline & $21-35$ & 0.258 & 2.271 & 1 & 1.13812 & 1.00660 & 0.05119 & 85528.81 & 0.0365 \\
\hline & $21-51$ & 0.227 & 2.177 & 1 & 1.09104 & 1.00660 & 0.05119 & 89219.12 & 0.0381 \\
\hline & $21-56$ & 0.2367 & 2.466 & 1 & 1.23577 & 1.00660 & 0.05119 & 78769.96 & 0.0336 \\
\hline & $22-26$ & 0.2664 & 2.251 & 2 & 1.12810 & 1.99990 & 0.10170 & 171436.27 & 0.0731 \\
\hline & $22-27$ & 0.2624 & 2.154 & 2 & 1.07952 & 1.99990 & 0.10170 & 179150.75 & 0.0764 \\
\hline & $23-32$ & 0.36 & 2.769 & 4 & 1.38752 & 3.98650 & 0.20273 & 277841.02 & 0.1185 \\
\hline & $23-33$ & 0.357 & 2.955 & 4 & 1.48066 & 3.98650 & 0.20273 & 260362.00 & 0.1111 \\
\hline & $23-43$ & 0.369 & 3.189 & 5 & 1.59785 & 4.97980 & 0.25324 & 301382.42 & 0.1286 \\
\hline & $24-06$ & 0.417 & 3.498 & 6 & 1.75260 & 5.97310 & 0.30375 & 329579.14 & 0.1406 \\
\hline & $24-06 b$ & 0.41 & 3.132 & 6 & 1.56931 & 5.97310 & 0.30375 & 368073.54 & 0.1570 \\
\hline & $24-10$ & 0.512 & 3.398 & 6 & 1.70252 & 5.97310 & 0.30375 & 339273.79 & 0.1447 \\
\hline & $24-13$ & 0.4894 & 3.727 & 6 & 1.86728 & 5.97310 & 0.30375 & 309337.31 & 0.1320 \\
\hline & $24 \cdot 14$ & 0.516 & 3.738 & 6 & 1.87279 & 5.97310 & 0.30375 & 308427.40 & 0.1316 \\
\hline & $24-35$ & 0.5712 & 3.467 & 6.5 & 1.73707 & 6.46975 & 0.32901 & 360173.39 & 0.1537 \\
\hline & $24-53$ & 0.4855 & 3.055 & 6.5 & 1.53074 & 6.46975 & 0.32901 & 408721.30 & 0.1744 \\
\hline & 1.13 & 0.4518 & 3.036 & 6.5 & 1.52123 & 6.46975 & 0.32901 & 411277.83 & 0.1755 \\
\hline & $1-30$ & 0.581 & 2.766 & 7.5 & 1.38601 & 7.46305 & 0.37952 & 520704.65 & 0.2222 \\
\hline & $1-36$ & 0.586 & 3.059 & 7.5 & 1.53275 & 7.46305 & 0.37952 & 470856.06 & 0.2009 \\
\hline & $1-45$ & 0.576 & 2.689 & 7.5 & 1.34745 & 7.46305 & 0.37952 & 535606.26 & 0.2285 \\
\hline & $2 \cdot 08$ & 0.633 & 1.893 & 8 & 0.94881 & 7.95970 & 0.40478 & 811255.73 & 0.3461 \\
\hline & $2-15$ & 0.643 & 2.322 & 8 & 1.16366 & 7.95970 & 0.40478 & 661475.60 & 0.2822 \\
\hline & $2-16$ & 0.646 & 2.522 & 8 & 1.26382 & 7.95970 & 0.40478 & 609052.38 & 0.2598 \\
\hline & $2-24$ & 0.618 & 2.161 & 9 & 1.08303 & 8.95300 & 0.45529 & 799412.48 & 0.3411 \\
\hline & $2-25$ & 0.628 & 2.122 & 9 & 1.06350 & 8.95300 & 0.45529 & 814093.74 & 0.3473 \\
\hline & 2.33 & 0.655 & 2.083 & 9 & 1.04397 & 8.95300 & 0.45529 & 829324.33 & 0.3538 \\
\hline & $2-45$ & 0.596 & $2: 3$ & 9.5 & 1.15264 & 9.44965 & 0.48054 & 792801.35 & 0.3382 \\
\hline & $2-46$ & 0.598 & 1.953 & 9.5 & 0.97886 & 9.44965 & 0.48054 & 933547.50 & 0.3983 \\
\hline & $2-54$ & 0.665 & 1.947 & 9.5 & 0.97586 & 9.44965 & 0.48054 & 936422.02 & 0.3995 \\
\hline & $2-4 b$ & 0.659 & 1.898 & 9.5 & 0.95132 & 9.44965 & 0.48054 & 960576.97 & 0.4098 \\
\hline & $2-56$ & 0.631 & 1.898 & 9.5 & 0.95132 & 9.44965 & 0.48054 & 960576.97 & 0.4098 \\
\hline & 2.58 & 0.614 & 2.214 & 9.5 & 1.10957 & 9.44965 & 0.48054 & 823574.50 & 0.3514 \\
\hline & $3-05$ & 0.679 & 1.378 & 9.5 & 0.69090 & 9.44965 & 0.48054 & 1322639.12 & 0.5643 \\
\hline
\end{tabular}


Gas Phase

qG reading qg actual qg dPG read P2 reading delP actual P2 actual $\quad \mathrm{K} \mathrm{krg} \quad \mathrm{krg}$ uncallb krg calib Expt Image Flle $\mathrm{cc} / \mathrm{min} \mathrm{cc} / \mathrm{min} \mathrm{cu}$. Ftday volts volts.

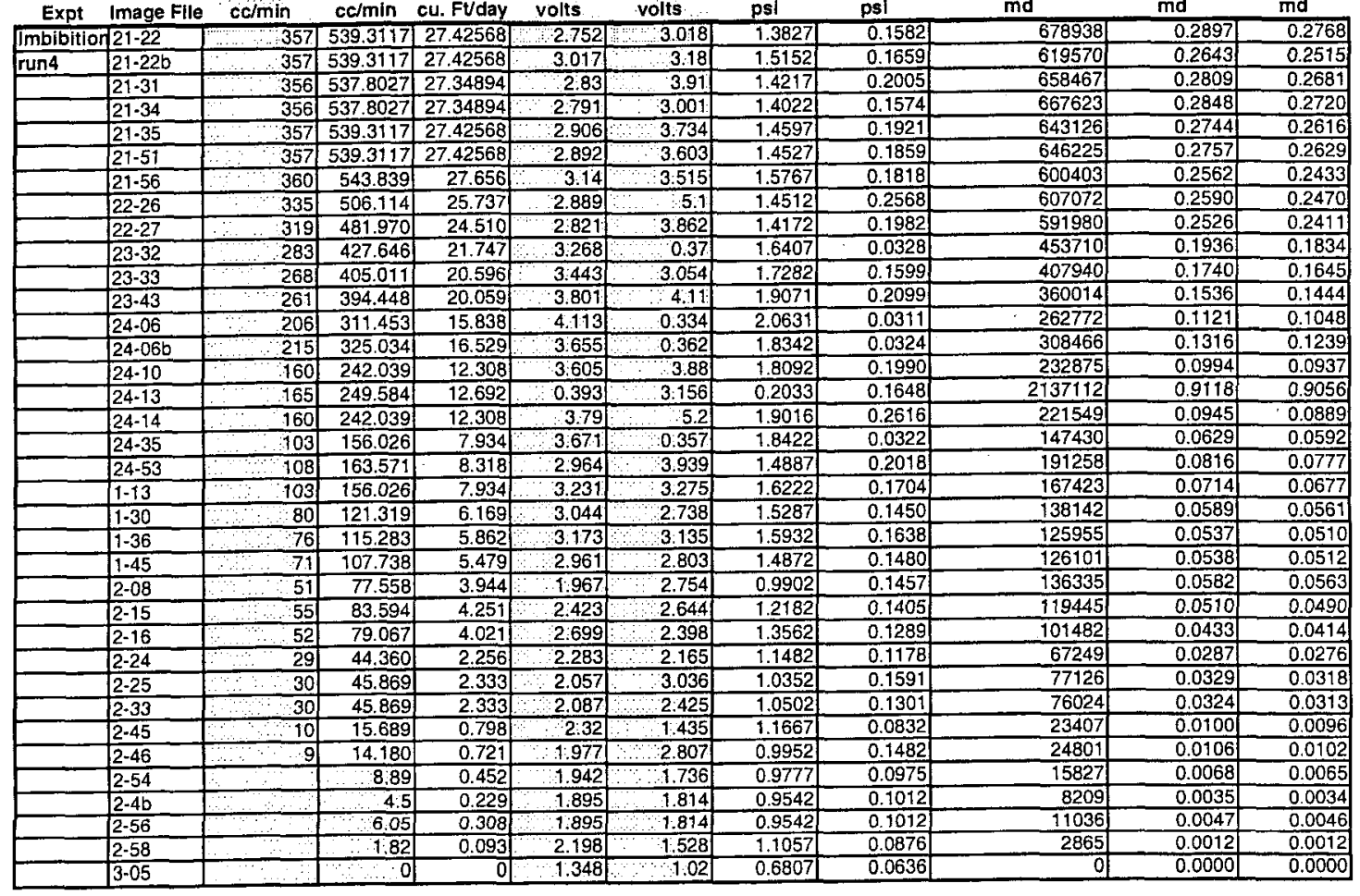


Homogeneous Single Phase Approach Dpave NreM Friction $\mathrm{f}$ 3.23/Nre^.75 dp Predicted

\begin{tabular}{|c|c|c|c|c|c|c|}
\hline Expt & File & 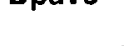 & 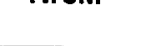 & & & \\
\hline run2 & & 0.60300 & 1.91737 & 1.81514 & 1.98232 & 0.65854 \\
\hline & & 0.51516 & 1.94599 & 1.52746 & 1.96041 & 0.66118 \\
\hline & 17h24.jpg & 0.56323 & 1.89691 & 1.71407 & 1.99833 & 0.65664 \\
\hline & 17h25.jpg & 0.58997 & 1.89691 & 1.79543 & 1.99833 & 0.65664 \\
\hline & 17h26.jpg & 0.60613 & 1.89691 & 1.84463 & 1.99833 & 0.65664 \\
\hline & 17h28.jpg & 0.58478 & 1.89691 & 1.77965 & 1.99833 & 0.65664 \\
\hline run3 & $10 h 53$ & 0.53868 & 1.94803 & 1.59550 & 1.95887 & 0.66137 \\
\hline & $11 \mathrm{~h} 00$ & 0.57247 & 1.88873 & 1.74987 & 2.00482 & 0.65587 \\
\hline & $11 \mathrm{~h} 54$ & 0.71081 & 2.51045 & 1.62417 & 1.61953 & 0.70878 \\
\hline & $11 \mathrm{~h} 59$ & 0.70956 & 2.51045 & 1.62130 & 1.61953 & 0.70878 \\
\hline & $12 \mathrm{~h} 14$ & 0.79562 & 2.81466 & 1.61635 & 1.48639 & 0.73165 \\
\hline & $12 \mathrm{~h} 29$ & 0.78561 & 2.81466 & 1.59601 & 1.48639 & 0.73165 \\
\hline & $14 h 40$ & 0.82888 & 3.41775 & 1.37807 & 1.28498 & 0.77289 \\
\hline & 12 h58 & 0.87794 & 3.41775 & 1.45963 & 1.28498 & 0.77289 \\
\hline & $13 \mathrm{~h} 15$ & 0.86443 & 4.30934 & 1.12919 & 1.07993 & 0.82672 \\
\hline & $13 h 35$ & 0.95829 & 4.89522 & 1.09517 & 0.98146 & 0.85880 \\
\hline & $13 \mathrm{~h} 46$ & 0.97152 & 4.60312 & 1.18440 & 1.02781 & 0.84307 \\
\hline & $14 \mathrm{~h} 05$ & 1.01179 & 5.47445 & 1.02762 & 0.90250 & 0.88860 \\
\hline & $14 \mathrm{~h} 09$ & 0.81714 & 5.76160 & 0.78614 & 0.86855 & 0.90280 \\
\hline & $14 h 10$ & 0.81039 & 5.47445 & 0.82307 & 0.90250 & 0.88860 \\
\hline & $14 \mathrm{~h} 14$ & 0.86520 & 5.47445 & 0.87873 & 0.90250 & 0.88860 \\
\hline & $14 h 16$ & 0.98776 & 5.47445 & 1.00320 & 0.90250 & 0.88860 \\
\hline & $14 \mathrm{~h} 17$ & 0.91071 & 5.47445 & 0.92495 & 0.90250 & 0.88860 \\
\hline & $14 h 18$ & 0.99203 & 5.18566 & 1.06693 & 0.93994 & 0.87395 \\
\hline & $14 h 44$ & 1.08934 & 6.33107 & 0.94794 & 0.80927 & 0.92999 \\
\hline & $14 \mathrm{h5} 5$ & 0.88546 & 8.27486 & 0.57723 & 0.66204 & 1.01555 \\
\hline & $15 h 17$ & 1.11436 & 8.27486 & 0.72645 & 0.66204 & 1.01555 \\
\hline & $15 h 35$ & 1.09009 & 8.27486 & 0.71063 & 0.66204 & 1.01555 \\
\hline & $15 h 45$ & 0.98403 & 9.61823 & 0.54379 & 0.59140 & 1.07019 \\
\hline & $16 h 18$ & 1.18113 & 12.94769 & 0.46704 & 0.47321 & 1.19675 \\
\hline & $16 h 30$ & 1.33552 & 12.19939 & 0.56527 & 0.49482 & 1.16907 \\
\hline & $17 \mathrm{ho1}$ & 1.30650 & 14.16947 & 0.46548 & 0.44227 & 1.24135 \\
\hline & 17 h25 & 1.18521 & 14.88778 & 0.39856 & 0.42617 & 1.26730 \\
\hline & $17 \mathrm{~h} 38$ & 1.46360 & 14.41012 & 0.51132 & 0.43672 & 1.25006 \\
\hline & $17 \mathrm{~h} 44$ & 1.29272 & 16.29244 & 0.39075 & 0.39830 & 1.31770 \\
\hline & 18h31 & 1.21220 & 18.98102 & 0.30457 & 0.35519 & 1.41369 \\
\hline & $18 h 45$ & 1.48689 & 21.10737 & 0.32732 & 0.32800 & 1.48997 \\
\hline & $18 \mathrm{~h} 46$ & 1.60522 & 18.54363 & 0.41501 & 0.36146 & 1.39807 \\
\hline & $19 h 15$ & 1.29430 & 25.45915 & 0.22360 & 0.28498 & 1.64963 \\
\hline & $19 h 30$ & 1.40029 & 23.00953 & 0.31575 & 0.30745 & 1.36346 \\
\hline & 19 h44 & 1.33800 & 24.05773 & 0.28368 & 0.29735 & 1.40244 \\
\hline & $19 h 59$ & 1.54467 & 24.57031 & 0.31798 & 0.29268 & 1.42177 \\
\hline & $20 h 16$ & 1.18618 & 25.53705 & 0.25075 & 0.28433 & 1.34502 \\
\hline & $20 \mathrm{~h} 31$ & 1.40880 & 24.64987 & 0.31415 & 0.29197 & 1.30933 \\
\hline & $20 h 53$ & 1.00599 & 25.02132 & 0.24909 & 0.28872 & 1.16601 \\
\hline & $21 \mathrm{~h} 23$ & 1.15034 & 23.66959 & 0.31240 & 0.30100 & 1.10833 \\
\hline & $21 \mathrm{~h} 53$ & 1.24891 & 20.20995 & 0.41121 & 0.33887 & 1.02920 \\
\hline & $21 \mathrm{~h} 57$ & 1.23487 & 14.25129 & 0.60220 & 0.44036 & 0.90302 \\
\hline & $21 \mathrm{~h} 58$ & 1.10729 & 14.44459 & 0.51881 & 0.43594 & 0.93042 \\
\hline & $22 \mathrm{~h} 27$ & 1.04949 & 14.77135 & 0.46020 & 0.42868 & 0.97761 \\
\hline & $22 h 41$ & 1.03471 & 14.82528 & 0.44886 & 0.42751 & 0.98551 \\
\hline & $23 h 08$ & 1.10676 & 15.85193 & 0.39437 & 0.40658 & 1.14100 \\
\hline & $24 \mathrm{~h} 17$ & 0.99616 & 12.44210 & 0.41624 & 0.48756 & 1.16685 \\
\hline & $24 \mathrm{~h} 19$ & 1.00742 & 12.44210 & 0.42095 & 0.48756 & 1.16685 \\
\hline & $24 \mathrm{~h} 45$ & 1.37770 & 14.00455 & 0.42685 & 0.44617 & 1.44006 \\
\hline & $24 \mathrm{~h} 50$ & 1.38567 & 14.00455 & 0.42932 & 0.44617 & 1.44006 \\
\hline
\end{tabular}


Homogeneous Single Phase Approach

\begin{tabular}{|c|c|c|c|c|c|c|}
\hline Expt & File & $\begin{array}{l}\text { Dpave } \\
\text { psi }\end{array}$ & NreM & Friction $f$ & $3.23 /$ Nre $^{\wedge} .75$ & $\begin{array}{c}\text { dp Predicted } \\
\text { psi }\end{array}$ \\
\hline \multicolumn{2}{|c|}{ Imbibition 21-22 } & 1.20757 & 13.07827 & 0.44430 & 0.46967 & 1.27650 \\
\hline \multirow[t]{32}{*}{ run4 } & $21-22 b$ & 1.32840 & 13.07827 & 0.48876 & 0.46967 & 1.27650 \\
\hline & $21-31$ & 1.26162 & 13.05560 & 0.46624 & 0.47028 & 1.27256 \\
\hline & $21-34$ & 1.23485 & 17.68264 & 0.32127 & 0.37458 & 1.43973 \\
\hline & $21-35$ & 1.29890 & 17.70713 & 0.33661 & 0.37419 & 1.44389 \\
\hline & $21-51$ & 1.27186 & 17.70713 & 0.32961 & 0.37419 & 1.44389 \\
\hline & $21-56$ & 1.40622 & 17.78052 & 0.36018 & 0.37303 & 1.45638 \\
\hline & $22-26$ & 1.28964 & 25.13572 & 0.22706 & 0.28773 & 1.63426 \\
\hline & $22-27$ & 1.24836 & 24.62945 & 0.23344 & 0.29215 & 1.56237 \\
\hline & $23-32$ & 1.51409 & 34.85008 & 0.18282 & 0.22519 & 1.86502 \\
\hline & $23-33$ & 1.60441 & 34.00072 & 0.20574 & 0.22940 & 1.78892 \\
\hline & $23-43$ & 1.75250 & 37.75596 & 0.18892 & 0.21206 & 1.96718 \\
\hline & $24-06$ & 1.90787 & 36.38536 & 0.22264 & 0.21803 & 1.86831 \\
\hline & $24-06 b$ & 1.70173 & 37.25717 & 0.18993 & 0.21419 & 1.91908 \\
\hline & $24-10$ & 1.75584 & 31.43101 & 0.26589 & 0.24332 & 1.60682 \\
\hline & 24-14 & 1.88722 & 31.43101 & 0.28578 & 0.24332 & 1.60682 \\
\hline & $24-35$ & 1.78961 & 24.34713 & 0.38951 & 0.29469 & 1.35398 \\
\hline & $24-53$ & 1.50971 & 25.14574 & 0.31356 & 0.28764 & 1.38493 \\
\hline & $1-13$ & 1.57170 & 24.34713 & 0.34208 & 0.29469 & 1.35398 \\
\hline & $1-30$ & 1.45735 & 21.20275 & 0.35031 & 0.32690 & 1.35993 \\
\hline & $1-36$ & 1.56296 & 20.41885 & 0.39457 & 0.33626 & 1.33201 \\
\hline & $1-45$ & 1.41732 & 19.41633 & 0.38171 & 0.34920 & 1.29662 \\
\hline & $2-08$ & 0.96952 & 15.35976 & 0.33171 & 0.41631 & 1.21678 \\
\hline & $2-15$ & 1.19093 & 16.27040 & 0.38024 & 0.39871 & 1.24876 \\
\hline & $2-16$ & 1.31000 & 15.58921 & 0.44033 & 0.41170 & 1.22484 \\
\hline & $2-24$ & 1.11562 & 10.27196 & 0.54759 & 0.56294 & 1.14689 \\
\hline & $2-25$ & 1.04936 & 10.53558 & 0.50079 & 0.55234 & 1.15739 \\
\hline & $2-33$ & 1.04709 & 10.53558 & 0.49970 & 0.55234 & 1.15739 \\
\hline & $2-45$ & 1.15967 & 5.10134 & 1.14845 & 0.95157 & 0.96086 \\
\hline & $2-46$ & 0.98704 & 4.80758 & 1.04012 & 0.99485 & 0.94408 \\
\hline & $2-54$ & 0.97679 & 3.76567 & 1.32714 & 1.19487 & 0.87944 \\
\hline & $2-4 b$ & 0.95277 & 2.88634 & 1.70288 & 1.45862 & 0.81611 \\
\hline & $2-56$ & 0.95277 & 3.19835 & 1.53227 & 1.35054 & 0.83977 \\
\hline
\end{tabular}


LIQUID PHASE

\begin{tabular}{|c|c|c|c|c|c|c|c|c|c|}
\hline Expt & File & Sw & $\begin{array}{l}\text { delPI read } \\
\text { Volts }\end{array}$ & $\begin{array}{l}\text { LIQUID PH } \\
\text { I reading } \\
\text { cc/min }\end{array}$ & $\begin{array}{l}\text { ASE } \\
\text { delP act } \\
\text { psi }\end{array}$ & $\begin{array}{c}\text { qact } \\
\mathrm{cc} / \mathrm{min}\end{array}$ & $\begin{array}{c}\mathrm{ql} \\
\mathrm{cu} . \mathrm{ft} / \mathrm{day}\end{array}$ & $\begin{array}{l}\text { kkrl } \\
\text { md }\end{array}$ & $\begin{array}{l}\mathrm{krl} \\
\mathrm{md} \\
\end{array}$ \\
\hline run5 & 125008 & 0.86866 & 1.316 & 8.5 & 0.6599 & 8.4564 & 0.4300 & 1239305 & 0.6995 \\
\hline & 125020 & 0.7724 & 1.257 & 8.5 & 0.6303 & 8.4564 & 0.4300 & 1297401 & 0.7323 \\
\hline & 125038 & 0.5547 & 0.985 & 8.5 & 0.4941 & 8.4564 & 0.4300 & 1655088 & 0.9341 \\
\hline & 125129 & 0.70226 & 2.23 & 8.5 & 1.1176 & 8.4564 & 0.4300 & 731720.3 & 0.4130 \\
\hline & 125140 & 0.8639 & 1.324 & 8.5 & 0.6639 & 8.4564 & 0.4300 & 1231826 & 0.6952 \\
\hline & 131247 & 0.5675 & 2.104 & 8.5 & 1.0545 & 8.4564 & 0.4300 & 775506.8 & 0.4377 \\
\hline & 131256 & 0.715 & 2.31 & 8.5 & 1.1576 & 8.4564 & 0.4300 & 706396.9 & 0.3987 \\
\hline & 131308 & 0.879 & 1.696 & 8.5 & 0.8502 & 8.4564 & 0.4300 & 961891.9 & 0.5429 \\
\hline & 131323 & 0.7754 & 1.608 & 8.5 & 0.8061 & 8.4564 & 0.4300 & 1014480 & 0.5726 \\
\hline & 131343 & 0.762 & $1: 64$ & 8.5 & 0.8221 & 8.4564 & 0.4300 & 994705 & 0.5614 \\
\hline & 131403 & 0.5898 & $1: 382$ & 8.5 & 0.6929 & 8.4564 & 0.4300 & 1180188 & 0.6661 \\
\hline & 132803 & 0.71498 & 1.921 & 8.5 & 0.9628 & 8.4564 & 0.4300 & 849322.5 & 0.4794 \\
\hline & 132905 & 0.7155 & 1.778 & 8.5 & 0.8912 & 8.4564 & 0.4300 & 917570 & 0.5179 \\
\hline & 141048 & 0.715 & $1: 608$ & 8.5 & 0.8061 & 8.4564 & 0.4300 & 1014480 & 0.5726 \\
\hline & 141149 & 0.6105 & 1.725 & 8.5 & 0.8647 & 8.4564 & 0.4300 & 945735.9 & 0.5338 \\
\hline & 141210 & 0.715 & 1.608 & 8.5 & 0.8061 & 8.4564 & 0.4300 & 1014480 & 0.5726 \\
\hline & 141218 & 0.691 & 1.278 & 8.5 & 0.6408 & 8.4564 & 0.4300 & 1276109 & 0.7202 \\
\hline & 141610 & 0.526 & $0: 957$ & 8.5 & 0.4801 & 8.4564 & 0.4300 & 1703432 & 0.9614 \\
\hline & 141619 & 0.681 & 1.506 & 8.5 & 0.7550 & 8.4564 & 0.4300 & 1083118 & 0.6113 \\
\hline & 141637 & 0.715 & 2.149 & 8.5 & 1.0770 & 8.4564 & 0.4300 & 759279.8 & 0.4285 \\
\hline & 145050 & 0.753 & 162 & 8.5 & 0.8121 & 8.4564 & 0.4300 & 1006973 & 0.5683 \\
\hline & 145132 & 0.766 & 1.597. & 8.5 & 0.8006 & 8.4564 & 0.4300 & 1021461 & 0.5765 \\
\hline & 145542 & 0.453 & 0.874 & 8.5 & 0.4385 & 8.4564 & 0.4300 & 1864904 & 1.0526 \\
\hline & 145551 & 0.576 & $1: 082$ & 8.5 & 0.5427 & 8.4564 & 0.4300 & 1506930 & 0.8505 \\
\hline & 145558 & 0.78 & $1: 567$ & $8: 5$ & 0.7856 & 8.4564 & 0.4300 & 1040997 & 0.5875 \\
\hline & 152952 & 0.531 & 1.341 & 8.5 & 0.6724 & 8.4564 & 0.4300 & 1216228 & 0.6864 \\
\hline & 153005 & 0.728 & 1735 & 8.5 & 0.8697 & 8.4564 & 0.4300 & 940290 & 0.5307 \\
\hline & 153011 & 0.775 & 2.634 & 8.5 & 1.3199 & 8.4564 & 0.4300 & 619557.9 & 0.3497 \\
\hline & 153014 & 0.623 & 2.726 & 8.5 & 1.3660 & 8.4564 & 0.4300 & 598660.6 & 0.3379 \\
\hline & 153457 & 0.583 & 1.605 & 8.5 & 0.8046 & 8.4564 & 0.4300 & 1016375 & 0.5736 \\
\hline & 153529 & 0.73 & 2.869 & 8.5 & 1.4376 & 8.4564 & 0.4300 & 568838.1 & 0.3211 \\
\hline path starts & 160910 & 0.678 & 2641 & 8.5 & 1.3234 & 8.4564 & 0.4300 & 617916.7 & 0.3488 \\
\hline & 161513 & 0.6801 & 241 & 85 & 1.2077 & 8.4564 & 0.4300 & 677105.2 & 0.3822 \\
\hline & 161717 & $0: 684$ & 2523 & 8.5 & 1.2643 & 8.4564 & 0.4300 & 646798.2 & 0.3651 \\
\hline & 173541 & 0.577 & 2.621 & 8.5 & 1.3134 & 8.4564 & 0.4300 & 622629 & 0.3514 \\
\hline & 173641 & 0.5788 & 2.554 & 8.5 & 1.2798 & 8.4564 & 0.4300 & 638952.4 & 0.3606 \\
\hline & 173717 & 0.581 & 2548 & 8.5 & 1.2768 & 8.4564 & 0.4300 & 640456.1 & 0.3615 \\
\hline & 173823 & 0.5885 & 2.683 & 8.5 & 1.3444 & 8.4564 & 0.4300 & 608249.6 & 0.3433 \\
\hline & 174050 & 0.5242 & $2: 587$ & 8.5 & 1.2964 & 8.4564 & 0.4300 & 630806.9 & 0.3560 \\
\hline & 174307 & 0.58746 & 2.654 & 8.5 & 1.3299 & 8.4564 & 0.4300 & 614891.8 & 0.3470 \\
\hline & 181754 & 0.5926 & 292 & 8.5 & 1.4631 & 8.4564 & 0.4300 & 558908.3 & 0.3155 \\
\hline & 181914 & 0.5869 & 2865 & 8.5 & 1.4356 & 8.4564 & 0.4300 & 569631.8 & 0.3215 \\
\hline & 182120 & 0.56727 & 2.881 & 8.5 & 1.4436 & 8.4564 & 0.4300 & 566470.1 & 0.3197 \\
\hline & 182427 & $0: 5644$ & 2887 & 8.5 & 1.4466 & 8.4564 & 0.4300 & 565293.4 & 0.3191 \\
\hline & 185428 & 0.53 & 3.015 & 8.5 & 1.5107 & 8.4564 & 0.4300 & 541307 & 0.3055 \\
\hline & 185527 & 0.5296 & 3.055 & 8.5 & 1.5307 & 8.4564 & 0.4300 & 534223.2 & 0.3015 \\
\hline & 185732 & 0.5389 & 3.042 & $8: 5$ & 1.5242 & 8.4564 & 0.4300 & 536505 & 0.3028 \\
\hline & 185809 & 0.55412 & 3.092 & 8.5 & 1.5493 & 8.4564 & 0.4300 & 527833.8 & 0.2979 \\
\hline & 185915 & $0: 5585$ & 2984 & $8: 5$ & 1.4952 & 8.4564 & 0.4300 & 546927.5 & 0.3087 \\
\hline & 193125 & 0.5005 & $2: 77.1$ & 7 & 1.3885 & 6.9664 & 0.3543 & 485176.3 & 0.2738 \\
\hline & 193242 & 0.5573 & 2702 & 7 & 1.3540 & 6.9664 & 0.3543 & 497558.8 & 0.2808 \\
\hline & 193412 & 0.47 .67 & 2,438 & 7 & 1.2218 & 6.9664 & 0.3543 & 551401.9 & 0.3112 \\
\hline & 193519 & 0.5173 & 2822 & 7 & 1.4141 & 6.9664 & 0.3543 & 476413.1 & 0.2689 \\
\hline & 193619 & 0.4797 & $2: 281$ & 7. & 1.1431 & 6.9664 & 0.3543 & 589328 & 0.3326 \\
\hline & 201116 & 0.513 & 2.323 & 6 & 1.1642 & 5.9731 & 0.3038 & 496169.5 & 0.2800 \\
\hline & 201304 & $0: 474$ & 244 & 6 & 1.2228 & 5.9731 & 0.3038 & 472393.3 & 0.2666 \\
\hline & 201529 & 0.473 & 2634 & 6 & 1.3199 & 5.9731 & 0.3038 & 437621.6 & 0.2470 \\
\hline & 201742 & 0.469 & 2787 & 6 & 1.3965 & 5.9731 & 0.3038 & 413610.9 & 0.2334 \\
\hline & 204350 & 0.45752 & 2.182 & 5 & 1.0935 & 4.9798 & 0.2532 & 440369.6 & 0.2485 \\
\hline
\end{tabular}


LIQUID PHASE

dPI read Ql reading delP act qact ql kkrl krl

\begin{tabular}{|c|c|c|c|c|c|c|c|c|c|}
\hline Expt & File & sw & Volts & $\mathrm{cc} / \mathrm{min}$ & osi & $\mathrm{cc} / \mathrm{min}$ & cu. ft /day & & \\
\hline run5 & 204512 & 0.464 & 2178 & 5 & 1.0915 & 4.980 & 0.253 & 441178 & 0.2261 \\
\hline drainage & 204820 & 0.456 & 2.403 & 5 & 1.2042 & 4.980 & 0.253 & 399896 & 0.2049 \\
\hline & 221045 & 0.454 & 2.512 & 4.5 & 1.2588 & 4.483 & 0.228 & 344402 & 0.1765 \\
\hline & 221223 & 0.4454 & 2.731 & 4.5 & 1.3685 & 4.483 & 0.228 & 316800 & 0.1623 \\
\hline & 221727 & 0.45121 & 2723 & 4.5 & 1.3645 & 4.483 & 0.228 & 317731 & 0.1628 \\
\hline & 225040 & 0.416 & 2314 & 3.5 & 1.1597 & 3.490 & 0.177 & 291019 & 0.1491 \\
\hline & 225305 & 0.441 & 2.354 & 3.5 & 1.1797 & 3.490 & 0.177 & 286078 & 0.1466 \\
\hline & 225517 & 0.4416 & 2,663 & 3.5 & 1.3344 & 3.490 & 0.177 & 252903 & 0.1296 \\
\hline & 225805 & 0.4547 & 2.296 & 3.5 & 1.1506 & 3.490 & 0.177 & 293299 & 0.1503 \\
\hline & 233209 & 0.392 & 2.276 & 3 & 1.1406 & 2.993 & 0.152 & 253768 & 0.1300 \\
\hline & 233533 & 0.3965 & 2.497 & 3 & 1.2513 & 2.993 & 0.152 & 231322 & 0.1185 \\
\hline & 233729 & 0.4045 & 2.595 & 3 & 1.3004 & 2.993 & 0.152 & 222592 & 0.1141 \\
\hline & 234013 & 0.4112 & 2.536 & 3 & 1.2708 & 2.993 & 0.152 & 227767 & 0.1167 \\
\hline & 240945 & 0.348 & 2.095 & 2 & 1.0500 & 2.000 & 0.102 & 184192 & 0.0944 \\
\hline & 241043 & 0.3427 & 1.989 & 2 & 0.9969 & 2.000 & 0.102 & 194001 & 0.0994 \\
\hline & 241209 & 0.3436 & 2.166 & 2 & 1.0855 & 2.000 & 0.102 & 178159 & 0.0913 \\
\hline & 241338 & 0.3449 & 1.906 & 2 & 0.9553 & 2.000 & 0.102 & 202442 & 0.1037 \\
\hline & 244335 & 0.2883 & 1942 & 1 & 0.9734 & 1.007 & 0.051 & 100007 & 0.0512 \\
\hline & 244422 & $0: 2995$ & 2.025 & 1 & 1.0149 & 1.007 & 0.051 & 95911 & 0.0491 \\
\hline & 244635 & 0.3073 & 1.968 & 1 & 0.9864 & 1.007 & 0.051 & 98686 & 0.0506 \\
\hline & 244717 & 0.3118 & 1979 & 1 & 0.9919 & 1.007 & 0.051 & 98138 & 0.0503 \\
\hline & 10935 & 0.252 & 1.771 & 0.5 & 0.8877 & 0.510 & 0.026 & 55551 & 0.0285 \\
\hline & 11007 & 0.2659 & 1.8 & 0.5 & 0.9022 & 0.510 & 0.026 & 54657 & 0.0280 \\
\hline & 11054 & 0.252 & 1.814 & 0.5 & 0.9093 & 0.510 & 0.026 & 54236 & 0.0278 \\
\hline & & 0.132 & & & & 0 & & & 0.0000 \\
\hline
\end{tabular}


Gas Phase

qG reading qg actual qg delPG read P2 reading delP actual P2 actual K krg $\mathrm{krg}$ uncalib $\mathrm{krg}$ calib

\begin{tabular}{|c|c|c|c|c|c|c|c|c|c|c|c|}
\hline Expt & File & cc/miln & $\mathrm{cc} / \mathrm{min}$ & cu. Ft/day & volts & volts & psi & psi & - &.- & \\
\hline & 125038 & 0 & 0.60 & 0.03 & 1.145 & 1.106 & 0.579 & 0.068 & 1803 & 0.00092 & 0.00091 \\
\hline & 125140 & 0 & 0.60 & 0.03 & 1.419 & 3.204 & 0.716 & 0.167 & 1458 & 0.00075 & 0.00073 \\
\hline & 131247 & -1 & 0.85 & 0.04 & 2.045 & 0.8 & 1.029 & 0.053 & 1438 & 0.00074 & 0.00071 \\
\hline & 131256 & 3 & 5.13 & 0.26 & 2.324 & 0.498 & 1.169 & 0.039 & 7634 & 0.00391 & 0.00376 \\
\hline & 131308 & 1 & 2.11 & 0.11 & 1.586 & 1.174 & 0.800 & 0.071 & 4588 & 0.00235 & 0.00229 \\
\hline & 131403 & 0 & 0.60 & 0.03 & 1.321 & 1.172 & 0.667 & 0.071 & 1562 & 0.00080 & 0.00078 \\
\hline & 132803 & 1 & 2.11 & 0.11 & 1.875 & 1.214 & 0.944 & 0.073 & 3886 & 0.00199 & 0.00193 \\
\hline & 132905 & 0 & 0.60 & 0.03 & 1.826 & 0.891 & 0.920 & 0.057 & 1133 & 0.00058 & 0.00056 \\
\hline & 141048 & 5 & 8.14 & 0.41 & 1.59 & 1.418 & 0.802 & 0.082 & 17681 & 0.00906 & 0.00882 \\
\hline & 141149 & 7 & 11.16 & 0.57 & 1.663 & 2.87 & 0.838 & 0.151 & 23178 & 0.01188 & 0.01155 \\
\hline & 141210 & 5 & 8.14 & 0.41 & 1.59 & 1.418 & 0.802 & 0.082 & 17681 & 0.00906 & 0.00882 \\
\hline & 145050 & 9 & 14.18 & 0.72 & 1.638 & 1.518 & 0.826 & 0.087 & 29891 & 0.01532 & 0.01490 \\
\hline & 145132 & 8 & 12.67 & 0.64 & 1.585 & 1.533 & 0.799 & 0.088 & 27596 & 0.01414 & 0.01377 \\
\hline & 145542 & 10 & 15.69 & 0.80 & 0.788 & 1.503 & 0.401 & 0.086 & 68141 & 0.03669 & 0.03620 \\
\hline & 145551 & 6 & 9.65 & 0.49 & 1.125 & 1.488 & 0.569 & 0.086 & 29516 & 0.01513 & 0.01484 \\
\hline & 145558 & 7 & 11.16 & 0.57 & 1.541 & 3.137 & 0.777 & 0.164 & 24997 & 0.01281 & 0.01248 \\
\hline & 152952 & .17 & 26.25 & 1.33 & 1.265 & 1.084 & 0.639 & 0.067 & 71483 & 0.03663 & 0.03585 \\
\hline & 153005 & .12 & 18.71 & 0.95 & 1.958 & 2.531 & 0.986 & 0.135 & 33034 & 0.01693 & 0.01638 \\
\hline & 153011 & .13 & 20.22 & 1.03 & 2.734 & 1.446 & 1.374 & 0.084 & 25616 & 0.01313 & 0.01254 \\
\hline & 153014 & 14 & 21.72 & 1.10 & 2.705 & 1.408 & 1.359 & 0.082 & 27822 & 0.01426 & 0.01363 \\
\hline & 153457 & 17 & 26.25 & 1.33 & $1: 548$ & 2.053 & 0.781 & 0.113 & 58528 & 0.02999 & 0.02922 \\
\hline & 153529 & 13 & 20.22 & 1.03 & 2.964 & 1.864 & 1.489 & 0.104 & 23638 & 0.01211 & 0.01153 \\
\hline path starts & 160910 & 26 & 39.83 & 2.03 & 2.574 & 1.674 & 1.294 & 0.095 & 53595 & 0.02746 & 0.02631 \\
\hline & 181914 & 43 & 65.49 & 3.33 & $2: 792$ & 2.863 & 1.403 & 0.151 & 81264 & 0.04164 & 0.03977 \\
\hline & 182120 & 43 & 65.49 & 3.33 & 2.822 & 2.506 & 1.418 & 0.134 & 80405 & 0.04120 & 0.03932 \\
\hline & 182427 & 42 & 63.98 & 3.25 & 2.788 & 2.62 & 1.401 & 0.139 & 79505 & 0.04074 & 0.03891 \\
\hline & 185428 & 57 & 86.61 & 4.40 & 2.992 & 2308 & 1.503 & 0.125 & 100329 & 0.05141 & 0.04893 \\
\hline & 185527 & 58 & 88.12 & 4.48 & 3.075 & 1743 & 1.544 & 0.098 & 99333 & 0.05090 & 0.04838 \\
\hline & 185732 & 56 & 85.10 & 4.33 & 3.021 & 3.377 & 1.517 & 0.175 & 97639 & 0.05003 & 0.04761 \\
\hline & 185809 & 60 & 91.14 & 4.63 & 3.038 & 2.375 & 1.526 & 0.128 & 103981 & 0.05328 & 0.05068 \\
\hline & 185915 & 57 & 86.61 & 4.40 & 2.957 & 2.902 & 1.485 & 0.153 & 101511 & 0.05202 & 0.04954 \\
\hline & 193125 & 66 & 100.19 & 5.10 & $2: 698$ & 3.23 & 1.356 & 0.168 & 128644 & 0.06592 & 0.06305 \\
\hline & 193242 & 58 & 88.12 & 4.48 & $2: 753$ & $2: 424$ & 1.383 & 0.130 & 110895 & 0.05683 & 0.05429 \\
\hline & 193412 & 61 & 92.65 & 4.71: & $2: 434$ & 2.284 & 1.224 & 0.123 & 131787 & 0.06753 & 0.06486 \\
\hline & 193519 & 60 & 91.14 & 4.63 & 2.84 & 2.103 & 1.427 & 0.115 & 111196 & 0.05698 & 0.05436 \\
\hline & 193619 & 66 & 100.19 & 5.10 & 2.236 & 2.417 & 1.125 & 0.130 & 155064 & 0.07946 & 0.07656 \\
\hline & 201116 & 69 & 104.72 & 5.33 & 2.426 & 2.743 & 1.220 & 0.145 & 149448 & 0.07658 & 0.07356 \\
\hline & 201304 & 69 & 104.72 & 5.33 & 2.465 & $\therefore 2.586$ & 1.239 & 0.138 & 147096 & 0.07538 & 0.07236 \\
\hline & 201529 & 74 & 112.26 & 5.71 & $2: 661$ & 2.211 & 1.337 & 0.120 & 146138 & 0.07489 & 0.07165 \\
\hline & 201742 & 67 & 101.70 & 5.17 & 2.886 & .1675 & 1.450 & 0.095 & 122115 & 0.06258 & 0.05965 \\
\hline & 204350 & 86 & 130.37 & 6.63 & $2: 369$ & 2.44 & 1.191 & 0.131 & 190509 & 0.09762 & 0.09385 \\
\hline
\end{tabular}


Gas Phase

QG reading qg actual qg delPG read P2 reading delP actual P2 actual K $\mathrm{krg} \quad \mathrm{krg}$ uncallb $\mathrm{krg}$ calib

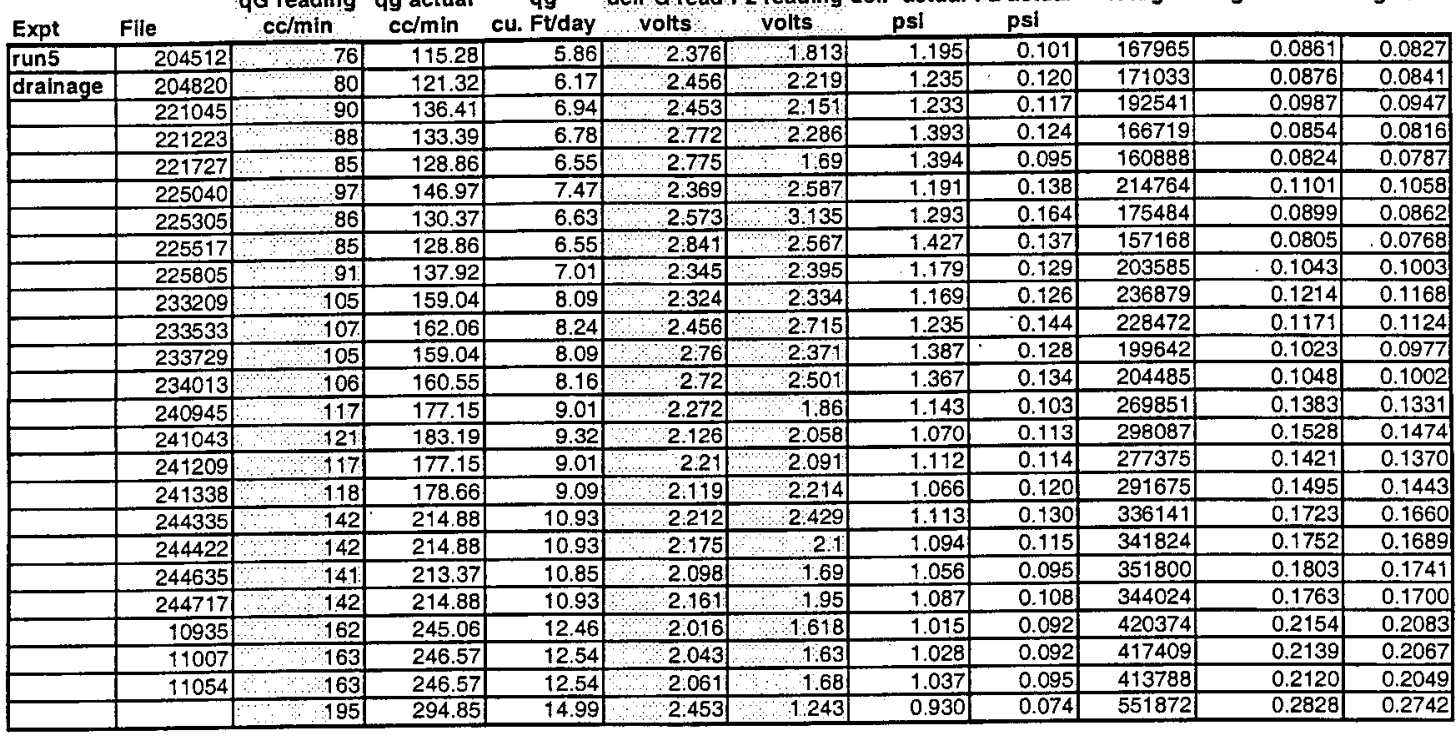




\begin{tabular}{|c|c|c|c|c|c|c|}
\hline Expt & File & $\begin{array}{l}\text { Homogene } \\
\text { Dpave } \\
\text { psi }\end{array}$ & $\begin{array}{l}\text { us Single } \mathrm{Pr} \\
\text { friction } f\end{array}$ & $\begin{array}{l}\text { lase Model } \\
\text { NreM }\end{array}$ & $\begin{array}{l}\text { Calculation } \\
2.8 / \mathrm{Nre}^{\wedge} 0.66\end{array}$ & $\begin{array}{c}\text { delP calc } \\
\text { psi }\end{array}$ \\
\hline run5 & 125008 & $\begin{array}{ll}0.6443 \\
\end{array}$ & 1.7897 & 1.7400 & 2.0055 & 0.7577 \\
\hline \multirow[t]{2}{*}{ drainage } & 125020 & \begin{tabular}{l|l}
0.6028 \\
\end{tabular} & 1.6491 & 1.7662 & 1.9859 & 0.7618 \\
\hline & 125038 & \begin{tabular}{l|l|}
0.5367 \\
\end{tabular} & 1.5072 & 1.7214 & 2.0199 & 0.7548 \\
\hline & 125129 & 1.1524 & 3.2364 & 1.7214 & 2.0199 & 0.7548 \\
\hline & 125140 & 0.6901 & 1.9380 & 1.7214 & 2.0199 & 0.7548 \\
\hline & 131247 & 1.0419 & 2.8473 & 1.7680 & 1.9845 & 0.7621 \\
\hline & 131256 & 1.1632 & 2.1768 & 2.5587 & 1.5549 & 0.8720 \\
\hline & 131308 & 0.8249 & 1.9857 & 2.0020 & 1.8283 & 0.7971 \\
\hline & 131323 & 0.7557 & 1.8190 & 2.0020 & 1.8283 & 0.7971 \\
\hline & 131343 & $\begin{array}{l}0.8107 \\
\end{array}$ & 1.9514 & 2.0020 & 1.8283 & 0.7971 \\
\hline & 131403 & 0.6801 & 1.9102 & 1.7211 & 2.0201 & 0.7548 \\
\hline & 132803 & 0.9535 & 2.2952 & 2.0020 & 1.8283 & 0.7971 \\
\hline & 132905 & 0.9055 & 2.5433 & 1.7211 & 2.0201 & 0.7548 \\
\hline & 141048 & 0.8039 & 1.2304 & 3.1089 & 1.3673 & 0.9376 \\
\hline & 141149 & 0.8515 & 1.1022 & 3.6527 & \begin{tabular}{|l|}
1.2293 \\
\end{tabular} & 0.9967 \\
\hline & 141210 & 0.8039 & 1.2304 & 3.1089 & 1.3673 & 0.9376 \\
\hline & 141218 & 0.6485 & 1.2137 & 2.5587 & $\begin{array}{l}1.5549 \\
\end{array}$ & 0.8720 \\
\hline & 141610 & |0.4554 & 0.6970 & 3.1089 & 1.3673 & 0.9376 \\
\hline & 141619 & 0.7586 & 1.4197 & 2.5587 & 1.5549 & 0.8720 \\
\hline & 141637 & 1.0834 & 1.5196 & 3.3816 & 1.2935 & 0.9679 \\
\hline & 145050 & 0.8189 & 0.9183 & 4.1902 & 1.1229 & 1.0509 \\
\hline & 145132 & 0.7999 & 0.9613 & 3.9223 & 1.1729 & 1.0243 \\
\hline & 145542 & 0.4196 & 0.4411 & 4.4567 & 1.0781 & 1.0765 \\
\hline & 145551 & 0.5560 & 0.7798 & 3.3816 & 1.2935 & 0.9679 \\
\hline & 145558 & |0.7814 & 1.0115 & \begin{tabular}{|c|}
3.6527 \\
\end{tabular} & 1.2293 & 0.9967 \\
\hline & 152952 & 0.6558 & 0.4788 & 6.2798 & 0.8597 & 1.2359 \\
\hline & 153005 & 0.9277 & 0.8663 & 4.9850 & 1.0013 & 1.1252 \\
\hline & 153011 & 1.3468 & 1.1912 & 5.2469 & 0.9680 & 1.1485 \\
\hline & 153014 & 1.3626 & 1.1447 & 5.5073 & 0.9375 & 1.1712 \\
\hline & 153457 & 0.7927 & 0.5787 & 6.2798 & 0.8597 & 1.2359 \\
\hline & 153529 & 1.4631 & 1.2941 & 5.2469 & 0.9680 & 1.1485 \\
\hline & & 1.2960 & 0.6787 & 8.5213 & $\begin{array}{l}0.7029 \\
\end{array}$ & 1.4086 \\
\hline & 160910 & 1.3086 & 0.6852 & \begin{tabular}{|l|l|}
8.5213 \\
\end{tabular} & 0.7029 & 1.4086 \\
\hline & 161513 & 1.2032 & 0.6301 & 8.5213 & 0.7029 & 1.4086 \\
\hline & 161717 & 1.2475 & 0.6533 & 8.5213 & 0.7029 & 1.4086 \\
\hline & 173541 & 1.3048 & 0.5322 & 10.6557 & 0.6065 & 1.5604 \\
\hline & 173641 & 1.2505 & 0.5101 & 10.6557 & 0.6065 & 1.5604 \\
\hline & 173717 & 1.2688 & 0.5051 & \begin{tabular}{l|l}
10.8866 \\
\end{tabular} & $\begin{array}{l}0.5979 \\
\end{array}$ & 1.5763 \\
\hline & 173823 & 1.3296 & 5423 & 10.6557 & 0.6065 & 1.5604 \\
\hline & 174050 & 1.2825 & 0.5106 & 10.8866 & 0.5979 & 1.5763 \\
\hline & 174307 & 1.3168 & 0.5507 & 10.4236 & 0.6153 & 1.5442 \\
\hline & 181754 & $\begin{array}{ll}1.4479 \\
\end{array}$ & 0.4933 & 12.4698 & $\begin{array}{l}0.5467 \\
\end{array}$ & 1.6840 \\
\hline & 181914 & 1.4191 & 0.4835 & 12.4698 & 0.5467 & 1.6840 \\
\hline & 182120 & 1.4306 & 0.4874 & 12.4698 & 0.5467 & 1.6840 \\
\hline & 182427 & 1.4236 & 0.4952 & 12.2471 & 0.5532 & 1.6690 \\
\hline & 185428 & 1.5067 & 0.3980 & 15.4717 & 0.4741 & 1.8837 \\
\hline & 185527 & 1.5375 & $\begin{array}{l}0.3997 \\
\end{array}$ & \begin{tabular}{l|}
15.6782 \\
\end{tabular} & 0.4700 & 1.8973 \\
\hline & 185732 & 1.5207 & $\begin{array}{l}0.4083 \\
\end{array}$ & 15.2641 & -0.4784 & 1.8700 \\
\hline & 185809 & 1.5375 & \begin{tabular}{l|l|}
0.3874 \\
\end{tabular} & 16.0883 & 0.4621 & 1.9244 \\
\hline & 185915 & 1.4902 & 0.3937 & 15.4717 & 0.4741 & 1.8837 \\
\hline & 193125 & 1.3721 & 0.3883 & 16.4913 & 0.4546 & 1.6856 \\
\hline & 193242 & 1.3686 & 0.4375 & 14.9732 & 0.4845 & 1.5907 \\
\hline & 193412 & \begin{tabular}{|l|l|}
1.2227 \\
\end{tabular} & 0.3728 & 15.5505 & \begin{tabular}{|l|l|}
0.4726 \\
\end{tabular} & 1.6267 \\
\hline & 193519 & 1.4204 & 0.4398 & 15.3591 & 0.4764 & 1.6148 \\
\hline & 193619 & 1.1339 & 0.3209 & 16.4913 & 0.4546 & 1.6856 \\
\hline
\end{tabular}


Homogeneous Single Phase Model Calculation

Dpave friction $f$ NreM 2.8/Nre^0.66 delP calc

\begin{tabular}{|c|c|c|c|c|c|c|}
\hline Expt & File & psi & & & & psi \\
\hline un 5 & 201116 & 1.1919 & 0.3794 & 16.3643 & 0.4569 & 1.5064 \\
\hline drainage & 201304 & 1.2310 & 0.3918 & 16.3643 & 0.4569 & 1.5064 \\
\hline & 201529 & 1.3286 & 0.3953 & 17.2094 & 0.4420 & 1.5589 \\
\hline & 201742 & 1.4231 & 0.4660 & 16.0190 & 0.4634 & 1.4852 \\
\hline & 204350 & 1.1424 & 0.3530 & 18.0827 & 0.4278 & 1.4530 \\
\hline & 204512 & 1.1431 & 0.3990 & 16.6238 & 0.4522 & $1: 3597$ \\
\hline & 204820 & 1.2195 & 0.4047 & 17.2188 & 0.4418 & 1.3972 \\
\hline & 221045 & 1.2460 & 0.4087 & 17.9854 & 0.4293 & 1.3735 \\
\hline & 221223 & 1.3806 & 0.4631 & 17.7246 & 0.4335 & 1.3560 \\
\hline & 221727 & 1.3793 & 0.4790 & 17.3268 & 0.4400 & 1.3297 \\
\hline & 225040 & 1.1754 & 0.4573 & 17.1476 & 0.4430 & 1.1950 \\
\hline & 225305 & 1.2364 & 0.5438 & 15.9459 & 0.4648 & 1.1091 \\
\hline & 225517 & 1.3808 & 0.6145 & 15.8317 & 0.4670 & 1.1012 \\
\hline & 225805 & 1.1649 & 0.4838 & 16.5043 & 0.4543 & 1.1482 \\
\hline & 233209 & 1.1547 & 0.4801 & 16.8124 & 0.4488 & 1.1329 \\
\hline & 233533 & 1.2430 & 0.5067 & 16.9883 & 0.4458 & 1.1475 \\
\hline & 233729 & 1.3435 & 0.5586 & 16.8124 & 0.4488 & 1.1329 \\
\hline & 234013 & 1.3188 & 0.5429 & 16.9006 & 0.4473 & 1.1402 \\
\hline & 240945 & 1.0963 & 0.5923 & 14.6017 & 0.4926 & 0.9569 \\
\hline & 241043 & 1.0333 & 0.5382 & 14.8345 & 0.4875 & 0.9822 \\
\hline & 241209 & 1.0986 & 0.5936 & 14.6017 & 0.4926 & 0.9569 \\
\hline & 241338 & 1.0108 & 0.5411 & 14.6605 & 0.4913 & 0.9632 \\
\hline & 244335 & 1.0430 & 0.8143 & 10.7572 & 0.6027 & 0.8102 \\
\hline & 244422 & 1.0546 & 0.8233 & 10.7572 & 0.6027 & 0.8102 \\
\hline & 244635 & 1.0210 & 0.8039 & 10.7259 & 0.6038 & 0.8049 \\
\hline & 244717 & 1.0395 & 0.8115 & 10.7572 & 0.6027 & 0.8102 \\
\hline & 10935 & 0.9512 & 1.0192 & 7.7638 & 0.7474 & 0.7321 \\
\hline & 11007 & 0.9652 & 1.0255 & 7.7866 & 0.7460 & 0.7369 \\
\hline & 11054 & 0.9732 & 1.0340 & 7.7866 & 0.7460 & 0.7369 \\
\hline
\end{tabular}




\begin{tabular}{|c|c|c|c|c|c|c|}
\hline \multirow[b]{2}{*}{ Expt } & \multicolumn{6}{|c|}{ Homogeneous Single Phase Model Calculation } \\
\hline & File & Dpave & friction $f$ & NreM & $6.5 / \mathrm{Nre}^{\wedge} .83$ & delP calc \\
\hline run6 & 432 & 2.0267 & 0.5925 & 14.2109 & 0.7182 & 2.4565 \\
\hline imbibition & 136 & 2.5708 & 0.3816 & 27.8902 & 0.4104 & 2.7647 \\
\hline & 130 & 2.7359 & 0.4061 & 27.8902 & 0.4104 & 2.7647 \\
\hline & 153 & 2.2681 & 0.3464 & 27.0090 & 0.4215 & 2.7593 \\
\hline & 156 & 2.4432 & 0.3732 & 27.0090 & 0.4215 & 2.7593 \\
\hline & $0156 \mathrm{~b}$ & 2.3757 & 0.3603 & 27.1239 & 0.4200 & 2.7689 \\
\hline & 236 & 2.6334 & 0.4056 & 26.3339 & 0.4304 & 2.7948 \\
\hline & 237 & 2.6359 & 0.4059 & 26.3339 & 0.4304 & 2.7948 \\
\hline & 238 & 2.7310 & 0.4206 & 26.3339 & 0.4304 & 2.7948 \\
\hline & 239 & 2.5708 & 0.3959 & 26.3339 & 0.4304 & 2.7948 \\
\hline & 256 & 2.5608 & 0.4197 & 25.2924 & 0.4451 & 2.7159 \\
\hline & 257 & 2.4382 & 0.3964 & 25.4247 & 0.4432 & 2.7258 \\
\hline & 258 & 2.5984 & 0.4258 & 25.2924 & 0.4451 & 2.7159 \\
\hline & 259 & 2.3607 & 0.3838 & 25.4247 & 0.4432 & 2.7258 \\
\hline & 309 & 2.4082 & 0.4354 & 23.0322 & 0.4810 & 2.6604 \\
\hline & 310 & 2.3282 & 0.4210 & 23.0322 & 0.4810 & 2.6604 \\
\hline & 311 & 2.3857 & 0.4354 & 22.8800 & 0.4837 & 2.6501 \\
\hline & 317 & 2.4358 & 0.4404 & 23.0322 & 0.4810 & 2.6604 \\
\hline & 31651 & 2.5052 & 0.4530 & 23.0322 & 0.4810 & 2.6604 \\
\hline & 31706 & 2.3983 & 0.4377 & 22.8800 & 0.4837 & 2.6501 \\
\hline & 31708 & 2.4158 & 0.4368 & 23.0322 & 0.4810 & 2.6604 \\
\hline & 31712 & 2.4658 & 0.4500 & 22.8800 & 0.4837 & 2.6501 \\
\hline & 318 & 2.3082 & 0.4173 & 23.0322 & 0.4810 & 2.6604 \\
\hline & 335 & 2.5183 & 0.5394 & 19.6987 & 0.5477 & 2.5569 \\
\hline & 336 & 2.4533 & 0.5255 & 19.6987 & 0.5477 & 2.5569 \\
\hline & 337 & 2.5258 & 0.5410 & 19.6987 & 0.5477 & 2.5569 \\
\hline & 338 & 2.4107 & 0.5164 & 19.6987 & 0.5477 & 2.5569 \\
\hline & 339 & 2.5033 & 0.5362 & 19.6987 & \begin{tabular}{|c|}
0.5477 \\
\end{tabular} & 2.5569 \\
\hline & 400 & 2.1531 & 0.5150 & 17.4316 & 0.6062 & 2.5343 \\
\hline & 401 & 2.2982 & 0.5422 & 17.6235 & 0.6007 & 2.5461 \\
\hline & 402 & 2.1706 & 0.5121 & 17.6235 & 0.6007 & 2.5461 \\
\hline & 410 & 2.0760 & 0.4898 & 17.6235 & 0.6007 & 2.5461 \\
\hline & 430 & 2.0753 & 0.6177 & 13.9971 & 0.7273 & 2.4434 \\
\hline & 431 & 2.3407 & 0.6967 & 13.9971 & 0.7273 & 2.4434 \\
\hline & 432 & 2.0267 & 0.5925 & 14.2109 & 0.7182 & 2.4565 \\
\hline & 450 & 2.3357 & 0.8931 & 10.7977 & 0.9021 & 2.3592 \\
\hline & 451 & 2.2657 & 0.8663 & 10.7977 & 0.9021 & 2.3592 \\
\hline & 453 & 2.0948 & 0.7819 & 11.0311 & 0.8862 & 2.3743 \\
\hline & 106 & 2.9336 & 0.4229 & 28.5857 & 0.4021 & 2.7894 \\
\hline & 102 & 2.8360 & 0.4088 & 28.5857 & 0.4021 & 2.7894 \\
\hline & 100 & 4.0244 & 0.6080 & 27.8863 & 0.4104 & 2.7169 \\
\hline & 1258 & 3.4189 & 0.4818 & 28.9266 & 0.3981 & 2.8256 \\
\hline & 1257 & 4.4547 & 0.6458 & 28.4996 & 0.4031 & 2.7803 \\
\hline & 1228 & 2.9936 & 0.4712 & 27.2616 & 0.4182 & 2.6567 \\
\hline & 1227 & 2.7234 & 0.4310 & 27.1957 & 0.4191 & 2.6481 \\
\hline
\end{tabular}


Homogeneous Single Phase Model Calculation

Dpave friction $f$ NreM $6.5 / \mathrm{Nre}^{\wedge} .83$ delP calc

\begin{tabular}{|c|c|c|c|c|c|c|}
\hline Expt & File & & & & & \\
\hline & 1226 & 2.6433 & 0.4183 & 27.1957 & 0.4191 & 2.6481 \\
\hline surge & 122409 & 2.3556 & 0.3788 & 26.9961 & 0.4216 & 2.6221 \\
\hline data & 122411 & 2.6133 & 0.4271 & 26.7942 & 0.4243 & 2.5961 \\
\hline & 122412 & 2.8285 & 0.4673 & 26.6581 & 0.4261 & 2.5788 \\
\hline & 122413 & 3.1313 & 0.5202 & 26.5897 & 0.4270 & 2.5702 \\
\hline & 1246 & 3.0136 & 0.4794 & 27.1294 & 0.4199 & 2.6394 \\
\hline & 1217 & 2.3631 & 0.4855 & 23.3924 & 0.4749 & 2.3116 \\
\hline & 1212 & 2.4707 & 0.5103 & 23.3399 & 0.4758 & 2.3033 \\
\hline & 1206 & 2.4557 & 0.5045 & 23.3924 & 0.4749 & 2.3116 \\
\hline & 1202 & 2.3356 & 0.4824 & 23.3399 & 0.4758 & 2.3033 \\
\hline & 1139 & 2.0379 & 0.5949 & 18.6350 & 0.5735 & 1.9646 \\
\hline & 1136 & 2.0379 & 0.5949 & 18.6350 & 0.5735 & 1.9646 \\
\hline & 1134 & 2.0254 & 0.5913 & 18.6350 & 0.5735 & 1.9646 \\
\hline & 1132 & 2.0253 & 0.5912 & 18.6350 & 0.5735 & 1.9646 \\
\hline & 1058 & 1.6673 & 0.8368 & 12.4880 & 0.7995 & 1.5931 \\
\hline & 1057 & 1.6758 & 0.8410 & 12.4880 & 0.7995 & 1.5931 \\
\hline & 1055 & 1.6013 & 0.8036 & 12.4880 & 0.7995 & 1.5931 \\
\hline & 1053 & 1.4439 & 0.7292 & \begin{tabular}{|l|}
12.4617 \\
\end{tabular} & 0.8009 & 1.5859 \\
\hline & 1012 & 1.4206 & 1.1103 & 8.6790 & 1.0814 & 1.3836 \\
\hline & 1011 & 1.4186 & 1.1087 & 8.6790 & 1.0814 & 1.3836 \\
\hline & 1010 & 1.4186 & 1.1087 & 8.6790 & 1.0814 & 1.3836 \\
\hline & 1008 & 1.2005 & 0.9382 & 8.6790 & 1.0814 & 1.3836 \\
\hline & 1002 & 1.5230 & 1.1903 & 8.6790 & 1.0814 & 1.3836 \\
\hline & 942 & 1.3979 & 1.0925 & 8.6790 & 1.0814 & 1.3836 \\
\hline & 940 & 1.4071 & 1.0997 & 8.6790 & 1.0814 & 1.3836 \\
\hline & 935 & 1.1732 & 0.9169 & 8.6790 & 1.0814 & 1.3836 \\
\hline & 4905 & 2.2855 & 1.7615 & 8.7227 & 1.0769 & 1.3973 \\
\hline run7 & 1022 & 2.6534 & 0.9904 & 11.0311 & 0.8862 & 2.3743 \\
\hline imbibition & 1023 & 2.6910 & 0.9587 & 11.4943 & 0.8565 & 2.4040 \\
\hline & 1024 & 2.7810 & 1.0380 & 11.0311 & 0.8862 & 2.3743 \\
\hline & 1025 & 2.3707 & 0.8849 & 11.0311 & 0.8862 & 2.3743 \\
\hline & 1028 & 1.9994 & 0.7289 & 11.2633 & 0.8710 & 2.3892 \\
\hline & 1058 & 2.4858 & 1.6204 & 6.6430 & 1.3500 & 2.0711 \\
\hline & 1059 & 2.2532 & 1.4688 & 6.6430 & 1.3500 & 2.0711 \\
\hline & 1100 & 2.2832 & 1.4883 & 6.6430 & 1.3500 & 2.0711 \\
\hline & 1102 & 2.0127 & 1.3120 & 6.6430 & 1.3500 & 2.0711 \\
\hline & 1104 & 2.0710 & 1.3500 & 6.6430 & 1.3500 & 2.0711 \\
\hline & 1147 & 2.0047 & 2.5909 & 3.3004 & 2.4127 & 1.8668 \\
\hline & 1149 & 2.1098 & 2.9952 & 3.0135 & 2.6019 & 1.8327 \\
\hline & 1150 & 2.0030 & 2.3838 & 3.5741 & 2.2583 & 1.8976 \\
\hline & 1151 & 2.2183 & 3.1367 & 3.0253 & 2.5934 & 1.8341 \\
\hline & 1154 & 2.1381 & 2.5445 & 3.5741 & 2.2583 & 1.8976 \\
\hline & 1224 & 0.9077 & 1.8651 & 2.0028 & 3.6522 & 1.7775 \\
\hline
\end{tabular}

